\title{
VIII Repräsentationsdomänen zwischen Wandel und Kontinuität
}

Seit der römischen Republik hingen politischer Status und gesellschaftliches Renommee der stadtrömischen Senatsaristokratie zu einem erheblichen Maß von der Möglichkeit der eigenen Repräsentation im öffentlichen Raum ab. Mit dem Prinzipat trat an die Stelle der senatorischen Repräsentation das kaiserliche Repräsentationsmonopol. ${ }^{1}$ Auch mit Konstantin, dem oft eine senatsfreundliche Politik oder zumindest die Neuorganisation des Senatorenstands nachgesagt wurde, ${ }^{2}$ änderte sich daran nichts. Umso bemerkenswerter ist, dass die stadtrömische Senatsaristokratie in der ersten Hälfte des 5. Jhs. offenbar in der Lage war, zumindest partiell alte Rechte für sich zurückzufordern. Die Gründe hierfür sind wohl am ehesten in der verhältnismäßig schwachen Position des Kaisers gegenüber der stadtrömischen Senatsaristokratie zu sehen, die vor allem aus der wachsenden Abhängigkeit von den senatorischen Finanzmitteln und administrativen Leistungen resultierte. Dass dies eben auch die senatorische Repräsentation begünstigte, ist naheliegend. Im Folgenden soll insbesondere danach gefragt werden, inwiefern sich die gestiegene politische Bedeutung der stadtrömischen Senatsaristokratie in einer erhöhten repräsentativen Präsenz im öffentlichen Raum der Stadt Rom widerspiegelte. Wichtig wird es dabei sein, neben den öffentlichen Gebäuden und Platzanlagen der Stadt die senatorische domus, die seit alters her das Herzstück senatorischer Repräsentation darstellte, in die Betrachtung mit einzubeziehen.

\subsection{Die statuarische Repräsentation - ein Instrumentarium der Krisenbewältigung?}

Zuvor wurde bereits deutlich, welche städtischen Räume im Besonderen die Aufmerksamkeit der stadtrömischen Senatsaristokratie und des Senats gefunden haben. Platzanlagen mit ihrem architektonischen Ensemble, Thermen und Bauten, die der öffentlichen Spielgebung dienten, standen sehr hoch auf der Agenda. ${ }^{3}$ Dies sind dann

1 Zur senatorischen Repräsentation in der frühen und hohen Kaiserzeit vgl. die einschlägigen Aufsätze von ECK in ECK/AMELING/HEINRICHS (2010); ferner die relevanten Beiträge in BECK/SCHOLZ/ WALTER (2008); ECK/HEIL (2005) und WEBER/ZIMMERMANN (2003) und besonders den Aufsatz BORG/WITSCHEL (2001) 47-120. Zum kaiserlichen Baumonopol vgl. u a. ZANKER (1997).

2 Pan. Lat. 4,35,2; die angesehensten Männer aus allen Provinzen werden für die Curie verpflichtet; zu Konstantin und dem Senat vgl. jetzt auch ROLLÉ DITZLER (2020) 270 - 287; ferner ARNHEIM (1972); CHASTAGNOL (1976) 49-69; ders. (1970) 30 - 314 und JONES (1964) 106f. Gegen ARNHEIMs Annahme, erst Konstantin habe hinsichtlich des Senats eine politische Kehrtwende vollzogen, argumentierten bereits ECK, Rez. Arnheim. Gnomon 46 (1974) 673-681 und CLEMENTE, Rez. Arnheim. Rivista di Filologia 101 (1973) 506-512.

3 Vgl. Kap. 6.3.

Ә OpenAccess. () 2021 Hendrik A. Wagner, publiziert von De Gruyter. (cc) BY-NC-ND Dieses Werk ist lizenziert unter der Creative Commons Attribution-NonCommercial-NoDerivatives 4.0 International Lizenz. https://doi.org/10.1515/9783110727630-008 
auch die Orte, auf die sich die senatorische Repräsentation konzentrierte. Da nachfolgend im Besonderen epigraphische Befunde vom Forum Traiani einbezogen werden, soll an dieser Stelle kurz auch auf die Nutzung und den Zustand dieser bedeutenden Platzanlage eingegangen werden.

Für die erste Hälfte des 5. Jhs. lässt sich feststellen, dass auf dem Trajansforum eine Vielzahl an administrativen Aufgaben, die zumeist auch in Verbindung mit der stadtrömischen Senatsaristokratie und dem Senat standen, erfüllt wurden. So diente die Platzanlage als Ort für die Ernennung der Konsuln, für Gerichtsverhandlungen und die Promulgation von Gesetzen. ${ }^{4}$ Damit ist das Trajansforum als besonders stark frequentierter öffentlicher Raum anzusehen. Schon allein aus funktionalen Gründen dürften Instandsetzungsmaßnahmen auch hier höchste Priorität gehabt haben. So wurde offenbar noch Mitte des 5. Jhs. die Basilica Ulpia renoviert. ${ }^{5}$ Zumindest die Bereiche, die als architektonischer Rahmen für die öffentlichen Handlungen und Ehren dienten, müssen weiter erhalten worden sein. Hinsichtlich der statuarischen Ehrungen betrifft dies vor allem die Portiken, die den Platz rahmten. ${ }^{6}$

Bevor im Einzelnen nun auf die senatorische Repräsentation einzugehen ist, muss zunächst deutlich werden, welchen Charakter diese eigentlich trägt. Würde die wichtige Bedeutung der senatorischen Repräsentation in der spätrömischen Gesellschaft nicht angemessen bedacht werden, so könnte leicht ein falscher Eindruck entstehen. Die hohen Aufwendungen, die die Senatsaristokratie hinsichtlich ihrer öffentlichen Repräsentation tätigten, könnten oberflächlich betrachtet als Ausdruck „spätrömischer Dekadenz ${ }^{\text {"7 }}$ missverstanden oder sogar als destruktiv für den von allen Seiten bedrohten und finanziell angeschlagenen Staat angesehen werden. Die senatorische Repräsentation war aber überaus wichtig für die Aufrechterhaltung der gesellschaftlichen Ordnung. Als horizontales und vertikales Kommunikationsmittel definierte sich an ihr eine

4 Vgl. Claud. VI. Cos. Hon. 643-648; Sid. carm. 2,554f.; CTh.10,10,31 (a. 422); CTh. 11,20,4 (a. 423 ); Nov. Val. 2,2 (a. 442); Nov. Val. 11 (a. 443); Nov. Val. 19 (a. 445); Nov. Val. 21 (a. 445/446); Nov. Val. 23 (a. 447); Nov. Val. 25 (a. 447); Nov. Val. 27 (a. 449) und Nov. Val. 31 (a. 451). Für weitere Funktionen vgl. BAUER (1996) 95-97, 128-131 u. 409-412. Speziell zur Ehrungspraxis vgl. auch MEURER (2019) 107-110; KALAS (2010) 108f.; NIQUET (2000) 18-20. Insbesondere zum geistigen Leben vgl. MARROU (1932) 93-110, bes. $99 \mathrm{ff}$.

5 CIL 6, 40808. Hierzu vgl. AMICI (1982) 17-28. Es handelt sich hierbei um ein Architravteil trajanischer Zeit, was die Renovierungsmaßnahmen, starke Eingriffe und die Spoliirung bezeugt. Vgl. ferner NIQUET (2001) 142 mit Anm. 129 und dies. (2000) 19. Für die Wahrnehmung des Forum Traiani Mitte des 4. Jhs. vgl. Amm. 16,10,15-17 und für Ende des 5. Jhs. Cassiod. Var. 7,6.

6 Vgl. BAUER (1996) 95 und MILELLA/PENSABENE (1989) 27-291, bes. $47 \mathrm{f}$.

7 Dies ist eine Betrachtungsweise, die insbesondere bis in die 50er-Jahre des letzten Jahrhunderts und teilweise auch darüber hinaus weit verbreitet war, im Grunde fußend auf der spätrepublikanischen moralisierenden Dekadenz-Geschichtsschreibung, die u. a. noch auf Ammian (bes. die zwei RomExkurse Amm. 14,6,7 und 16,10,5), Aurelius Victor und Prokop nachwirkte. Hierzu vgl. DEMANDT ${ }^{2}$ (2007) 583ff., bes. 586f.; ders. (2002) 99-110; ders. (2013b) 207-209 [1993] und ders. (1984) $198-215$ u. 431- 464 mit der einschlägigen Literatur; ferner zur älteren Forschungsmeinung vgl. WERNER (1939). Zur Zeitkritik in den Quellen vgl. DEMANDT (1984) 44-70; ders. (1965); speziell zum Anonymus De rebus bellicis vgl. BRANDT (1988). 
wohlgeordnete römische Welt. In der horizontalen Ebene, die mit dem sehr unscharfen Sammelbegriff ordo senatorius zu benennen wäre, diente die individuelle Repräsentation den Angehörigen der Senatsaristokratie zur eigenen Verortung und zur standesinternen Distinktion ${ }^{8}$. Den wichtigsten Bezugspunkt stellten dabei die Standesgenossen dar, zu welchen prinzipiell auch die Heermeister und Kaiser ${ }^{9}$ zählten. Hier wirkte noch immer der agonale Charakter, der der römischen Aristokratie seit republikanischer Zeit $\mathrm{zu}$ eigen war. ${ }^{10}$

Noch wichtiger für die gesellschaftliche Ordnung war die vertikale Sozialstruktur, auf welche die senatorische Repräsentation einwirkte. Hier definierte und verteidigte die Senatsaristokratie nicht nur ihren Status als Elite, sondern gab das gesellschaftliche Leitbild vor. Normen und Werte, die eine Gesellschaft zusammenhielten und über die es einen Grundkonsens gab, fanden in den senatorischen Ehrenmonumenten ihre Fixierung für die Ewigkeit. Besonders in einer Zeit zunehmender Unsicherheit bot dies Halt und Orientierung. Damit war die senatsaristokratische Repräsentation mehr als nur Ausdruck eines übersteigerten Egozentrismus einzelner Senatoren. Vorbilder waren und sind für eine vitale Gesellschaft als Antrieb für die soziale Mobilisierung ${ }^{11}$ und einen gesunden gesamtgesellschaftlichen Optimismus von großer Bedeutung.

Zumindest für die erste Hälfte des 5. Jhs. kann nicht die Rede davon sein, dass die Ehrung von Senatoren im öffentlichen Raum einen gravierenden Einbruch ${ }^{12}$ erlebte. Gegenüber dem 4. Jh. scheinen die epigraphischen Zeugnisse sogar eine Zunahme zu verzeichnen. So lassen sich etwa für das Trajansforum ebenso viele Ehreninschriften für die erste Hälfte des 5. Jhs. anführen wie zuvor für das ganze 4. Jh. zusammen. ${ }^{13}$ Hierbei fällt auch der beträchtliche Umfang der Inschriftenformulare auf. In ihrem Wort- und

8 Hierzu jetzt auch WEISWEILER (2012) 319-350; zuvor NIQUET (2000) und NÄF (1995) 28ff.; wegweisend ALFÖLDY (1982) 37-53.

9 Vgl. SCHLINKERT (1996a) 229 und LOEHKEN (1982) $56 \mathrm{ff}$.

10 Hierzu bereits Kap. 7.2 und 7.3. Entgegen der Auffassung FLAIG (2000) 228- 230 und ders. ${ }^{2}(2019)$ 90 f. [1992].

11 Angewendet auf die spätantike Gesellschaft heißt dies nicht, dass gleich zwangsläufig der Aufstieg in den ordo senatorius angestrebt war oder für eine breite Masse die Verbesserung ihrer Lebensbedingungen möglich erschien. Die doch verhältnismäßig große soziale Mobilität schloss dies zwar nicht gänzlich aus, doch die Chance hierzu hatten nur wenige. Zur sozialen Mobilität in der Spätantike vgl. DEMANDT 2(2007) 299f. u. 328 und KRAUSE (1987) 230 f. u. 334 f.; ferner die wichtigen Aufsätze MEIER (2003b) 193-213; ALFÖLDY (2002) 123-148; DEMANDT (2013a) 55-59 [1980] und MACMULLEN (1964) 49-53. Im Kontext der Hofadministration vgl. jetzt auch REBENICH (2017) $23 \mathrm{f}$.

12 Hiergegen trat bereits NIQUET (2000) 232 und WITSCHEL (2012) 362- 371 ein. Ein starker Rückgang des epigraphischen Materials lässt sich so erst für das Ende des 5. Jhs. feststellen. Zum Rückgang seit der Mitte des 3. Jhs. vgl. WITSCHEL (2006) 359f. Einen starken quantitativen Rückgang konstatieren BAUER (2007) 86; BORG (2007) 50f. und BORG/WITSCHEL (2001) 47-120, hier 78f. Vgl. jetzt auch WARD-PERKINS/MACHADO (2013) 353-364 mit aktueller Auflistung; ferner MACHADO (2010a) bes. 243-252 mit Statistiken. Vgl. ferner auch LIVERANI (2015) 112, der hier eine differenziertere Untersuchung fordert.

13 Vgl. NIQUET (2000) 262-269 (tabellarische Zusammenstellung, allerdings nicht ganz vollständig). 
Detailreichtum ${ }^{14}$ entziehen sie sich einer flüchtigen Betrachtung. Neben dem aus den vergangenen Jahrhunderten vertrauten Ämterkatalog nehmen nun insbesondere moralisierende Inhalte breiten Raum ein. Im Wesentlichen wurden hierbei die Werte und Normen tradiert und in Stein gemeißelt, die dem Wertekanon des mos maiorum ${ }^{15}$ entsprachen. Hier nehmen die Ehreninschriften schon fast einen gesellschaftsdisziplinierenden Charakter an.

Spätestens zu Beginn des 5. Jhs. verfestigte sich hierbei eine Praxis der Ehrung, die offenbar eine Domänentrennung zwischen Kaiser und Senat vorsah. ${ }^{16}$ So übte auf dem Forum Romanum der Senat das Recht der Ehrenvergabe aus, wohingegen auf dem Trajansforum dieses dem Kaiser zustand. Dementsprechend finden sich auf den Ehrenmonumenten auf dem Forum Romanum oftmals Formulierungen wie EX S(enatus) $\mathrm{C}(\text { onsulto })^{17}$ oder S(enatus) $\mathrm{P}$ (opulus) Q(ue) R(omanus) ${ }^{18}$ bzw. POPVLVS ROMANVS ${ }^{19}$, die zum Ausdruck bringen, dass hier der Senat im Einvernehmen mit dem Volk von Rom als Dedikant fungierte. Eine Ausnahme stellen Ehrungen im Umfeld der Curia Iulia dar, die offenbar nicht durch den Senat, sondern auf Weisung des Kaisers (iussu principum) ${ }^{20}$ erfolgten.

Während eine Ehrung auf dem Forum Romanum eine sehr exklusive Auszeichnung blieb $^{21}$, eröffnete sich die Möglichkeit hierzu auf dem Trajansforum schon einem deutlich größeren Kreis. Für die Herrschaftszeit des Honorius und Valentinians III. sind immerhin noch neun Ehrenmonumente vom Forum Traiani ${ }^{22}$ fassbar. Was bei den Neuzugängen auf dem Forum Traiani jedoch auffällt, ist das weitgehende Fehlen von

14 Vgl. NIQUET (2000) 135.

15 Vgl. SCHOLZ (2011) bes. 89-215; ferner die Aufsätze in HALTENHOFF/HEIL/MUTSCHLER (2005); zur Spätantike NIQUET (2000) 151-172; BRANDT (1999b) und NÄF (1995) 3ff. u. 57 ff.

16 Vgl. hierzu auch BAUER (1996) 76 u. 133; erstmals ausführlich diskutiert in CHASTAGNOL (1960) $51 \mathrm{ff}$.

17 CIL 6, 1730 (Stilicho, nahe dem Severusbogen).

18 CIL 6, 31987 (Stilicho?); CIL 6, 41389 (Aëtius).

19 CIL 6, 1731 (Stilicho, nahe dem Severusbogen).

20 Z. B. CIL 6, 41389 (Aëtius; wobei auch S.P.Q.R.) und CIL 6, 41398 (Petronius Maximus); die Curia Iulia scheint eine kaiserliche Domäne gewesen zu sein, wofür auch die Instandsetzungsarbeiten sprechen, die auf kaiserlichen Befehl durchgeführt wurden; (CIL 6, 1718 und CIL 6, 37128; PVR vice sacra iudicans).

21 NIQUET (2000) 86: Ehrungen auf dem „Forum Romanum, der bevorzugten Repräsentationsstätte der Augusti und ihrer domus“, wurden nur besonders verdienten Persönlichkeiten zuteil, da hierdurch ein enges Verhältnis zum Kaiserhaus angezeigt wurde. Dies trifft so auf Stilicho (CIL 6, 1730; 1731 und 31987?) und Petronius Maximus zu (CIL 6, 41398; hierzu vgl. PANCIERA (1996) 295); Aëtius, der nie ein enges Vertrauensverhältnis zu Valentinian III. aufbauen konnte, versuchte dennoch, seine Nähe zum Kaiserhaus öffentlich zu demonstrieren (CIL 6, 41389; ferner auch durch die beabsichtigte Ansippung). Vgl. ferner NIQUET (2001) 125-146; auch RUCK (2001) 209-225; ferner BAUER (1996) 38-49.

22 CIL 6, 1710 (Claudian); CIL 6, 1715 (Cronius Eusebius, 399); CIL 6, 1724 (Merobaudes, 435); CIL 6, 1725 (Draucus; 441); CIL 6, 1749 (Petronius Maximus, 421); CIL 6, 1783 (Nicomachus d. Ä. und d. J., 431) und CIL 6, 41380 (Mallius Theodorus); ohne Überlieferung des Namens CIL 6, 1789; 41417 u. 41418. 
Senatoren aus den übrigen Reichsteilen oder homines novi. ${ }^{23}$ Die „Ruhmeshalle verdienter Persönlichkeiten“ ${ }^{\text {24 }}$, wie Bauer das Trajansforum nannte, entwickelte sich mehr und mehr zu einer Ruhmeshalle der stadtrömischen Senatsaristokratie. Als Dedikanten treten hierbei die Kaiser in Erscheinung, wobei die Ehrung zumeist auf Eingabe des Senats (ad petitionem $)^{25}$ erfolgte. Der Stadtpräfekt, der mit der Ausführung betraut wurde, agierte dabei als vice sacra iudicans ${ }^{26}$ - als Vertreter des Kaisers. Die Ehrung von Angehörigen der stadtrömischen Senatsaristokratie im öffentlichen Raum war demnach immer eine Angelegenheit, die zwischen Kaiser und Senat entschieden wurde.

Eine der bemerkenswertesten Ehreninschriften, die jemals für einen Angehörigen der Senatsaristokratie auf dem Forum Traiani gesetzt wurde, fällt in die Herrschaftszeit Valentinians III. In der entsprechenden Inschrift, die unter CIL 6, 1783 (ILS 2948) ${ }^{27}$ einzusehen ist, wurde ein Fall wieder aufgerollt, der siebenunddreißig Jahre zurücklag. Im Jahr 431 wurde Virius Nicomachus Flavianus senior, der PPO und Konsul des Usurpators Eugenius, offiziell rehabilitiert. Allein, dass dies nach so langer Zeit doch noch möglich wurde, verdeutlicht, wie stark mittlerweile der Einfluss ${ }^{28}$ der stadtrömischen Senatsaristokratie war. Mit Virius Nicomachus Flavianus senior wurde 431 ein Vertreter der Senatsaristokratie postum zum bonum exemplum erklärt, der so gar nicht zu dem vom theodosianischen Kaiserhaus geförderten Leitbild passte. Als überzeugter Heide, erwiesener Gegner des christlichen Kaiserhauses und letzten Endes, in der Rebellion unversöhnlich verharrend, durch eigene Hand gestorben, verkörperte sein Andenken all das, was 394 am Frigidus eigentlich sein Ende gefunden haben sollte. Im entscheidenden Passus der Inschrift, die Flavianus wieder in alle Ehren ${ }^{29}$ einsetzt, heißt es in der für den Senat verfassten Begründung:

23 Eine Ausnahme stellen die Ehrungen des Claudian (CIL 6, 1710), Merobaudes (CIL 6, 1724) und Sidonius Apollinaris (Sid. carm. 8,7f.) dar.

24 BAUER (1996) 133; wiederholt BAUER (2007) 79. Von einem primär senatorischer Repräsentationsraum sprechen MEURER (2019) 109 und CHENAULT (2012) 105-108.

25 Z. B. CIL 6, 1749 (Petronius Maximus): ADPEDITIONE SENATVS AMPISSIMI POPVLIQ. ROMANI oder CIL 6, 1710 (Claudian): SENATV PETENTE.

26 Vgl. hierzu EICH (2005) 360 f.; NIQUET (2000) 131f.; KASER/HACKL ${ }^{2}(1996) 535$ f. und MOMMSEN (ND 1961) 270 [1899]. Aus diesem Grund dürfte CIL 6, 1719 (Constantius reparator rei publicae; 420) doch eher dem Trajansforum zuzurechnen sein; vgl. Kap. 6.3; entgegen NIQUET (2000) 23f. u. 72. Bei Ehrungen des Kaisers auf dem Forum Romanum (z. B. CIL 6, 1194; Honorius) konnte der PVR ebenfalls als vice sacra iudicans agieren, wobei das S.P.Q.R. nicht entfällt. Hierzu vgl. MEURER (2019) 99f.; MACHADO (2006) 186 und CHASTAGNOL (1960) 51.

27 Hierzu vgl. aktuell ROLLÉ DITZLER (2020) 62-64 und WEISWEILER (2012) 36-42; ausführlich GRÜNWALD (1992) 462-487; ferner HEDRICK (2000) 1-89 und MATTHEWS (1997) 96-213, bes. 212f. $28 \mathrm{Zu}$ dieser Erkenntnis kommt auch noch SZIDAT (2010) 337. Eine Fürsprache des Aëtius in dieser Sache zogen bereits STICKLER (2002) 290; HEDRICK (2000) 223f. und GRÜNWALD (1992) 486 in Betracht; ebenfalls schon SOLARI (1936) 357-360, hier 359. Im Hinblick auf die später erfolgte Ehrung des Aëtius im Atrium Libertatis (vgl. Kap. 5.3), welche noch einmal die enge Bindung des Heermeisters an die stadtrömische Senatsaristokratie und den Senat unterstrich, ist dies nicht unwahrscheinlich.

29 CIL 6, 1783 v. 3-6 [...] / VIRTVTIS AVCTORITATISQ(ue) SENATORIAE ET IVDICIARIAE ERGO / REDDITA <memoria et dignitas> IN HONOREM FILII NICOMACHI FLAVIANI CONS(ularis) 
[...] FLAVIANI FILIV[s] / HONOR SEMIPLENVS ETIAM SVB PRAFECTVRAE PRAETORIANAE APICE QVEM PROVIDE[ntia] / ET INDVSTRIA SVA COTTIDIE AVGET DELATVS EXSISTIMETVR NISI INTEGER TANDEM ET ABS[ $q(u e)$ ullo / re]LIGIOSI MVNERIS DEBITO TOTIVS DOMVS EIVS FAMILIAEQ(ue) SIT [.....$^{30}$

Der Sohn des Flavianus [senior]. Seine Ehre kann nur als eine halbe angesehen werden, selbst wenn er mit der höchsten Ehre der Prätorianerpräfektur ausgezeichnet worden ist, die er durch seine Weitsicht und seinen Fleiß täglich mehrt, wenn er nicht endlich unbescholten und frei von jeglicher Schuld religiöser Verpflichtung gegenüber seinem ganzen Haus und seiner Familie ist.

Auffällig ist die Erwähnung des religiosum munus. Während Niquet diese Wendung etwas zu neutral als „Liebesdienst“31 übersetzte, sah Hedrick hierin wohl zu Recht einen Bezug „to traditional cults and practices associated with the dead“32. Dass Galla Placidia oder Valentinian III. alte religiöse Praktiken ${ }^{33}$ gut hießen, zu welchen neben der Verehrung der Ahnen in den Totenmasken, deren Mitführen in Prozessionen und dem Totenmahl am Grab auch Opfer zählten, ist wohl schwer vorstellbar. Eher scheint dies die Handschrift der ,altgläubigen“ bzw. stark traditionell gesinnten Senatoren zu tragen.

Hierzu passt auch, dass hier nicht der Kaiser als Dedikant in Erscheinung trat, sondern der Enkel des Rehabilitierten, Appius Nicomachus Dexter, ${ }^{34}$ der hierbei offenbar als privatus agierte, was für die Ehrenpraxis auf dem Forum Traiani ungewöhnlich ist. Nicht einmal der praefectus Urbi wird als vice sacra iudicans beauftragt, wie dies sonst üblich war. Auch auffallend knapp fällt die kaiserliche Nomenklatur aus. ${ }^{35}$ Dennoch kann hier keineswegs die Rede davon sein, dass der Kaiser nur eine

CAMP(aniae) / PRCONS(ulis) ASIAE PRAEF(ecti) VRBI SEPIVS NVNC PRAEF(ecti) PRAET(orio) / ITALIAE ILLYRICI ET AFRICAE / [...]; zum Einschub vgl. NIQUET (2000) 79 und GRÜNWALD (1992) 465 Anm. 9. Selbstverständlich entfielen die unter Eugenius geführten Ämter und Würden (PPO und Cos.). 30 CIL 6, 1783 v. 31-33; zum Text vgl. WEISWEILER (2012) 41f.; HEDRICK (2000) 247-258; eine etwas freie Übersetzung der Passage bietet NIQUET (2000) 79; ein vollständige Textübersetzung GRÜNWALD (1992) 465 f., der in diesem Fall die Stelle auch mit „,religiöse Verpflichtung“ übersetzt. Hier ein freierer Übersetzungsvorschlag.

31 NIQUET (2000) 79.

32 HEDRICK (2000) 106.

33 Von christlicher Seite wurde der pagane Totenkult abgelehnt (so Zen. 1,25,10 f.; Aug. ep. 22,6 oder Aug. conf. 6,2). Vgl. hierzu PIEPENBRINK 2(2009) 322-329 mit weiteren Quellenbelegen und Literaturverweisen. Zur celebris memoria für den älteren Nicomachus Flavianus vgl. Symm. ep. 6,1,3.

34 CIL 6, 1783 v. 36f.: APPIVS NICOMACHVS DEXTER V. C. EX PRAEF. VRB. AVO OPTIM[o] [sic. Flavianus senior]/ STATVENDAM CVRAVIT // DEDICAT [...]; zur Person vgl. PLRE 2, 357.

35 IMPERATORES CAES(ares) FL(avius) THEODOSIVS ET FL(avius) PLACIDIVS VALENTINIANVS / SEMPER AVG(usti) SENATVI SVO SALVTEM. Zum Vergleich ziehe etwa CIL 6, 1710; 1724; 1725 oder 1749 heran. Die übrigen Zeugnisse vom Forum Traiani und Forum Romanum verzichten, soweit sich dies noch sagen lässt, nicht auf das D. N. bzw. DD. NN. Zur Herrschertitulatur vgl. KOLB (2001) 130 u. 220 f. und besonders RÖSCH (1978) 76-83. Das D. N. wurde in der Regel dort vorangestellt, wo der kaiserliche Name von anderen gebraucht wurde (i. B. in Inschriften und Münzlegenden); hierzu auch DEMANDT ${ }^{2}(2007) 260$ und MARTIN 2(1990) 96f. Die Titulatur IMPERATORES CAES(ares) ist auch für das Konzil von Ephesus 431 überliefert, wobei auch hier das DD. NN. fehlt, aber dafür das Lob auf die Kaiser 
untergeordnete Rolle einnahm. Gut über die Hälfte des Textes beruft sich auf eine kaiserliche Willenserklärung, welche offenbar im Vorfeld zu dieser Ehrung vor dem Senat verlesen worden war. An der Authentizität dieser kaiserlichen Erklärung lässt sich wohl nicht zweifeln. Allerdings kann danach gefragt werden, wessen Wille hier tatsächlich maßgebend war. Valentinian III. war im Jahr 431 gerade einmal zwölf Jahre alt.

Entgegen der Behauptung, der Kaiser habe diese Entscheidung aus freiem Antrieb, ohne Ermahnung ${ }^{36}$ dritter getroffen, muss angenommen werden, dass genau dies der Fall war. Die Erwähnung des Ahnenkults oder auch die Angabe praefectus urbis saepius $^{37}$, welche die illegitim unter dem Usurpator Eugenius geführte Stadtpräfektur des Nicomachus Flavianus iunior miteinschloss, und die zweite genannte Prätorianerpräfektur des Vaters, die gleichfalls unter den Usurpator fiel, verweisen auf einen starken senatorischen Einfluss. Die Nicomachier erreichten nicht bloß ihre Rehabilitierung, sie erwirkten auch die Anerkennung der unter Eugenius geführten Ämter. Der Dienst galt letztlich dem Gemeinwesen, nicht dem Herrscher. An der Inschrift für Nicomachus Flavianus senior wird dies sehr deutlich, wenn davon die Rede ist, dass die Rehabilitierung „aufgrund seiner Tüchtigkeit und seines Ansehens sowohl im Bereich der senatorischen Tätigkeit als auch in der Verwaltung der Provinzen“38 erfolgt ist.

Die damnatio memoriae ${ }^{39}$ wurde aufgehoben, ohne nur mit einer Silbe diese und die Hintergründe überhaupt genau benannt zu haben. Auf der einen Seite ersparte dies dem Hof, die Entscheidung vergangener Kaiser offen als Fehler zu revidieren und auf der anderen Seite gerieten die Nicomachier nicht in die Verlegenheit, den Verrat an der theodosianischen Dynastie und die Rechtmäßigkeit der damnatio memoriae einzugestehen. Dementsprechend wird nicht mit der kaiserlichen clementia operiert, sondern lediglich auf Basis der Rechtmäßigkeit, die sich im Hinblick auf die Verdienste des Nicomachus Flavianus senior und seiner Nachkommen regelrecht aufzwingt, argumentiert. Ein versöhnlicher Kompromiss war dies aber gewiss nicht. Grünwald wird sicherlich damit Recht behalten, dass dies „gegen erhebliche Widerstände durchgesetzt werden mußte“ ${ }^{640}$ und vor allem eine selbstbewusst und stark auftretende Senatsaristokratie voraussetzte. Stickler täuscht sich, wenn er meint, dass dies zu gewähren leicht

deutlich umfangreicher ausfiel: Imperatores Caesares Theodosius et Valentinianus victores triumphatores maximi semper venerabiles Augusti (Rescriptum legis sacrae contra Nestorium zur Einberufung des Konzils von Ephesus; Acta conciliorum Ecumenicorum ACO 1.3.1, 181).

36 CIL 6, 1783 v. 27-29: [...] VT NON INMERIT[o] PATIENTIAE VESTRAE GRATIAS AGAMVS, NE QVID ERGA RESTITVTIONEM HONORIS EIVS ADMONITI POTIVS QVAM SPONTE FECISSE VIDEAMVR, [...]. Dass es nicht als selbstverständlich vorausgesetzt wurde und folglich in Zweifel stand, lässt dies umso mehr verdächtig werden. Vgl. auch GRÜNWALD (1992) 485.

37 CIL 6, 1783 v. 5.

38 CIL 6, 1783 v. 3f.: [...] / VIRTVTIS AVCTORITATISQ(ue) SENATORIAE ET IVDICIARIAE ERGO / REDDITA <memoria et dignitas $>$.

39 Hierzu ausführlich GRÜNWALD (1992) 482- 484 mit entsprechenden Belegen, der hierbei plausibel darlegen kann, dass höchstwahrscheinlich Theodosius, obgleich seine clementia oft propagiert wurde (so auch in CIL 6, 1783, v. 16), dies gebilligt haben muss. Vgl. ferner auch HEDRICK (2000) $109 \mathrm{f}$.

40 GRÜNWALD (1992) 485. 
für den Hof gewesen wäre. ${ }^{41}$ Gewiss lagen zwei Generationen und mittlerweile fast vierzig Jahre dazwischen. Doch dies änderte nichts daran, dass Virius Nicomachus Flavianus noch immer als einer der größten Verteidiger des Heidentums galt. Sowohl die Saturnalia des Macrobius ${ }^{42}$ als auch das carmen contra paganos ${ }^{43}$ bezeugen dies vom heidnischen wie auch vom christlichen Standpunkt aus. Das 431 gewährte Monument war die letzte fassbare Ehrung eines hoch angesehenen Vertreters der heidnischen Senatsaristokratie überhaupt. ${ }^{44}$

Dieses Beispiel belegt, dass die Entscheidung darüber, wer offiziell als bonum exemplum zu gelten habe und folglich für eine Ehrung im öffentlichen Raum in Betracht zu ziehen war, nicht im alleinigen Ermessen des Kaisers lag. Der Senat und die Senatsaristokratie konnten hierauf ebenfalls stark Einfluss nehmen. Das Recht des Senats, dem Kaiser Vorschläge zu unterbreiten oder direkt Männer zu benennen, die geehrt werden sollen, ${ }^{45}$ war offenbar keine leere Formalität, sondern wurde vom Senat durchaus ernsthaft praktiziert. Hart geführte Verhandlungen zwischen dem Senat bzw. Teilen der Senatsaristokratie auf der einen und dem Hof auf der anderen Seite waren gewiss höchst selten, aber nicht ausgeschlossen. Nicht geehrt wurde der Konsul von 394. Genauso wenig wurde Flavianus der Priester oder Flavianus der in vielen Mysterien Eingeweihte $^{46}$ geehrt. Mit einem solchen bonum exemplum konnte und wollte das christliche Kaiserhaus keinen Konsens herstellen. Dafür wurden alle übrigen Ämter und Würden offiziell anerkannt. Mit einem ,halben' Flavianus arrangierte man sich. Ein Mann von vorzüglichem Charakter, hoher Bildung ${ }^{47}$ und großen Verdiensten für das Gemeinwesen ließ sich ehren. Die zweite Hälfte, seine große Hingabe für das Heidentum stand dennoch im Raum. Mit der Erwähnung des Ahnenkults und der Nennung des

41 STICKLER (2002) 290.

42 Etwa Macr. Sat. 1,1,13 u. 3,10,1; Nicomachus gehört zu den Hauptprotagonisten des Symposions. 43 Dies ist nicht unumstritten. Vgl. u. a. COSKUN (2004b) 152-178; ADAMIK (1995) 185-233 und GRÜNWALD (1992) 474-481; für eine alternative Datierung und Zuweisung vgl. z. B. CLOVER (1985) 163-176 und CRACCO RUGGINI (1979) 1-141. Für eine Auflistung der gesamten Forschungsstandpunkte vgl. BEHRWALD (2009) 120 f. mit Anm. 17. Für Flavianus spricht sich zuletzt wieder RATTI (2012) $120-124$ aus.

44 Zum religionspolitischen Kurs vgl. u. a. CTh. 16,7,7; CTh. 16,8,28 und CTh. 16,10,13 (alle 426) und aus der Osthälfte CTh. 16,5,65 (428) und CTh. 16,8,29 (429).

45 Hierzu vgl. NIQUET (2000) 77-86.

46 Einen guten Eindruck hiervon vermittelt die Grabinschrift für Praetextatus und seine Gattin Paulina CIL 6, 1777: D. M. VETTIVS AGORIVS PRAETEXTATVS AVGVR PONTIFEX VESTAE PONTIFIX SOLIS QVINDECEMVIR CVRALIS HERC[u]LIS SACRATVS LIBERO ET ELEVSINIIS HIEROPHANTA NEOCORVS TAVROBALIATVS [...]; zur Inschrift vgl. NIQUET (2000) 239f.; zur Person und den Kulten LEPPIN (2004) 76-78; zum Engagement des Flavianus senior für das Heidentum vgl. Ruf. hist. eccl. 11,33; Macr. Sat.1,24,17 (augur); Symm. ep. 2,34 (Magna Mater) und das Nicomachi-Symmachi-Diptychon (Abb. 25). Hierzu vgl. WEISWEILER (2012) 38f. und GRÜNWALD (1992) 474-481; ausführlicher HONORÉ/MATTHEWS (1989); bes. HONORÉ (1989) 9-17 und WYTZES (1977) 149-176. Sohn und Enkel des Flavianus senior zählten zwar als Christen, dürften dies aber nicht aus innerer Überzeugung gewesen sein. Hierzu vgl. auch VON HAEHLING (1978) $323 \mathrm{ff}$. u. $411 \mathrm{ff}$.

47 Hierzu vgl. auch GRÜNWALD (1992) 471-473. 
divus Theodosius, ${ }^{48}$ was zumindest in heidnischen Kreisen nur den konsekrierten Kaiser als Staatsgott meinen konnte, tritt zumindest unterschwellig eine heidnisch-traditionelle Konnotation zu Tage.

Um einen ausgewogenen Eindruck von den Ehrenmonumenten auf dem Forum Traiani zu gewinnen, sollen im Folgenden noch weitere Beispiele herangezogen werden. Die Inschrift CIL 6, 1725 ist hierbei eines der letzten Zeugnisse statuarischer Ehrung auf dieser Platzanlage. Da dieses Zeugnis von Niquet nicht berücksichtigt wurde, soll dies hier nachgeholt werden. Die Ehreninschrift wurde im Jahr 441 dem FL. AVXENTIVS DRAVCVS gesetzt, der sich als vir clarissimus et inlustris und Mann aus patrizischer Familie ausweist. ${ }^{49}$ Bauer hatte bereits darauf aufmerksam gemacht, dass bei dieser Art von Inschrift die Erinnerungsmodi ${ }^{50}$ von großer Wichtigkeit waren. In diesem konkreten Fall wird dies auf einen Nenner gebracht im folgenden Passus:

DD. NN. FFLL. / THEODOSIVS ET PLACIDIVS VALENTINIANVS [...] / AD REMVNERATIONEM TITVLOSQVE VIRTVTVM QVIB(us) / CIRCA REM PVBLICAM EXIMIA SEMPER PROBITAS / INVITATVR STATVAM AVRO FVLGENTEM ERIGI CONLOCARIQVE IVSSERVNT.

Unsere Herren Theodosius und Placidius Valentinianus [...] befahlen, als Entlohnung und Auszeichnung für die Tugend, durch welche stets zur höchsten Redlichkeit gegenüber der res publica aufgefordert wird, eine in Gold glänzende Statue zu errichten..$^{51}$

Begriffe wie virtus und probitas werden hochgehalten und als besonders verdienstvoll und förderlich für die res publica ausgewiesen. Konkretisiert wird dies an den gelisteten Ämtern und Würden. Draucus hatte sich so als ein Mann, der allen Verpflichtungen im Senat ${ }^{52}$ mit Hingabe nachgekommen war, ausgezeichnet. Ebenso war er comes am Hof ${ }^{53}$ und vicarius urbis Romae, hatte einen Sitz im consistorium und wurde schließlich auch Stadtpräfekt. Dem Betrachter wurde damit eine mustergültige Laufbahn vorgeführt, die nicht nur bewunderungswürdig war, sondern auch zur Nachahmung auffordern sollte. Eine Anleitung für eine vorzügliche Amtsführung

48 CIL 6, 1783 v. 2 u. 15: QVAEST(or) AVLAE DIVI THEODOSIANI [...] DIVI AVI NOSTRI. Vgl. hierzu CLAUSS (2001) 214f. Zur Divinisierung der Kaiser durch den Senat jetzt auch ECK (2016a) 37-56, bes. $39-48$.

49 Zur Person vgl. PLRE 2, 380; Die Inschrift wird besprochen von SALWAY (2015) 364-396, hier 382384 (mit Text und Übersetzung); BAUER (2007) 84 und ANDERSON (1984) 171f.

50 BAUER (2007) 79-92, bes. 84f. Hierzu vgl. nachfolgend auch WITSCHEL (2012) und jetzt auch MEURER (2019) 107-114.

51 CIL 6, 1725 v. $14 \mathrm{ff}$. Die Übersetzung weicht leicht von BAUER (2007) 84 ab.

52 CIL 6, 1725 v. 3: VIRO SENATVS MVNIS PROMPTA DEVOTIONE PERFVNCTO; neben der Teilnahme an den Sitzungen dürfte dies auch die Quästur und Prätur umfassen, die mit aufwendigen Spielen begangen wurden; so auch PLRE 2, 380(b).

53 Damit dürfte vermutlich das Amt eines tribunus et notarius gemeint sein; durch die Angabe ordinis primi (vir inlustris) muss er darüber hinaus auch eines der höchsten Hofämter erreicht haben, wobei es sich im Fall von Angehörigen der Senatsaristokratie meistens um das Amt des QSP, CSL oder mag. off. handelt. Auf das Amt des vicarius urbis Romae kann sich dies nicht beziehen, da dieser nur im Rang eines vir spectabilis stand. 
wurde auch gleich mitgeliefert. Durch Integrität, umsichtiges Abwägen bzw. Rechtsprechen und Mäßigung (integritas, censura moderatio) war die gute Amtsführung gekennzeichnet. Eine erhaben ausgeübte Amtsgewalt (sublimis potestas), in der die ehrfurchtsvolle Autorität (honorifica auctoritas) und gleichzeitig auch die Menschlichkeit (humanitas) in der Rechtsprechung gewahrt blieb, zeichneten den guten Amtsträger aus. ${ }^{54}$

Die Bereitschaft, sich für die res publica im öffentlichen Dienst aufzuopfern und durch eine vorbildliche Amtsführung Recht und Ordnung zu wahren, stellte nur eine Facette des bonum exemplum dar. Im Hinblick auf den mos maiorum deckte dies die Prinzipien res publica und labor ab, welche das staatliche Wohl vor die privaten Bedürfnisse stellten. Hinzu kommt das senatorische Bildungsideal, welches neben rhetorischer Begabung und klassischer Gelehrsamkeit auch die eigene literarische Tätigkeit umfassen konnte. Im Fall des Flavianus wurde dies durch seine Annales, die in der Inschrift eigens Erwähnung fanden, ${ }^{55}$ besonders hervorgehoben. Draucus wurde hingegen nicht so explizit als ein Mann von hoher Bildung und Gelehrsamkeit dargestellt. Die mustergültige Amtsführung dürfte dies vermutlich aber impliziert haben.

Spannungen und Divergenzen innerhalb des ordo wurden in den Inschriften bewusst ausgeblendet. Dies zeigt sich sehr deutlich am Umgang mit der Streitfrage der Religion. Wie bereits für andere Bereiche des öffentlichen Lebens aufgezeigt werden konnte, ${ }^{56}$ wurde der Friede zwischen Christen und ,Heiden' vor allem dadurch gewahrt, dass der öffentliche Raum der Stadt - Platzanlagen, Thermen und selbst die altehrwürdigen Tempel ${ }^{57}$ - von religiösen Inhalten freigehalten wurde. Was sich an der statuarischen Ausstattung öffentlicher Gebäude und Platzanlagen bereits erkennen ließ, findet nun auch hier Anwendung. Nicht nur heidnische Inhalte werden aus dem Formular der Inschriften gestrichen, auch christlich konnotierte Aussagen fehlen. Tatsächlich lässt sich anhand der epigraphischen Zeugnisse keine Aussage über die konfessionelle Ausrichtung der Geehrten machen. ${ }^{58}$ Dies fällt nicht nur bei Virius Nicomachus Flavianus auf, sondern eben auch auf christlicher Seite bei Männern wie Flavius Mallius Theodorus ${ }^{59}$, Anicius Auchenius Bassus ${ }^{60}$, Anicius Acilius Glabrio Faustus $^{61}$ oder Petronius Maximus ${ }^{62}$.

54 Vgl. CIL 6, 1725 v. 6 ff.

55 CIL 6, 1783 v. 19f. Vgl. auch CIL 6, 1782: HISTORICO DISERTISSIMO. Zu den nicht überlieferten Annales vgl. u. a. BLECKMANN (1995) 83-99; GRÜNWALD (1992) 471-473 und SCHLUMBERGER (1985) 305-329. Diskutiert wird vor allem, welchen Zeitraum die Annales abdeckten und inwiefern möglicherweise spätantike Historiker diese als Quelle heranzogen.

56 Vgl. Kap. 6.3.

57 Vgl. Kap. 6.4 zum Saturntempel.

58 Vgl. NIQUET (2000) 185.

59 CIL 6, 41380; zur Religionszugehörigkeit vgl.VON HAEHLING (1978) 437; zu den Aniciern allgemein DISSELKAMP (1997) 206.

60 CIL 6, 1679; zur Religionszugehörigkeit vgl. VON HAEHLING (1978) $318 \mathrm{f}$.

61 CIL 6, 41390; zur Religionszugehörigkeit vgl. VON HAEHLING (1978) 326.

62 CIL 6, 1749 und CIL 6, 41398 vgl. VON HAEHLING (1978) $324 \mathrm{f}$. 
Die senatorischen Ehrenmonumente sorgten hierbei nicht nur für ein allgemein verbindliches Leitbild bzw. Leistungs- und Lebensprofil. Sie demonstrierten auch öffentlichkeitswirksam die unerschütterliche Stabilität der gesellschaftlichen und politischen Ordnung. Die statuarische Ehrung nicht abreißen zu lassen, entsprach so ganz dem erhöhten Bedürfnis nach politischer Stabilität und Sicherheit sowie nach einer krisenbeständigen, gesellschaftlichen Orientierungsgrundlage. Insbesondere der gesellschaftsdisziplinierende Charakter ${ }^{63}$, der den Ehreninschriften des 5. Jhs. inhärent ist, erfolgte unter dem Leitgedanken pro bono publico - zum Wohle der Öffentlichkeit. Unter dieser Grundmaxime wurden nicht zuletzt auch der cursus honorum, die hohe Bildung und die charakterlichen Vorzüge des Geehrten präsentiert. Das Setzen von Ehrenmonumenten wurde so auch zu einem wichtigen Instrumentarium der Krisenbewältigung.

Ein früheres Beispiel hierfür stellt die im Jahr 399 dem Cronius Eusebius auf dem Trajansforum gewährte Ehrung dar. ${ }^{64}$ Als ehemaliger consularis Aemiliae und amtierender vicarius Italiae ${ }^{65}$ lässt sich Eusebius nicht gerade zu der höchsten Spitze der Reichsadministration zählen. Dafür aber war der vicarius Italiae in der Versorgungskrise, die durch die Gildo-Rebellion verursacht worden war, ${ }^{66}$ besonders gefragt. Diesem oblag die Aufsicht und Organisation der sieben norditalischen Provinzen, welche als landwirtschaftlich ertragreiche Regionen (Italia annonaria) ${ }^{67}$ für die Versorgung Roms in den Jahren 397/398 sicherlich von erhöhter Wichtigkeit waren. Den vicarius Italiae Eusebius in Rom als kompetenten Administrator zu präsentieren, der mit Wachsamkeit,

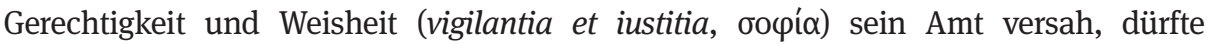
durchaus beruhigend auf das Volk von Rom gewirkt haben. Der Senat selbst konnte sich darin bestätigt fühlen, dass ein Mann, der mit seiner tadellosen Lebensführung und

63 Vgl. hier auch den Beitrag: LIVERANI (2015) 93-121, bes. 104-112 zum Verhältnis zwischen Ehrenmonument und Betrachter.

64 CIL 6, 1715 (=ILS 1274 = IG XIV 1075 = IGVR I 65): (a) CRONIO EVSEBIO V. C. / CONSVLARI AEMILIAE ADDITA / PRAEDICTAE PROVINCIAE CONTVITV / VIGILANTIAE ET IVSTITIAE EIVS / ETIAM RAVENNATIVM CIVITATE QVAE / ANTEA PICENI CAPVT PROVINCIAE / VIDEBATVR VICARIO ITALIAE QVAE / POTESTAS SVPRA DICTO VIRO OB TESTI/MONIVM ANTE ACTI HONORIS EST / ADTRIBVTA PETITIONE SENATVS / CONTEMPLATIONE VITAE ATQVE / ELOQVENTIAE EIVS AB INVICTISSIMIS / PRINCIPIBVS

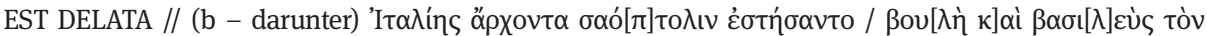

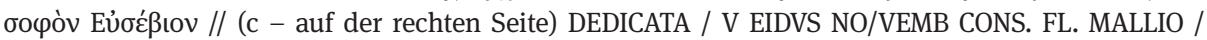
THEODORO V. C.; zur Inschrift vgl. auch CHASTAGNOL (1994) 184; FEISSEL (1984) 549 und MICHELI (1983) 70; zur Person PLRE 2, 433.

65 Zum Amt vgl. CHASTAGNOL (1963) 348-379, hier 351-354 und MOMMSEN, GS 6 (1910 ND 1994) 395-397. Diese Inschrift stellt die letzte zu fassende Erwähnung eines vicarius Italiae dar.

66 Vgl. Kap. 5.1; unter den angeführten Quellen vgl. etwa Claud. Gild. 64-69; hierzu JANSSEN (2002) $73 \mathrm{ff}$.

67 Diese umfasst die oberitalischen Provinzen: Aemilia et Liguria, Venetia et Histria und Flaminia et Picenum Annonarium, die für die Versorgung der kaiserlichen Residenzstädte Mailand und Ravenna sowie für die in Italien stationierten Truppen zuständig waren; allerdings sind die Bezeichnungen Italia annonaria und Italia suburbicaria moderne Wortschöpfungen (antik: regio annonaria und regiones urbicariae). Vgl. DEMANDT 2(2007) 296; RÉGERAT (1996) 193-206, hier 199 mit Anm. 30 und AUSBÜTTEL (1988) 138 mit Anm. 64; ausführlich CRACCO RUGGINI (1961). 
Eloquenz (vita atque eloquentia) die senatorischen Ideale bravourös verinnerlicht hatte, in der Krise nicht versagte.

Werden die epigraphischen Zeugnisse von ihrem historischen Kontext her gelesen, so lassen sich speziell für die Zeit nach 410 zahlreiche ähnlich geartete Beispiele anführen, in denen sich die senatorischen Ehrenmonumente als Instrumentarium der Krisenbewältigung zu erkennen geben. Um nur ein weiteres Beispiel zu nennen, sei das 421 für Petronius Maximus auf dem Trajansforum errichtete Ehrenmonument ${ }^{68}$ angeführt. Eine Besonderheit des Formulars stellt der Ämterkatalog ${ }^{69}$ dar, der ungewöhnlich minuziöse Angaben hinsichtlich des Alters des Amtsträgers und der Dauer seiner Amtszeit macht. Mit seinem cursus honorum, der bereits mit der Prätur ${ }^{70}$ vor etwa zehn Jahren und nachfolgend mit der Position eines tribunus et notarius und einem Sitz im consistorium begonnen hatte, wurde der aufmerksame Leser gedanklich in die schwierige Zeit unmittelbar nach der Plünderung Roms und den Machtkämpfen am Hof zurückversetzt. Durch die Geradlinigkeit des Ämteraufstiegs des Petronius Maximus wird jedoch der Eindruck erweckt, die zurückliegenden zehn Jahre seien von politischer Stabilität und Sicherheit geprägt gewesen.

Am Ende ist stets Vorsicht geboten bei der Herstellung von solchen Kausalzusammenhängen. Dennoch wird davon auszugehen sein, dass nahezu jede Ehrung eines Senators, Heermeisters oder auch des Kaisers ein Erzeugnis spezifischer politischer Umstände ist. Andernfalls müsste der Ehrung im öffentlichen Raum und ihren epigraphischen Inhalten ein hohes Maß an Willkür zugesprochen werden. Doch dies lässt sich, selbst wenn die hier aufgezeigten Zusammenhänge keine Zustimmung erfahren sollten, gewiss nicht vertreten. Neben dem Verhältnis zwischen Kaiser und Senatsaristokratie wirkte sich mit Sicherheit auch die politische Gesamtlage sowohl in Rom als auch im Imperium auf die Ehrungen im öffentlichen Raum aus. Wenn die statuarischen Ehrungen in ihrem historischen Kontext bewertet werden, so stellen sie durchaus mehr als nur ein senatorisches Repräsentationsmedium dar. Sollte die Interpretation der Inschriften das Richtige treffen, besaßen die senatorischen Ehrenmonumente eine gesellschaftsstabilisierende Wirkung. Zum einen demonstrieren sie öffentlichkeitswirksam den Konsens zwischen Kaiser und Senatsaristokratie, womit die politische und gesellschaftliche Stabilität betont wurde. Zum anderen schufen die Ehrungen ein Leitbild, welches Orientierung und Sicherheit, gerade auch in unsicheren Zeiten, versprach.

68 CIL 6, 1749 (ILS 809).

69 CIL 6, 1749 v. 10 ff.: [...] ORNATVR QVI PRIMAEVVS IN CONSISTORIO / SACRO TRIBVNVS ET NOTARIVS MERVIT NONO DECIM(o) / AETATIS ANNO SACRARVM REMVNERATIONVM / PER TRIENNIVM COMES POST PRAEF(ectus) VRB(i) ANNO ET SEX / MENSIB(us) HASQVE OMNES DIGNITATES INTRA VICE/ SIMVM QVINTVM ADSECVTVS AETATIS ANNVM / [...]; vgl. NIQUET (2000) 143f.

70 CIL 6, 1749 v. 7 ff. [...] CVIVS A PROVIS / ATABISQ(ue) NOBILITAS PARIB(us) TITVLORVM INSIGNIB(us) / ORNATVR [...] kann möglicherweise dahingehend gedeutet werden - immerhin waren mit der Quästur und der Prätur die Aufnahme in den Senat verbunden; zu den prätorischen Spielen Olymp. fr. 41,2; vgl. hierzu CHASTAGNOL (1958) 219. 


\subsection{Die senatorische Spielgebung - ein Sinnbild der Roma regina orbis terrarum}

Mit dem Spielwesen in der Spätantike hatte sich zuletzt Puk in seiner 2014 veröffentlichten Dissertation ${ }^{71}$ befasst. Ausführlich und facettenreich ist diese Abhandlung ausgefallen, so dass es sich im Folgenden erübrigen wird, das sehr weit ausgreifende Thema der Spielgebung erneut umfassend aufzurollen. Stattdessen soll zunächst eine zeitliche Präzisierung ${ }^{72}$ erfolgen, die die Spielgebung in der ersten Hälfte des 5. Jhs., und zwar in Rom, in den Fokus rückt. Im Besonderen wird der Schwerpunkt auf einem von Puk nur knapp thematisierten Aspekt der spätantiken Spielgebung liegen. Die ideologische Bedeutung der Spielgebung für die gesellschaftliche und politische Stabilität wird zu beleuchten sein. Damit verbunden ist die Frage, inwiefern sich die exorbitanten Ausgaben für die Spielgebung über einen konkreten Nutzen für das Gemeinwohl rechtfertigen lassen. Denkbar ist durchaus, dass die opulenten Spiele des 5. Jhs. im Sinn von panem et circenses ${ }^{73}$ zur Krisenbewältigung beitrugen.

$\mathrm{Zu}$ Beginn des 5. Jhs. stand das Spielwesen aber auch unter Kritik, die insbesondere hochrangige Vertreter der Kirche ${ }^{74}$ vorbrachten. Auch die öffentlichen Spiele waren von den restriktiven Gesetzen, die gegen die heidnischen Kulte gerichtet waren, betroffen. ${ }^{75}$ Nicht wenige dieser öffentlichen Spektakel lassen sich mit der heidnischen Kultpraxis verbinden. ${ }^{76}$ Die zu den Spielen dazugehörige pompa circensis $^{77}$ und der processus consularis waren religiös höchst aufgeladene Ereignisse. Ebenso sorgte die Anbindung an den römischen Festkalender, der noch immer die Festtage an den cultus für die Götter band, für den heidnischen Charakter der Spiele. Zahlreiche Spielstätten waren überdies oft auch architektonisch mit Kultstätten verbunden.

71 Hierzu vgl. LAMBRECHT, Rez. In: H-Soz-Kult, 13.04.2015.

72 PUK setzt den zeitlichen Rahmen von der Zeit der Tetrarchen bis ins 7. Jh. sehr weitgefasst an, wobei er sowohl den römischen Osten als auch den Westen betrachtet.

73 Der Ausdruck stammt von Juv. Sat. 10,81; als politisches Instrument der Kaiser zur Beruhigung der Massen Front. princ. hist. 18: populum Romanum duabus praecipue rebus, annona et spectaculis, teneri. Vgl. u. a. THUILLER (1999) 173-186; BERNSTEIN (1998); WEEBER (1994) bes. 145-155; CAVALLARO (1984) und besonders die sozilogische Studie VEYNE (1976).

74 U. a. Chrys. De in glor. 6 -12; Ambr. Off. 2,21,109 und Aug. c. acad.1,2. Ausführlich hierzu PUK (2014) 21-52; ferner LUGARESI (2007) 21-34; MRATSCHEK (2007) 21- 57 und KLEIN (2004) 155 - 174; knapper LIM (2009) 497-511, hier 500 f. und NÄF (1995) 86, 89, 98 u. 114. Zur moralischen Kritik vgl. PUK (2014) $64-68$.

75 Vgl. hierzu jetzt auch LATHAM (2016) bes. 207-233.

76 Für die republikanische Zeit vgl. etwa BERNSTEIN (1998) 23-118 (besonders im Zusammenhang mit dem Kult des Iuppiter Optimus Maximus, des Apollon und der Magna Mater). Für die Spätantike PUK (2014) 55 f.; MACHADO (2010b) 287-313; BEHRWALD (2009) 107 f. und CURRAN (2000) 185f., 221230 u. 252-258; ferner WELCH (1998) 547-569, hier 558; ROUECHÉ (1993) 2-3; MARKUS (1991) 253- 272 und CAMERON (1976) 152. Archäologisch sind kleinere Tempel innerhalb oder in der Nähe von Spielstätten belegt. Hierzu vgl. HUGONIOT (1996) 241-245 und HANSON (1959).

77 Hierzu aktuell LATHAM (2016). 
Besonders eindrücklich zeigt dies eine Diptychontafel auf, welche wahrscheinlich das Monogramm der Symmachi ${ }^{78}$ trägt (Abb. 14) ${ }^{79}$. Das Diptychon zeigt die Apotheose (consecratio) einer Person, die vermutlich als Kaiser ${ }^{80}$ anzusprechen ist. Von geflügelten

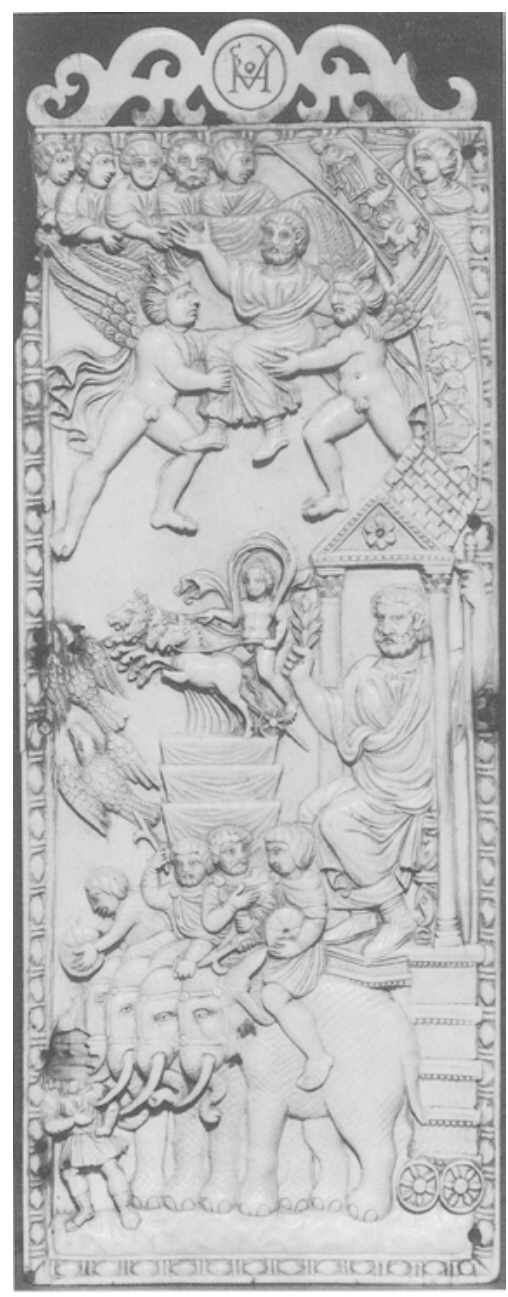

Abb. 14: Diptychon mit Apotheose.

78 Die Zuweisung SYMMACHORVM bleibt umstritten; auch ALFÖLDI (1942/1943) 63; DELBRUECK (1929) 299 löst das Monogramm (M oder H?) über dem Bildfeld als: HORMISDAS VIR CLARISSIMVS auf; CAMERON (2011) 721 und 739 schlägt die Auflösung MEMMIVS SYMMACHORVS vor (datiert 401); dieses Problem kann an dieser Stelle nicht gelöst werden und ist für die Betrachtung auch von untergeordneter Bedeutung.

79 Abbildung nach KINNEY (2008) Fig. 1; vgl. DELBRUECK (1929) Nr. 59, Taf. 59; VOLBACH ${ }^{2}(1952)$ Nr. 56, Taf. 14; heute London, British Museum Inv.-Nr. I/645. Abbildung nach PUK (2014) Taf. 66, Abb. 82.

80 Für Julian Apostata (†363) sprechen sich aus u. a. BRANDT (1998) 188-190; STUTZINGER (1983) 671-673, Kat.-Nr. 248 und STRAUB (ND 1972b) 159-177, hier 172ff., der aber auch Antoninus Pius (†161) 
Wesen, die wohl Genien darstellen sollen, wird der Vergöttlichte in den Himmel emporgehoben, wo er von fünf Himmelsbewohnern empfangen wird. Aufgrund der Tracht sind diese wohl nicht als die olympischen Götter anzusprechen, sondern stellen eher die divinisierten Vorgänger dar. Das untere Bildfeld dominiert eine Elefantenquadriga, auf der in einer aedicula thronend der konsekrierte Kaiser in einem triumphartigen Aufzug präsentiert wird. Ohne sich hierbei in der Diskussion ${ }^{81}$ der sehr vielschichtigen Darstellung zu verlieren, bleibt, auf das Wesentliche hinzuweisen. Dies betrifft die Szenerie mit der Elefantenquadriga, ${ }^{82}$ die so auch real denkbar ist, wobei es sich dabei um ein Abbild des konsekrierten Kaisers handeln würde. Anlass für die Herausgabe des Diptychons könnte das Konsekrationsjubiläum eines heidnischen Kaisers gewesen sein. Ein solches Jubiläum konnte mit dem processus consularis und den Feierlichkeiten im Circus zusammenfallen.

Ganz abgesehen von der Frage, ob die Senatsaristokratie mit solchen Bildern einen Gegenentwurf zum christlichen Kaisertum präsentierte und sich solche Bilder als „Kampfmittel“"83 zu verstehen geben, ist kaum zu übersehen, dass in solchen Aufzügen Circus und Stadt zu einer Bühne für die heidnische Weltanschauung wurden. Die Kaiser ihrerseits konnten hier nicht mit gleicher Härte reagieren, wie dies hinsichtlich der Tempel der Fall war. Um die öffentlichen beneficia, ${ }^{84}$ die von der stadtrömischen Senatsaristokratie entscheidend mitgetragen wurden, nicht zu gefährden, mussten gewisse Freiheiten gestattet bleiben. Hier lässt sich der Feststellung Currans ${ }^{85}$ folgen. Das Spielwesen lässt sich nicht vom ,Paganen“ trennen. Heidnische Bildwelten und Inhalte blieben ein fester Bestandteil der Spiele und Spielstätten, wie dies auch für die kaiserlichen und senatorischen Repräsentationsbilder und die Panegyrik ${ }^{86}$ galt. Allerdings

erwägt (ebd. S. 174). Denkbar sind des Weiteren Marc Aurel (†180), Pertinax (†193) und Septimius Severus (†211). Letztere kämen im Jahr 393 und 411 auf ihr 200-jähriges Konsekrationsjubiläum; für sie ist die consecratio überliefert bei Cass. Dio 74,4,1-5 (Pertinax; allerdings erst 197 durch Septimius Severus) und Herod. 4,2,1-11 (Septimius Severus). Eine Datierung des Diptychons Anfang des 5. Jhs. wird durch den eher klassizistischen Stil nahegelegt. Vgl. CAMERON (2011) 739f. Zur Divinisierung vgl. ECK (2016a) 43f. u. 48-53.

81 Hier sei verwiesen auf CAMERON (2011) 719-729; KINNEY 2008, 152-154; ARCE (1988) 151-155; DELBRUECK (1929) 299f.; grundlegend WEIGAND (1939) 121-126.

82 Hierzu vgl. auch WIENAND (2012) 490-495.

83 BRANDT (1998) 190 nach ALFÖLDI/ALFÖLDI-ROSENBAUM (1990) 42; in Zweifel wurde dies schon von WYTZES (1977) 335 gezogen. Vgl. auch CAMERON In: ALFÖLDI/ALFÖLDI-ROSENBAUM (1990) 63-65; ferner CALLU, Rez. Alföldi/Alföldi-Rosenbaum. Gnomon 65 (1993) 169f. Eine friedliche Koexistenz von ,Heiden‘ und Christen vertrat vor allem MAZZARINO (1951) 121-148.

84 Zur Begrifflichkeit im Zusammenhang mit der römischen Herrschideologie vgl. u. a. WIENAND (2012) 92, 156 u. 412 und KOLB (2001) 57, 86, 124 u. 197-223; im Zusammenhang mit dem senatorischen Patronat vgl. KRAUSE (1987) 20 - 23, 28f. u. 65f.; knapp HEIL (2005) 107-124, hier 120 f. und LENTANO (2005) 125-142, bes. 136 und DREXLER (1988) 44: maiestas.

85 CURRAN (2000) 218-259, bes. 259.

86 Hier ist z. B. an das Probus-Diptychon (DELBRUECK (1929) Nr. 1) zu denken oder die Panegyrik Claudians. 
wurde auch hier ein Kompromiss eingegangen, der zur Folge hatte, dass sich im Verlauf des 5. Jhs. eine religiös neutrale Spielgebung ${ }^{87}$ etablieren konnte.

Reminiszenzen an das Heidentum, Mythos und Götterwelt, wurden als profanes, religiös unbedenkliches Traditionsgut ${ }^{88}$ uminterpretiert und bewahrt. CTh.16,10,17 ${ }^{89}$ aus dem Jahr 399, welches allerdings an den proconsul von Africa ausgestellt war, belegt dies. So werden die Spiele nicht allgemein als ,pagan“ verworfen. Für die Repräsentation der Kaiser $^{90}$ und auch der christlichen Senatsaristokratie waren die Spiele viel zu wichtig. Nicht mal das alte Brauchtum (vetus consuetudo) und die Gastmäler (festa

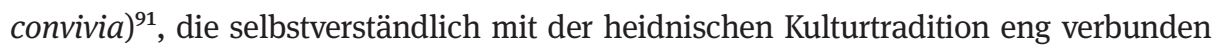
waren, werden abgelehnt. Lediglich das Opfer (sacrificium) und der schädliche Aberglaube (superstitio) sind zu unterlassen. Im Grund wurde damit derselbe Kompromiss geschlossen, der auch die paganen Bauten, den statuarischen Schmuck und die senatorischen Ehrenmonumente zu einem religiös neutralen Kulturgut werden ließ. Der cultus wurde verboten, womit die Spiele lediglich ihre religiöse Funktion verloren, aber nicht ihre ,pagane‘ Prägung. Zum einen wurde es hierdurch möglich, dass der Kaiser und auch die christliche Senatsaristokratie weiterhin als Spielgeber fungieren konnten. Zum anderen wurde damit auch sichergestellt, dass kein wichtiger Bevölkerungsteil von den Spielen ausgeschlossen war. Zu einer scharfen Trennung zwischen ,christlich ${ }^{\star}$ und ,pagan“ konnte es in der Spielgebung schon deswegen nicht kommen, da gerade für die Repräsentation des Spielgebers ein möglichst großes Publikum wünschenswert war. So war hier vieles vom Wunsch der Öffentlichkeit (votum publicum) abhängig, zumal die öffentliche Meinung maßgeblich über den Erfolg und Misserfolg von Spielen entschied.

Auf die fortschreitende Christianisierung der Bevölkerung musste auch die heidnische Senatsaristokratie Rücksicht nehmen. An der Neuauflage der Kontorniat-Medaillons, die noch im 4. Jh. stark von der heidnischen Bildwelt geprägt waren, so dass Alföldi diese gar als „Propagandamittel der stadtrömischen heidnischen Aristokratie“992 verstand, lässt sich eine bis Mitte des 5. Jhs. stärker werdende Zurückhaltung feststellen. Waren noch im 4. Jh. Philosophen und Dichter, ${ }^{93}$ Herrscher, Heroen ${ }^{94}$ und Gottheiten ${ }^{95}$

87 Hierzu auch PUK (2014) 56-62.

88 Dies ist nicht die Perspektive der Kirchenväter, die ihre Kritik auch weiterhin aufrechterhielten. Hierzu auch RATTI (2012) 67-76, wobei hier die Polemik im Theater bzw. der Komödie deutlich überbewertet wird.

89 Vgl. CTh. 16,10,17 (20.08.399): Ut profanos ritus iam salubri lege submovimus, ita festos conventus civium et communem omnium laetitiam non patimur submoveri. Unde absque ullo sacrificio atque ulla superstitione damnabili exhiberi populo voluptates secundum veterem consuetudinem, iniri etiam festa convivia, si quando exigunt publica vota, decernimus. (Übersetzung bei PUK (2014) 56).

90 Vgl. hierzu PUK (2014) 53-84 und CURRAN (2000) 230-236.

91 Hier ist z. B. an die Saturnalia des Macrobius zu denken.

92 ALFÖLDI/ALFÖLDI-ROSENBAUM (1990) 25-63; bereits ALFÖLDI (1943).

93 Euripides, Demosthenes, Sokrates, Theophrastos, Homer, Solon, Nikokreon, Anaxarchos, Horaz, Terenz, Sallust, Apuleius, Apollonius von Tyana, Accius, Pythagoras (ALFÖLDI/ALFÖLDI-ROSENBAUM (1990) 94-104, Nr. 82-111). Hieran lässt sich auch gut ein Einblick in den spätantiken ,Bildungskanon' gewinnen; es überwiegen - gemäß dem erhaltenen Bestand - die griechischen Autoren 
im Bildprogramm der Kontorniaten fest verankert, so fehlen diese aus dem Heidentum entlehnten Idealgestalten im 5. Jh. fast völlig. An ihre Stelle treten auf dem Revers nun verstärkt Darstellungen, die im Zusammenhang mit der öffentlichen Spielgebung stehen. Zum Bildrepertoire gehört der Konsul mit Zepter und mappa auf der sella curulis ${ }^{96}$, der siegreiche Wagenlenker mit Palmzweig in seiner Quadriga ${ }^{97}$, Darstellungen von venationes, Wagenrennen in der Arena ${ }^{98}$ und musischen Darbietungen, die Ehrung der Athleten ${ }^{99}$ sowie die Abbildung der Orgel ${ }^{100}$. Eine Fokussierung auf religiös neutrale Handlungsabläufe wird hieran ersichtlich. Gänzlich fehlen Hinweise auf den Inhalt der Darbietungen.

Eine Fokussierung auf Handlungsabläufe statt auf Inhalte kann ebenfalls an den Diptychen beobachtet werden. Während die frühen Exemplare wie etwa das Symmachus-Nicomachus-Diptychon ${ }^{101}$, das Asklepios-Hygieia-Diptychon ${ }^{102}$ und das oben angeführte Konsekrationsdiptychon sich auf Inhalte beziehen, die ganz allgemein ge-

(zum Teil mit griechischer Legende). Zugleich lässt sich eine Rangfolge der Autoren erkennen (z. B. Sallust (49-mal), Homer (47-mal), Horaz (18-mal) ... Sokrates (1-mal)?), welche aber nicht in allen Belangen den senatorischen Vorlieben entspricht. Vgl. MITTAG (1999) 115-126.

94 Nur als Revers-Motiv Schild des Achill (ALFÖLDI/ALFÖLDI-ROSENBAUM (1990) 118, Nr. 30); Achill und Penthasilea (152, Nr. 77-79), Hercules (123-126, ausführlich 145-151, Nr. 40 - 44), Dioskuren (126, Nr. 45), Hero und Leander (132, Nr. 53), Bellerophon, die Chimaera tötend (133-136, Nr. 58 u. 59), Jason im Kampf mit den Stieren (140, Nr. 67), Odysseus und Kirke (155, Nr. 80 u. 81), Laokoon (158, Nr. 87-89), Aeneas mit Anchises und Ascanius (158, Nr. 90 u. 91), Lupa mit den Zwillingen (160, Nr. 92) etc.; dies spiegelt sehr gut den bis in die Spätantike bewahrten Mythenkanon wider, deren Kern immer noch der Sagenkreis um den Trojanischen Krieg und die Gründung Roms bildet; hinzu kommt Hercules, der sich als Erretter der Menschen großer Beliebtheit erfreute. Vgl. MITTAG (1999) 94-114, bes. 113. Auf dem Avers treten neben dem Kaiserbildnis auch Alexander d. Gr. mit Löwenfell oder Diadem (ALFÖLDI, Nr. 80-85), Olympias mit Schleier und Zepter oder als Omphale mit den Attributen des Hercules (Nr. 85-87) in Erscheinung. Hierzu vgl. auch MITTAG (1999) 127-146.

95 Serapis (ALFÖLDI/ALFÖLDI-ROSENBAUM (1990) 105f., Nr. 112, Nr. 581); nur als Rev.-Motive: Sol Invictus auf der Quadriga (112, Nr. 12, 13), Bacchus (113f., Nr. 10-22), Kybele und Attis (115-118, Nr. 23 -29), Apollon (119f., Nr. 31-33), Mars Propugnator (120, Nr. 34), Athena/Athena-Sapientia (121123, Nr. 35, 38, 39), Minerva zusammen mit Hercules (123, Nr. 40 und 41); Isis Pharia (128, Nr. 48); ferner zahlreiche Roma-Darstellungen (S. 163-167); zzgl. zahlreicher Personifikationen, die sich auf allgemeines Wohlergehen (auch Annona) und Sieghaftigkeit (Krieg/Wettkampf) beziehen. Insbesondere das häufige Auftreten Romas versinnbildlicht die Verbundenheit der Kontorniatenprägung mit der Stadt. Vgl. KLEER (1983) $70-74$.

96 ALFÖLDI/ALFÖLDI-ROSENBAUM (1990) Kat.-Nr. 461 (1-2; Taf. 188) mit Darstellung des Petronius Maximus.

97 ALFÖLDI/ALFÖLDI-ROSENBAUM (1990) Kat.-Nr. 450 u. 451 (1-9 und 10; Taf. 186); Kat.-Nr. 452, 456, 457 (2, 5, 6-7 Taf. 187); Kat.-Nr. 462 (3-4; Taf. 188); Kat.-Nr. 476 (6-7; Taf. 191).

98 ALFÖLDI/ALFÖLDI-ROSENBAUM (1990) Kat.-Nr. 468 (3 u. 4; Taf. 190).

99 Dieser Bildtyp hat mit Abstand die größte Variationsbreite; hier ALFÖLDI/ALFÖLDI-ROSENBAUM (1990) Kat.-Nr. 463(5).

100 ALFÖLDI/ALFÖLDI-ROSENBAUM (1990) Kat.-Nr. 480 (3; Taf. 192); zum Einsatz der Orgel im Circus, Theater etc. vgl. Claud. Cos. Mall. 316-319; MARKOVITS (2003) 49, 187 u. 337.

101 DELBRUECK (1929) Nr. 54; hierzu noch Kap. 9.1.

102 DELBRUECK (1929) Nr. 55. 
sprochen, sich mit der heidnischen Oikumene verbinden lassen, kommen auf den Elfenbeinbildwerken späterer Zeit fast nur noch religiös neutrale Handlungsabläufe zur Darstellung. Analog zu den Kontorniaten des 5. Jhs. beschränken sich die gewählten Motive auf das Repräsentationsbild des Konsuls, die Circusrennen und vor allem auf die venationes. Befreit von heidnisch konnotierten Inhalten passte sich das Spielwesen zwar seiner zunehmend christianisierten Umwelt an und konnte sich sein Publikum erhalten, verlor aber ohne Anbindung an seine religiöse Funktion ${ }^{103}$ seinen ursprünglichen Sinngehalt.

An die Stelle der alten religiösen Inhalte mussten neue Inhalte treten, die der Spielgebung über das reine Amüsement hinaus eine gesellschaftliche und politische Funktion verliehen. Diesbezüglich lohnt nun ein Blick auf die Panegyrik Claudians, in der die Spielgebung immer wieder aufgegriffen wird. In seiner Lobrede auf den Konsul des Jahrs 399, Mallius Theodorus, preist Claudian auch die zu erwartenden Spiele:

Sammelt dem Volk die reichsten Wunder! In Theatern verherrlicht würdig den Namen! [...] Erbitte geflügelte Vierergespanne [...], welchen die Palme des Siegs Arion nimmer entreiße! [...] Es fördere Letos Tochter die Pracht in der Arena! Sie wähle die Mutigen selbst, die mit Kunstfertigkeit um den Nacken der Bestien Fesseln zu schlingen und Speere mit sicherem Schwung zu werfen verstehen! Sie führe auch selbst in Fesseln die ungeheuren Wunder der Tierwelt [...]! Da mag hoch an den Sternen staunen Lycaons Helice über der Bären Gewicht und dem Wehschrei dieser Riesen! Schaudernd erblasse das Volk beim Sturz durchstoßener Löwen, wie sie Rhea mit Lust vor ihren mygdonischen Wagen anspannt und Hercules sie stolz mit dem Arm bändigen möchte! [...] Was Gätuliens heißes Gebiet an Bestien ernährt, was im Eis in den Alpen sich verbirgt, was gallische Wälder an Wild durchtobt, das falle gesamt! Reich wälze das Blut sich durch die Arena! Das Spiel entvölkere ganze Gebirge! ${ }^{104}$

Zunächst fällt die Affinität der claudianischen Dichtung zur paganen Metaphorik und Mythologie auf, ${ }^{105}$ die die Realität eng mit der pagan-mythologischen Bildsprache verknüpft. So soll die Jägerin Diana die Pracht in der Arena steigern, Lycaons Helice, die selbst in das Sternbild des großen Bären versetzt wurde, ${ }^{106}$ soll angesichts der Größe der in der Arena präsentierten Bären das Staunen ergreifen. Die mächtigen Löwen, die Kybele gebändigt vor ihren Wagen spannt oder Hercules mit bloßen Händen erlegte, sollen nun dem venator zum Opfer fallen. Die Bezüge auf Götter und

103 Hierzu vgl. jetzt auch LIM (2012) 61-82.

104 Claud. Cos. Mall. 280 -332: miracula plebi colligite et claris nomen celebrate theatris. [...] oratum volucres [...] quadrigas, a quibus haud umquam palmam rapturus Arion. [...] non aspernata rogantem amphitheatrali faveat Latonia pompae. audaces legat ipsa viros, qui colla ferarum arte ligent certoque premant venabula nisu. ipsa truces fetus captivaque ducat ab antris prodigia [...]. conveniant ursi, magna quos mole ruentes torva Lycaoniis Helice miretur ab astris, perfossique rudant populo pallente leones, quales Mygdonio curru frenare Cybele optet et Herculei mallent fregisse lacerti. [...] quidquid monstriferis nutrit Gaetulia campis, Alpina quidquid tegitur nive, Gallica siquid silva tenet, iaceat; largo ditescat harena sanguine; consumant totos spectacula montes. Zusammenfassend PUK (2014) 128.

105 Hierzu jetzt auch SCHINDLER (2015) bes. 28-31 zur panegyrischen Überbietung des mythischen Vorbilds.

106 Vgl. Ov. Met. 2,401. 
mythologische Gestalten entsprachen dabei gewiss keiner kultischen Verehrung, sondern dienten in rhetorischer Manier der Übertreibung. Zugleich diente hierbei die göttliche Sphäre als Referenzrahmen für die irdischen spectacula.

Vor allem im letzten Abschnitt der Textpassage wird deutlich, wie stark der Herrschaftsanspruch Roms ${ }^{107}$ über die römische Welt noch war. In der Arena wurde die gesamte (Tier-)Welt versammelt. Wilde Bestien aus der Hitze der afrikanischen Provinzen fallen in der Arena genauso wie die Tierwelt aus dem Eis der Alpen und den tiefen Wäldern Galliens. ${ }^{108}$ Der Siegeszug und die Herrschaft Roms über die Völker des Erdkreises erfuhr im Sand der Arena eine öffentlichkeitswirksame Bestätigung. Die Spielgebung sorgte dafür, dass das Idealbild einer noch immer unangefochtenen Herrschaft Roms über die Welt in der öffentlichen Wahrnehmung weiterhin verankert blieb. Dies lenkte von der tatsächlichen Lage $a b,{ }^{109}$ dem Kontrollverlust der kaiserlichen Zentralgewalt und dem zunehmenden Auseinandertriften der einzelnen Reichsteile. Insofern wird die Spielgebung gerade im 5. Jh. zu einem wichtigen Instrument der Krisenbewältigung.

Unlängst wies Vespignani ${ }^{110}$ darauf hin, dass die venationes allgemein als Metapher für die Sieghaftigkeit, vor allem die militärische, aufzufassen waren. Die von Claudian gepriesene Herrschaft Roms, die Stilicho gegen die Machtansprüche Konstantinopels verteidigt und zurückgewonnen habe, ${ }^{111}$ findet in der Vorbereitung zu den Spielen des Jahrs 400 sein unmittelbares Gegenstück. Mehr als ein Drittel des gesamten panegyricus $^{112}$ nimmt der Katalog der in der Arena präsentierten Tierwelt und ihrer Bezwinger ein: Kreter mit struppigem Haar, hagere Spartaner und Britannier ${ }^{113}$ stellen sich den wilden Tieren entgegen. Dalmatiens Wälder, der gallische Forst und die Moore Germaniens ${ }^{114}$ werden zum Jagdgebiet. Vom Rhein über die Alpen bis nach Spanien erstreckt sich die Jagd. ${ }^{115}$ Gallische Eber, Bären aus den Alpen, Hirsche von Sizilien und Korsika ${ }^{116}$, Löwen, Leoparden und Luchse aus Libyen, Elefanten und Tiger aus dem

107 Verg. Aen. 6,847-853.

108 Hier fällt auf, dass es sich 399 ausschließlich um Tiere aus dem Westen handelt, was wahrscheinlich auf die gespannte politische Lage zwischen Ost und West zurückzuführen ist. Symmachus präsentiert 401 aber auch Tiere aus dem oströmischen Reichsteil (Krokodile; vgl. Symm. ep. 9,151); vielleicht auch schon Stilicho 400 (Elefanten und Tiger aus Indien; vgl. Claud. Cos. Stil. 3,333-369). 109 Vgl. hier Isid. Pel. ep. 5,185 (1469) (Évieux, SC 454 (2000) mit französischer Übersetzung). Hierzu knapp PUK (2014) 69f. und KLEIN (2004) 168f.; ausführlich LIM (1997) 66 - 74, bes. 66f. (mit englischer Übersetzung).

110 Vgl. VESPIGNANI (2002) 13-37, bes. 21; nachfolgend PUK (2014) 261 f.; ENENKEL (2014) 15-56, bes. 39f.; SGUAITAMATTI (2012) 174; MANN (2011) 43f. und MEIER (2009) 203-232, bes. $211 \mathrm{f}$.

111 Claud. Cos. Stil. 3,125-139ff. mit Lobpreis auf Rom Claud. Cos. Stil. 3,130-173. Vgl. hierzu auch DÖPP (1980) 181.

112 Claud. Cos. Stil. 3,237-369.

113 Claud. Cos. Stil. 3,300 f.

114 Claud. Cos. Stil. 3,302-304.

115 Claud. Cos. Stil. 3,305-309. Zum aristokratischen Ideal der Jagd vgl. PUK (2014) 282-287.

116 Claud. Cos. Stil. 3,310 - 314. 
fernen Indien ${ }^{117}$ fanden ihren Weg nach Rom. Libyens wilde Löwen zu erlegen und dem Land damit Sicherheit und Wohlstand garantieren zu können, ${ }^{118}$ trug so ganz dem römischen Herrschaftsauftrag Rechnung, als dessen Vollstrecker sich Stilicho nur zu gerne sah. Die Analogie zum wilden Treiben des Gildo, seiner Bezwingung und der Befriedung des Landes dürfte dem Publikum sicher nicht entgangen sein. Weder auf den Herrschaftsbereich des weströmischen Hofes noch auf die Grenzen des Reichs blieb die Suche nach Tieren beschränkt. Deutlich ist hierbei der Wille zu erkennen, dem verwöhnten und äußerst anspruchsvollen stadtrömischen Publikum immer neue Exoten ${ }^{119}$ vorzuführen. Für den Spielgeber verband sich mit solch außergewöhnlicher Exotik und dem zu erhoffenden Staunen der Menge die Aussicht auf etwas beständigeren Nachruhm. Dementsprechend wurde mit Vorliebe das Aufwändigste an den Spielen, das Auftreiben, der Transport und die Verschiffung der für die Arena bestimmten Exoten, in der senatorischen Repräsentationskunst festgehalten.

Für das 4. Jh. stellt etwa das große Ambulatio-Mosaik der villa von Piazza Armerina $^{120}$ ein prominentes Beispiel dar. Hier hielt der Besitzer des Anwesens für seine Familienangehörigen, Klienten und Gäste fest, zu welcher Leistung er imstande war. Der gesamte bekannte Erdkreis bis in die entferntesten Winkel wird hier zum aristokratischen Jagdgebiet. Die Personifikationen Africa bzw. Mauritania und India, ${ }^{121}$ welche sich in den äußeren Apsiden finden, markieren in ihrer exotischen Gestalt die äußersten Grenzen der bekannten Welt. Für Rom lässt sich mit dem Jagdmosaik, welches nahe Santa Bibiana auf dem Esquilin freigelegt wurde und heute in der Centrale Montemartini ausgestellt ist, ein entsprechendes Beispiel anführen. ${ }^{122}$ Die Darstellung zeigt das Treiben und Einfangen von Bären, Gazellen und Ebern in Netzen und Transportkisten. Weniger die Exotik der Tiere als vielmehr die Vielfalt der Jagdgebiete scheint hierbei im Vordergrund zu stehen. Von der Flora her zu urteilen wird der Eindruck einer

117 Claud. Cos. Stil. 3,333-369.

118 Claud. Cos. Stil. 3,333-344.

119 Vgl. auch Symm. ep. 9,144: Antilopen und Gazellen; Symm. ep. 9,151: Krokodile (vgl. hierzu Kap. 7.2). Hierzu auch PUK (2014) 280.

120 Raum 25 (nach KÄHLER); zu den Mosaiken sind die Publikationen CARANDINI (1982); KÄHLER (1973); CARANDINI (1964); sowie speziell GENTILI (1964) heranzuziehen. Die Datierung und Interpretation sind zum Teil überholt, das Bildmaterial jedoch vorbildlich publiziert; aktueller zum Forschungsstand PENSABENE (2010). Für weitere Beispiele vgl. PUK (2014) Taf. 67-106.

121 Nördliche Apsis: Das nur fragmentarisch erhaltene Mosaik lässt eine weibliche Personifikation mit einem Löwenfell über den Schultern und einem Löwenjungen auf dem Arm erkennen; KÄHLER (1973) 33 (nicht abgebildet): benennt die Personifikation als Mauritania, als äußersten westlichen Bereich der römischen Welt, analog zu India bzw. Asia. Südliche Apsis (CARANDINI 1982, Fig. 131): Die dunkelhäutig dargestellte weibliche Personifikation, welche von einem Elefanten und einem Tiger umgeben ist und im Arm den Stoßzahn eines Elefanten hält, scheint Asia oder India zu meinen; hinzu kommt am südlichen Rand des Ambulatio-Mosaiks die Darstellung eines Greifs, welcher ebenfalls auf den fernen Osten verweisen soll. Vgl. KÄHLER (1973) 33.

122 Vgl. CIMA (2000) 100 -103, Abb. 5. Vgl. BERTOLETTI/CIMA/TALAMO (1999) 110f. Zur Einordung in den architektonischen Kontext und der repräsentativen Wirkung vgl. knapp MIELSCH (2016) $29 \mathrm{f}$. 
zusammenhängenden Landschaft erweckt, was jedoch in Anbetracht der dargestellten Fauna nicht möglich ist.

Bei den venationes und Tierschauen spielte nicht nur die Exotik ${ }^{123}$ und Monstrosität der Bestien eine Rolle. Auch die widernatürliche Kombination von Tieren, die in ihrem natürlichen Lebensraum nie aufeinandertreffen würden, barg einen besonderen Reiz. Einige nordafrikanische Terra-Sigillata-Schalen ${ }^{124}$ greifen dies auf, wenn Löwen, Elefanten, Stiere und Bären zusammen präsentiert werden. Die venationes und Tierschauen wurden so zu einem Abbild der den Erdkreis umfassenden römischen Universalherrschaft. Im Mikrokosmos der Arena wurde dem Publikum die geographische Größe des Römischen Reichs, die durch Siege erkämpft und erhalten wurde, aufs Eindrücklichste ins Bewusstsein zurückgerufen. Je größer hierbei der betriebene Aufwand, umso deutlicher zeigte der senatorische Spielgeber, wie leicht er aufgrund seiner auctoritas und potestas wie auch seines Vermögens und seiner Kontakte über die Kapitalien des Reichs verfügen konnte. Damit war es der stadtrömischen Senatsaristokratie möglich, den Beweis anzutreten, dass ihr noch immer alle Reichtümer des Erdkreises unterstanden. So dienten die venationes und Tierschauen den senatorischen Häusern Roms zur öffentlichkeitswirksamen Präsentation ihres gewaltigen Besitzes und Einflusses in allen Reichsteilen.

Als potenzielles Publikum kam neben der stadtrömischen Bevölkerung, den senatorischen Häusern und ihrer großen, nicht nur stadtrömischen Klientel, gerade im 5. Jh. auch wieder der Kaiser und der Hof in Frage. Da die senatorischen Spielgeber für die Beschaffung ihrer Attraktionen reichsweit auf ihr umfangreiches Klienten- und Beziehungsnetzwerk zurückgriffen, ${ }^{125}$ fand die Spielgebung auch über Rom hinaus Beachtung. Entsprechend vielfältig waren die genutzten Repräsentationsmedien. Während die Elfenbeindiptychen vor allem für die eigenen Standesgenossen und den Kaiser geschaffen wurden, ließ sich über seriell gefertigte Stücke wie die Kontorniaten oder Terra-Sigillata in großer Zahl Angehörige aus niedrigeren sozialen Schichten, auch außerhalb Roms, erreichen. In der Spielgebung ließen sich somit auch die Beziehungsnetzwerke und zentripetalen Kräfte stärken, die Rom mit den Provinzen verband.

Mit dem Verlust wichtiger Reichsteile und der Unsicherheit in weiten Teilen des Westens wurde gerade die Durchführung der venationes zu einer gewaltigen logistischen und finanziellen Herausforderung. Spätestens 439 gingen mit der Einnahme der wichtigsten Küstenstädte Nordafrikas durch die Vandalen die wichtigsten Umschlag-

123 Hierzu vgl. auch PUK (2014) 278-282.

124 Vgl. PUK (2014) Abb. 92 u. 94; vgl. VAN DEN HOECK (2013) 73-100, Fig. 10 f., 13f. u. 20.

125 Hier ist auf die Korrespondenz des Symmachus zu verweisen: z. B. Symm. ep. 4,62 (spanische Rennpferde über einen gewissen Euphrasius); daneben auch Zahlreiche regionale und überregionale Amtsträger: z. B. Symm. ep. 6,59; 7,59; 9,16; 9,21; 9,22; 9,137; vgl. hierzu PUK (2014) 273 mit einer vollständigen Auflistung. Zum senatorischen Beziehungsnetzwerk allgemein vgl. ROLLÉ DITZLER (2020) 133-150. Speziell zu Symmachus vgl. auch Kap. 8.1. 
plätze für exotische Tiere ${ }^{126}$ verloren. Mit Versagen des administrativen Netzes ${ }^{127}$ und dem damit einhergehenden Fall des kaiserlichen Monopols auf bestimmte Tierarten und Dienstleistungen ${ }^{128}$ stieg der Grad der Selbstverantwortlichkeit für den senatorischen Spielgeber. Im Grunde hätte sich die desaströse militärische Lage unmittelbar auf die Spielgebung auswirken müssen. Dass dies nicht der Fall war, ist im Besonderen der stadtrömischen Senatsaristokratie zu verdanken.

Dafür, dass der kaiserliche Fiskus nicht mehr in allen Belangen den finanziellen und materiellen Bedarf der Spielgebung zu decken imstande war, zeugen die Kontorniaten der sog. Reparatio-Muneris-Serie ${ }^{129}$. Auf dem Avers, der eine Roma-Büste ${ }^{130}$ zeigt, steht die Legende INVICTA ROMA - FELIX SENATVS. Die Rückseite, die entweder einen venator oder aber einen Gladiator darstellt, ist mit REPARATIO MVNERIS FELICITER umschrieben. Bild und Schrift verweisen auf eine Wiederherstellung der munera, in diesem Fall des Tier- und Gladiatorenkampfs, durch den Senat. In der Interpretation und Datierung wird im Wesentlichen Mittag $^{131} \mathrm{zu}$ folgen sein, der die reparatio muneris in Zusammenhang mit der Schließung der kaiserlichen Gladiatorenschulen 399 brachte. ${ }^{132}$ Mit Einstellung der kaiserlichen Finanzierung sprang offensichtlich der Senat finanziell ein, um die Sparte der Gladiatur weiter am Leben zu erhalten. Entgegen der These Camerons, wonach im 5. Jhs. das Spielwesen zunehmend einem Prozess der Verstaatlichung unterworfen wurde, ${ }^{133}$ muss für den Westen, insbesondere aber für Rom, im Grunde genau das Gegenteil festgestellt werden. Kaiserliche Regulationsversuche blieben vergebens und auch die Möglichkeiten der Einflussnahme auf das senatorische

126 Vgl. Symm. ep. 2,76,2 (congressio Libyca) oder Lux. PLM 4,514 (= AL 360). Hierzu vgl. auch PUK (2014) $274 \mathrm{f}$.

127 Auf dieses griff noch Symmachus zurück (Symm. ep. 2,46,3; 9,22; 9,25; 9,142). Hierzu vgl. VILELLA (1996) 51-72, hier 69-71. Zugleich beklagt Symmachus die Zölle, die auf die nach Italien importierten Tiere erhoben wurden (Symm. ep. 5,62 und 5,65).

128 U. a. CTh. 15,11,1-2 (414 und 417): für die Transportroute vom Euphrat über Hierapolis; hierzu knapp PUK (2014) 273f.; ausführlicher JIMÉNEZ SÁNCHEZ (2010) 111-114 und BERTRANDY (1987) 211241, hier 230-233.

129 Vgl. PUK (2014) Abb. 79 und 77b.; original Cabinet des Médailles, Bibliothèque Nationale Paris (Inv. 17131) und Kunsthistorisches Museum Wien. Weitere Exemplare sind katalogisiert bei MITTAG (1999) Nr. 205, 206, 208.

130 Typ Roma VI (ALFÖLDI). Vgl. MITTAG (1999) 55f. (Typ 4).

131 MITTAG (1999) 77-81, bes. 80 f.; nachfolgend PUK (2014) 243.

132 Annot. ad Dion. Exig. cycl. a. 399 (MGH IX, 755) und Max. Taur. serm. 107,2; ferner Theod. hist. eccl. 5,26. Schriftliche Zeugnisse, die bis etwa 413 reichen, bezeugen jedoch die Fortführung der Gladiatorenspiele (z. B. Aug. Civ. Dei 3,14). Erstmals darauf hingewiesen wurde von USENER (1882) $479 \mathrm{f}$. Hierzu vgl. aktuell PUK (2014) 246f.; zur Gladiatur insgesamt ebd. 230-263 mit weiterführender Literatur und i. B. JIMÉNEZ SÁNCHEZ (2008) 123-143; zur christlichen Sicht, i. B. aus der Warte des Prudentius, vgl. KROLLPFEIFER (2017) 191-216.

133 CAMERON (1976) 10 u. 218-221; nachfolgend MATTER (1996) 151-156; ROUECHÉ (1993) 9 und GASCOU (1976) 185-212, hier 192. Hier vgl. auch die etwas differenziertere Betrachtung PUK (2014) 86-88 u. 97-107 (wobei nur ungenügend zwischen Ost und West unterschieden wird), für Italien und Rom ebd. 126-130 und abschließend zum Modell der „Fiscalisazion“ 143-147. 
Spielwesen und die damit einhergehende senatorische Repräsentation minimierten sich eher noch, als dass sie sich verstärkt hätten.

Dieser Umstand wird so auch an den Spielbauten selbst spürbar, die nun häufiger unter der Federführung der Stadtpräfekten instandgesetzt wurden und dessen Namen in den Bauinschriften mehr und mehr Gewicht zufiel. Eine Bauinschrift aus dem Pompeiustheater ${ }^{134}$, die um 400 eine Instandsetzung dokumentierte, rühmte noch allein die Kaiser. Spätere Bauinschriften aus dem Marcellustheater ${ }^{135}$ und dem Kolosseum ${ }^{136}$ verzichten dann nicht mehr auf die Nennung des Stadtpräfekten, der durchweg nun als treibende Kraft hinter den Maßnahmen dargestellt wurde, während die Kaiser nicht länger als Akteure, sondern nur noch in einer vom Handlungsgeschehen losgelösten Huldigungsformel Erwähnung fanden. Die Inschrift auf einer Statuenbasis aus dem Marcellusthealter verzichtet sogar ganz auf die Nennung der Augusti. ${ }^{137}$ Die Spielstätten wie auch die Spiele selbst wurden in Rom so zu einer repräsentativen Domäne der Senatsaristokratie. Der Kaiser trat demgegenüber eher zurück.

Die bereits besprochene Kontorniaten-Prägung des Petronius Maximus ${ }^{138}$ gibt hierbei sehr gut zu erkennen, welche repräsentativen Freiheiten mittlerweile mit der Spielgebung verbunden waren. Selbiges gilt für die statuarische Ehrung, die kostbaren Elfenbeinbildwerke und vor allem für das öffentliche Auftreten des Spielgebers. Aus dem 5. Jh. sind gleich zwei Standbilder erhalten geblieben, die einen Spielgeber präsentieren. Es handelt sich um die Statuen des sog. Älteren und Jüngeren Konsuls (Abb. 15) ${ }^{139}$, zwei togati, die in Tracht und Körperhaltung nahezu identisch dargestellt wurden. Unabhängig von der Frage, ob es sich hierbei tatsächlich um zwei Konsuln

134 CIL 6, 1191 (= CIL 6, 31258 = ILS 793): DD. NN. ARCADIVS ET HONORIVS [invicti] / PERPETVI AVGG THEATRVM POMPEI [collapso] / EXTERIORE AMBITV MAGNA ETIAM [ex parte] / INTERIOR[e] R[uen]TE CONVVLSVM [ruderibus] / SVBDVCTIS ET EXCITATIS INVICE[ $m$ fabricis] / [novis restituerunt]. Hierzu vgl. BAUER (2001) 90 f. (mit Übersetzung).

135 CIL 6, 1660: PETRONIVS / MAXIMVS V. C. / PRAEF. VRBI / CVRAVIT (420/421; Petronius Maximus) betreffend die Umsetzung von Statuen.

136 CIL 6, 32085-32087 (um 411; [Iunius] Vale[rius Be]llicius) und CIL 6, 1763 (444/445; Ruf[ius] Caecina Felix Lampadius); zu diesen Baumaßnahmen und Inschriften vgl. JIMÉNEZ SÁNCHEZ 2008, 132-134; ORLANDI 2004, 42-46; BAUER (2001) 90 - 94; REA/ORLANDI (2001) 182-188 und ORLANDI (1999) 249-263.

137 Das Fehlen des kaiserlichen Namens stellt auf Statuenbasen des 5. Jhs. keine Seltenheit dar (z. B. CIL 6, 36956; CIL 6, 37109 und CIL 6, 37110: Basilica Aemilia, Petronius Maximus 421- 439 und u. a. CIL 6, 1658c; CIL 6, 1658d und CIL 6, 31886: Basilica Iulia?, Probianus 416?); konnte aber genauso auch mit angeführt werden (z. B. CIL 6, 1659: Decius-Thermen, Albinus 414); zu den Inschriften vgl. Kap. 6.3. Eine knappe Zusammenstellung findet sich bei WITSCHEL (2012) 368-369.

138 Vgl. Kap. 3.3.

139 Abbildung nach KOVACS (2014) Taf. 31, Nr. 1 u. 2; vgl. auch GEHN (2012a) W9 und W10, Abb. 18 und 19. Aufbewahrungsort: Rom, Centrale Montemartini, Musei Capitolini Inv.-Nr. 895 u. 896; GOETTE (1990) 146f., E 8 f.; HELBIG ${ }^{4}(1966)$ Nr. 310f. [1913] und STUART JONES (1926) 114f., Nr. 66f. Aufgefunden in den Ruinen des sog. Tempels der Minerva Medica; erstmals publiziert in VISCONTI (1883) $17-32$. 
handelt, ${ }^{140}$ lässt sich festhalten, dass sich hier zwei Magistrate in ihrer Funktion als Spielgeber präsentieren. Beide halten in der erhobenen Rechten die mappa ${ }^{141}$ zum Wurf bereit. Die similitudo (Ähnlichkeit/Übereinstimmung), die nur durch die individuelle Gestaltung des Porträtkopfs aufgebrochen wird, deutet auf eine enge Bezugnahme zueinander in der Aufstellung hin. Möglicherweise waren sie Teil einer Ahnengalerie. ${ }^{142}$ Vergleichbares ist sowohl für die senatorische domus, die fora privata als auch für das Trajansforum feststellbar. ${ }^{143}$

Am repräsentativen Auftreten des Spielgebers, wie es die Diptychontafel der Lampadii (Abb. 16) ${ }^{144}$ festhält, wird ebenfalls ersichtlich, dass die Spielgebung Raum für die Repräsentation der gesamten gens bot. Im Tribunal sind dem Spielgeber zwei weitere Angehörige seines Hauses ${ }^{145}$ zur Seite gestellt. Einer der beiden, der Rechte, hält dabei die mappa, was ihn vermutlich ebenfalls als Spielgeber ausweisen soll. Ein Lampadius $^{146}$ als consul ordinarius ist für das 5. Jh. jedoch nicht zu nennen. Wohl aber lässt sich ein Vertreter der Rufii anführen, Fl. Rufius Postumius Festus ${ }^{147}$, der 439 das Konsulat bekleidete. Den Blick auf die gens Rufia auszudehnen, verlangt neben der ohnehin

140 Vgl. aktuell KOVACS (2014) 289, B124 u. B125; GEHN (2012a) 523-353 und ders. (2010) 36-45, hier 48-53 mit der älteren Literatur. Zu berücksichtigen ist der Größenunterschied: „Älterer Konsul“ 2,26 m und „Jüngerer Konsul“ 1,88 m; KOVACS (2014) 103, Abb. 3; ferner JOHANNING (2003) 174.

141 Auf den Diptychen, Terra-Sigillata-Tafeln, Kontorniaten und Münzen, die den Konsul mit der mappa zeigen, präsentiert sich der Konsul zumeist als orator (Redegestus); hier wird die mappa - i. B. wenn die Spiele selbst nicht dargestellt sind - zu einem (selbstständigen) Amtsattribut des Konsuls, welches von seiner eigentlichen Funktion als Startzeichen für die Wagenlenker losgelöst wurde. Zur Diskussion vgl. PUK (2014) 187-189; CAMERON (2013) 196-204; SGUAITAMATTI (2012) 26-31, 175182; BOSCHUNG (2008) 202 und DAGRON (2007) 203-219; OLOVSDOTTER (2005) 88-90; ENGEMANN (1999) 162f. und CAMERON (1998) 385-403.

142 Vgl. GEHN (2012a) 525.

143 Vgl. KOVACS (2014) 103-107; BEHRWALD (2009) 138; HILLNER (2004) 126; NIQUET (2000) 25; bes. PALMER (1990) 50: „hall of family fame“; zum Trajansforum u. a. MEURER (2019) 107-114 und BAUER (1996) $95 \mathrm{f}$.

144 Abbildung nach KINNEY (2008) Fig. 2. Vgl. DELBRUECK (1929) 218, Nr. 56; VOLBACH 2(1952) Nr. 54, Taf. 18.; Brescia, Mus. della Città Inv.-Nr. MR5770; zu vgl. wären ebenfalls das Diptychon mit Hirschjagd (Liverpool) oder die bereits besprochenen Terra-Sigillata-Tabletts mit Tribunalszene (vgl. Kap. 7.3). Abbildung nach PUK (2014) Abb. 33.

145 So bereits DELBRUECK (1929) 218 und VOLBACH 22(1952) 39. CHASTAGNOL (1992) 58f. sprach sich etwa für einen Prätor in Begleitung zweier Familienmitglieder aus; nachfolgend noch NIQUET (2000) 137.

146 CAMERON (1986) 53-62 schlug u. a. Postumius Lampadius 7 (PLRE 2, 656; Cons. suff. 396) vor; nachfolgend auch ders. (2011) 733f. Vgl. auch SGUAITAMATTI (2012) 164f.; ENGEMANN (2008) 59 und ders. (1998) 119f. Möglich erscheint auch Rufius Caecina Felix Lampadius (PLRE 2, 655 f.; Cons. suff. 426? und PVR 429/450); LATHAM (2016) 208; CHRIST (2015) 186 f.; CAMERON (2011) 733; KINNEY (2008) 153f. und OLOVSDOTTER (2005) 18-20.

147 PLRE 2, 467 (Festus 2). Die unter Kap. 7.3 besprochene Terra-Sigillata-Platten mit venator und Leopard könnet, sofern die Zuweisung korrekt ist, zumindest die Spielgebertätigkeit des Fl. Rufius Postumius Festus beweisen. Noch im Jahr 472 wird ein gleichnamiger Nachfahre das Konsulat antreten; PLRE 2, $467 \mathrm{f}$. (Festus 5). 

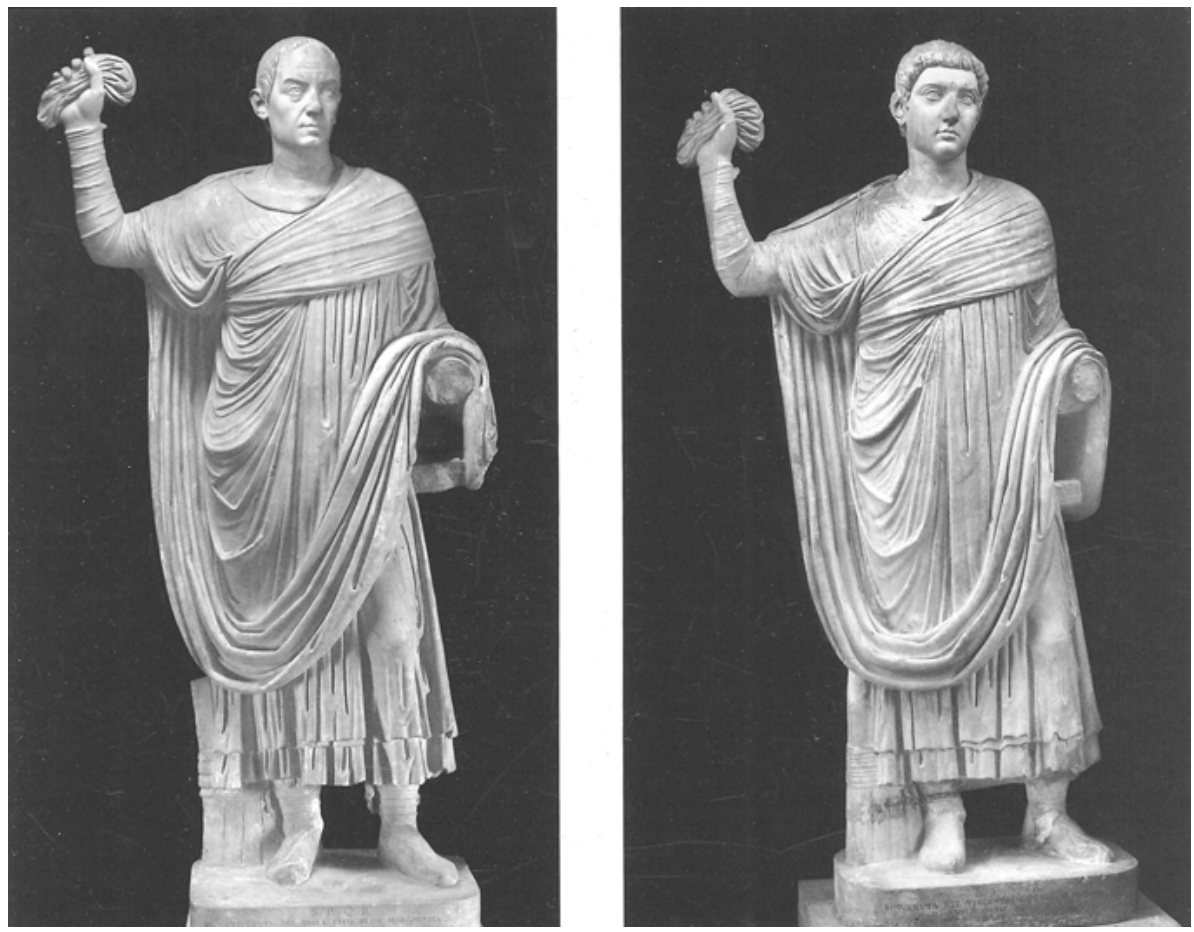

Abb. 15: Standbild des „Älteren“ und „Jüngeren Konsuls“.

engen familiären Verbindung zwischen den Lampadii und Rufii ${ }^{148}$ auch das Diptychon selbst, dessen zweite nicht erhaltene Tafel offenbar mit RVFIORVM ${ }^{149}$ überschrieben war. Bei der verlorenen Tafel müsste es sich überdies auch um die Hauptseite ${ }^{150}$ gehandelt haben, so dass die Rufii wohl den aktuellen Spielgeber stellten. Zugleich wurde aber auch auf die Spielgebung der Lampadii verwiesen, die möglicherweise die Empfänger des Diptychons waren. Hier erweitert sich die Repräsentation auf einen stark vergrößerten und mehrere Generationen umfassenden Familienverband. Darüber hin-

148 Hierzu vgl. CAMERON (2011) 193f. u. 733-735; die Namen Caeionius Rufius Volusianus signo Lampadius (PLRE 1, 976) und Rufius Caecina Felix Lampadius (PLRE 2, 655f.) belegen dies für das 4. und 5. Jh.

149 Hierzu vgl. FORMIS (1967) 187-191; CAMERON (2011) 730 - 737 ging hierbei von einer Hochzeit zwischen beiden Häusern aus; die Darstellung von Circusspielen, die wohl kaum in den Kontext einer Hochzeit gehört, spricht aber eher dagegen.

150 In der Regel ist der Blick der Hauptfigur zur Innenseite ausgerichtet (vgl. u. a. Monza-Diptychon, Diptychonen des Fl. Anicius Auchenius Bassus (Terra-Sigillata), sog. Kaiserpriester-Diptychon, FelixDiptychon, Asturius-Diptychon), so dass die Tafel mit der Aufschrift LAMPADIORVM die rechte Tafel des Diptychons gewesen sein muss und damit im zusammengeklappten Zustand die Vorderseite war, die in der Regel im Westen als Nebenseite fungierte. Vgl. ENGEMANN (1999) 159f.; ausführlich ders. (1998) 109-130; ferner DELBRUECK (1929) 16. 


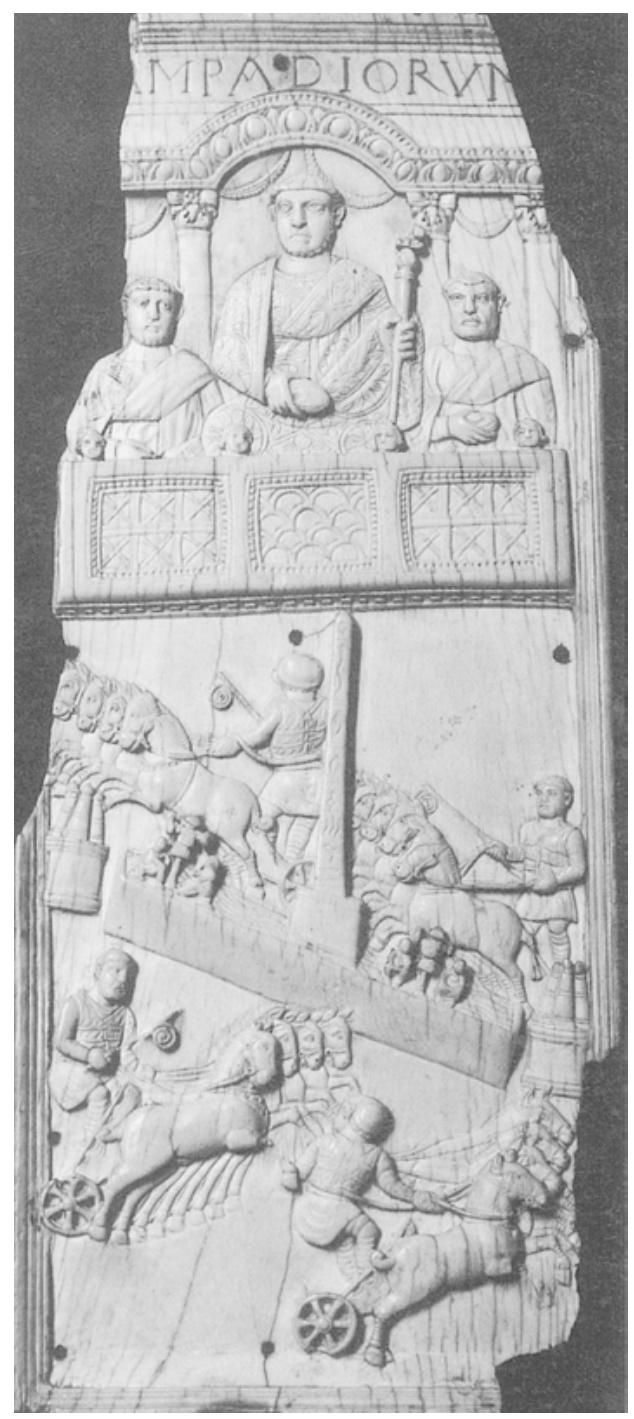

Abb. 16: Diptychontafel der Lampadii.

aus wurden zusammen mit der aktuellen Spielgebung wohl auch an vergangene Spielgebertätigkeit erinnert und zukünftige in Aussicht gestellt. Hierdurch war es der stadtrömischen Senatsaristokratie möglich, ihren kontinuierlichen Einsatz als Euergeten, die Größe und Beständigkeit der senatorischen gentes, ihren Zusammenhalt und ihre ungeminderte finanzielle Potenz zu demonstrieren. Auch dies suggerierte letztlich Kontinuität, Stabilität und Sicherheit. 
Gerade in einer Zeit, in der die Rahmenbedingungen für die Bewältigung liturgischer Leistungen ${ }^{151}$ alles andere als optimal waren, gelang es der stadtrömische Senatsaristokratie, den Spielbetrieb weiter aufrechtzuerhalten. ${ }^{152}$ Dies stellte in Anbetracht der Kostspieligkeit und des Aufwands, gerade in Rom, ${ }^{153}$ eine beachtliche Leistung dar. Der Kaiser war hier stark auf den senatorischen Spielgeber angewiesen. Dementsprechend großzügig fielen die repräsentativen Freiheiten aus. Nachdem die Festlichkeiten und Spiele Anfang des 5. Jh. zu einer religiös neutralen Form finden mussten und damit ihren ursprünglichen Sinngehalt verloren, stellte sich die Frage, welche gesellschaftliche und politische Relevanz die Spielgebung noch hatte. Als neue Sinnkonstruktion ließ sich hier vorschlagen, die Spiele, insbesondere in Verbindung mit den venationes, als Demonstration der Roma regina orbis terrarum zu verstehen. Damit trug die Spielgebung zur Stabilisierung der Gesellschaft entscheidend bei, gerade weil sie von der tatsächlichen Lage ablenkte.

\subsection{Die senatorische domus zwischen Kontinuität, Wandel und Niedergang}

Die senatorische domus darf als Raum verstanden werden, in dem sich die senatorische Repräsentation am stärksten verdichtete. Als Mittelpunkt senatorischer Identifikation und Distinktion ${ }^{154}$ sowie Zentrum aristokratischer Traditionspflege und Memorialkultur stellte die domus auch noch im 5. Jh. die wohl wichtigste senatorische Repräsentationsdomäne ${ }^{155}$ überhaupt dar. Dementsprechend von hoher Bedeutung sind jegliche Veränderungsprozesse, die sich an den senatorischen Anwesen und dem Umgang mit ihnen feststellen lassen. Mit ihrem zum Teil öffentlichen Charakter und ihrer dementsprechend repräsentativ-politischen Funktion muss die domus zumindest als „halb öffentlicher“ - „halb privater Raum“156 klassifiziert werden.

In vielen Fällen ist die Existenz einzelner senatorischer Häuser und ihre Besitzerschaft in Rom über wenig aussagekräftige literarische oder epigraphische Zeugnisse nur noch vage fassbar. ${ }^{157}$ Aus der Zeit vom 1. bis 5. Jh. sind etwa 211 domus bekannt. ${ }^{158}$ Stark

151 Vgl. PUK (2014) 112f.; ferner MÜLLER (2003) 82-86; CRAMME (2001) 15-36 und LANGHAMMER (1973) 239.

152 Zum Spielwesen unter ostgotischer Herrschaft vgl. PUK (2014) 79-82.

153 Vgl. Olymp. fr. 41,2 (Blockley). Vgl. hierzu auch Kap. 7.2.

154 So im Grunde bereits HILLNER (2004); NIQUET (2000) 26-33; SCHLINKERT (1996a) 143; NÄF (1995) $44 \mathrm{f}$. und LÖHKEN (1982) 74f. Vgl. ferner jetzt auch VON HESBERG (2005a) 19-52. Zum öffentlichen Charakter der domus, allerdings vorwiegend am Beispiel Pompeji und Herculaneum, vgl. i. B. DICKMANN (1999); WALLACE-HADRILL (1994) und ders. (1988) 43-97.

155 Vgl. i. B. BORG/WITSCHEL (2001) 114f.; NÄF (1995) 44f. und SCHNEIDER (1983) bes. 58-84.

156 Hierzu vgl. RILINGER (1997) 73-90; nachfolgend HILLNER (2004) $131 \mathrm{f}$.

$157 \mathrm{Zu}$ den Quellen (i. B. fistulae aquariae (Wasserleitungen), Ehreninschriften, Patronatstäfelchen und Sklavenhalsbänder) und den damit verbundenen Problemen vgl. ECK (2010a) 207-240 [1997]. Ferner vgl. auch MIELSCH (2016) $34 \mathrm{f}$. 
relativiert wird diese Zahl durch die Angaben in der Notitia und dem Curiosum Urbis Romae, ${ }^{159}$ die für das 4./5. Jh. eine Zahl von 1.535 bzw. 1.682 domus festhalten. Auch wenn letztlich offenbleiben muss, ob denn alle in den Regionenkatalogen genannten domus wirklich senatorische oder rangmäßig vergleichbare Residenzen waren, wird an der hohen Zahl der unbekannten Anwesen deutlich, dass der archäologisch fassbare Bestand nur punktuell Informationen liefern kann.

Ein flüchtiger Blick in die senatorische Literatur reicht aus, um zu ermessen, welch hoher Stellenwert dem senatorischen Anwesen noch immer beigemessen wurde. Nicht wenige Briefe des Symmachus zeugen von seiner intensiven Sorge für die eigenen Immobilien. ${ }^{160}$ Mit Stolz blickte Symmachus auf die Aufwendungen, die er für seine Domizile tätigte. ${ }^{161}$ Gleichzeitig verlor er auch die Häuser seiner Standesgenossen nicht aus dem Blick. ${ }^{162}$ Marmorluxus, Wandmalerei, der Komfort der Bäder und die Opulenz der Gastmähler beschäftigten den Hausherren. Macrobius seinerseits lässt die Saturnalia in den Häusern des Praetextatus, Flavianus und Symmachus ${ }^{163}$ stattfinden und präsentierte eindrücklich, auch entgegen der konträren Auffassung bei Ammian, ${ }^{164}$ dass das senatorische Haus noch immer ein Zentrum der Philosophie, Gelehrsamkeit und Bildung sein konnte. Bibliotheken, ${ }^{165}$ Statuensammlungen und Kunstwerke waren hier nicht nur dekorativ, sondern verliehen dem senatorischen Haus beinahe einen musealen Charakter. Der dominus selbst mochte sich hierbei sogar antiquarisch-museal in Szene setzen. ${ }^{166}$

158 Vgl. die Tabelle bei ECK (2010a) $225 \mathrm{f}$.

159 Vgl. zur Quelle BEHRWALD (2009) 185-212; ders. (2006) 743-764 und BAUER (2004) 9-11; die Zahl diskutiert erneut MACHADO (2012a) 136-158, hier 137 f.; zuvor GUIDOBALDI (1999a) 53-68; hier 55; GERKAN (1940) 149-195, hier 165 und VALENTINI/ZUCCHETTI (1940) 162 u. 188.

160 Z. B. Symm. ep. 3,12 (Caelium nostrum); Symm. ep. 6,6 (proxima urbi praedia) und Symm. ep. 1,6; 2,52; 3,82; 6,72 (Ostia). Vgl. u. a. GRIESBACH (2010) 55-70, hier 60-63; POLARA (1995) 225-239 und VERA (1986) 231-270. Vgl. allgemein SAVINO (2005) 159-170; DE FRANCESCO (2004) 16- 22 u. 29-31; ferner NÄF (1995) 44-46 und KRAUSE (1987) 68-72.

161 Auf dem Caelius Symm. ep. 7,18f. (Mosaiken und Malerei) und Symm. ep. 6,70; 8,42; 9,17; 9,50 (Marmorausstattung und Instandsetzung); Symm. ep 6,70 (Klagen über die nie endenden Arbeiten. 162 Z. B. Symm. pro Tryg. 6 (domus sobria); Symm. ep. 3,14 (domus des Iulius Naucellius) und Symm. ep. 5,54 (in einem Streit über eine domus).

163 Vgl. Macr. Sat. 1,2,15f.; noch Sid. ep. 1,9,1: nos Pauli [...] tam doctrina quam sanctitate venerandis Laribus exepti rühmt explizit die Gelehrsamkeit als Merkmal eines ehrwürdigen senatorischen Hauses. Hierzu vgl. GERTH (2013) 65f. u. $195 \mathrm{f}$.

164 Amm. 28,4,14f. Vgl. GERTH (2013) 94f.; BRANDT (1999b) 89-120; SCHLINKERT (1996a) 187 f. und NÄF (1995) 56-60.

165 Zum archäologischen Befund vgl. knapp MIELSCH (2016) 113-116. Zum Bildungskanon in der Spätantike vgl. zusammenfassend CAMERON (1994) 178-199.

166 Im Fall des Praetextatus ist dies offenbar nicht nur durch die inhaltlichen und sprachlichen Spezifika seiner Grabinschrift (CIL 6, 1779; ILS 1259) geschehen, sondern auch durch die Gestaltung des Grabaltars, der als letzter seiner Art in Rom noch als Säulenaltar - und zwar aus zwei Fragmenten nach Vorbildern des 3. Jh. n. Chr. gefertigt worden war; hierzu knapp NIQUET (2000) 239; ausführlicher BOSCHUNG (1987) 60 u. 105, Nr. 129 u. 797; HELBIG, Bd. $2^{4}(1966)$ 76-79, Nr. 1223 und STUART JONES 


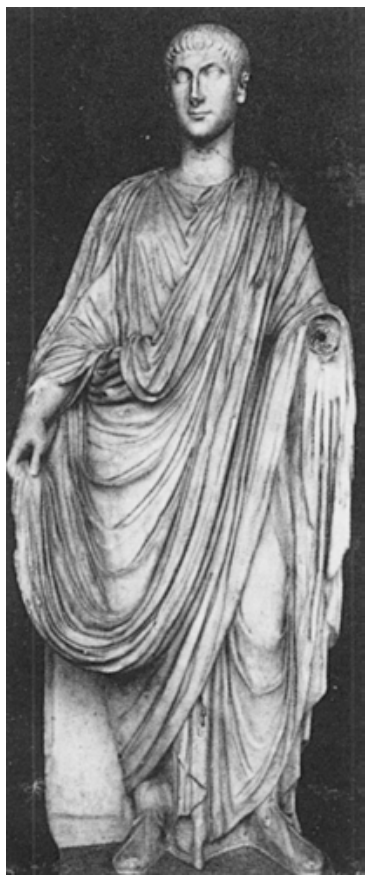

Abb. 17: Togatus, Thermenmuseum.

Eine wiederverwendete Togastatue des 2. Jhs. (Typ Goette Bb), ${ }^{167}$ der nur ein zeitgenössischer Porträtkopf aufgesetzt wurde, ist womöglich in diese Richtung zu deuten. Es handelt sich hierbei um das Statuenmonument eines jungen Senators (Abb. 17) $)^{168}$ ohne Namensüberlieferung, welches um 400 anzusetzen ist. Die Diskussion über diese spoliierten Ehrenstatuen ${ }^{169}$ verlief bisher recht einseitig. Besonders Blanck ${ }^{170}$ ließ nur einen ökonomischen Erklärungsansatz gelten und verwies unter Bezugnahme auf entsprechende Quellenbelege ${ }^{171}$ eher auf den negativ zu wertenden Charakter einer solchen Praxis. Jüngst hatte Gehn ${ }^{172}$ diese Interpretation in Zweifel gezogen und darauf hingewiesen, dass solch ein aus heutiger Sicht zusammengestückelt wirkendes Gesamtbild sehr wohl dem ästhetischen Empfinden entsprochen haben kann. An zeitgenössischen

(1926) 77, Nr. 9. Zum „Traditionalismus“ der Senatsaristokratie Roms vgl. u. a. HEATHER (2013) 438447.

167 GOETTE (1990) Taf. 20,3; vgl. GOETTE (1990) 49 u. 134.

168 Abbildung nach GEHN (2012a) Taf. 38, W8; vgl. GEHN (2012a) 519-523; Rom, Museo Nationale delle Terme Inv.-Nr. 247; MNR I,2 (1981) Kat.-Nr. 26.

169 Vgl. hier auch die Dogmatius-Statue (um 330); Mus. Greg. Prof. Inv.-Nr. 10493; LSA 1412; GOETTE (1990) 134, Bb 83; HELBIG ${ }^{4}(1963)$ Nr. 1133 f. Hierzu vgl. LENAGHAN (2016) 267-279, hier 270 f.; KOVACS (2014) 290 (B131); GEHN (2013) 56f.; ders. (2012a) 498 - 504 (W3). Ferner MEISCHNER (1991) 385-407, hier $401 \mathrm{ff}$. und GOETTE (1990) 134; CALZA (1972) $354 \mathrm{f}$.

170 BLANCK 2(1969) 105.

171 Ebd. 11-19.

172 GEHN (2013) 47-83, hier $61 \mathrm{f}$. 
Togastatuen mangelte es jedenfalls nicht. ${ }^{173}$ Umgeben von antiquarischen Dingen ${ }^{174}$ konnte so der dominus für sich selbst das Bild einer ,Antiquität' annehmen und damit seine Anbindung an eine ehrwürdige Tradition und Historie unterstreichen.

Diese Vorüberlegung, die erst einmal ohne einen genauen Blick auf eine domus auskommt, verdeutlicht doch recht anschaulich, welchen Charakter solch ein senatorisches Haus und sein dominus annehmen konnten. Nicht allein nur die Pracht des Ausstattungsluxus oder die Größe des Hauses waren ausschlaggebend, sondern eben auch ein gewisser Habitus, ${ }^{175}$ der hier durchaus als museal bzw. kulturkonservierend bezeichnet werden kann. Damit besaß das senatorische Haus neben seiner repräsentativen und politischen Funktion im spätantiken Kulturleben eine große Bedeutung. ${ }^{176}$

Der senatorische Hausstand war äußerst umfangreich. Nach der Beschreibung Ammians ordnen die Haushofmeister den Aufzug der städtischen Dienerschaft wie erfahrene Feldherren:

Wenn dann gleichsam die Parole ausgegeben ist, marschiert vor dem Wagen die gesamte Webstube einher; hieran schließt sich die rußgeschwärzte Bedienung der Küche an, dann folgt durcheinander die ganze Dienerschaft zusammen mit den plebejischen Nichtstuern der Nachbarschaft. An letzter Stelle geht die Menge der Verschnittenen. ${ }^{177}$

Auch wenn die karikatureske Kritik $^{178}$ an der stadtrömischen Senatsaristokratie nicht zu überhören ist, darf zumindest der Umfang der senatorischen Dienerschaft ernst genommen werden. So erfahren wir auch aus der Vita Melaniae und von Palladius, dass Melania und Pinian 8.000 Sklaven auf ihren Anwesen in Rom und Umgebung besessen haben sollen. ${ }^{179}$ Hieran wird ersichtlich, welch großen wirtschaftlicher Faktor, allein schon hinsichtlich der menschlichen Arbeitskraft und deren Versorgung ${ }^{180}$ die senatorischen Anwesen darstellten. In Anbetracht dessen ist es wohl kaum

173 Vgl. Kap. 8.2 zu den Statuen des „Älteren“ und „Jüngeren Konsuls“.

174 Hierzu vgl. auch BAUER (2007) 79-109.

175 Einzuordnen ist dies über den Habitus-Begriff BOURDIEUs, der den Habitus als ein „dauerhaft wirksames System von (klassenspezifischen) Wahrnehmungs-, Denk- und Handlungsschemata“, welches sich durch Einverleibung bzw. Inkorporierung der sozialen Umwelt ausformt, definiert; BOURDIEU (1979) 165. Hierzu vgl. u. a. auch BOURDIEU (2001) 177-188; ders. (1997) 59-78; ders. (1993) 97-121.

176 Indirekt bestätigt dies auch die Kritik Ammians (Amm. 28,4,14f.), in welcher zumindest der Anspruch des senatorischen Hauses, ein Ort der Gelehrsamkeit, Bildung und Wissenschaften sein zu müssen, deutlich formuliert wird.

177 Amm. 14,6,17: [...], quos insignes faciunt virgae dexteris aptatae velut tessera data castrensi iuxta vehiculi frontem omne textrinum incedit: huic atratum coquinae iungitur ministerium, dein totum promiscue servitium cum otiosis plebeiis de vicinitate coniunctis: postrema multitudo spadonum a senibus in pueros desinens, obluridi distortaque lineamentorum conpage deformes, [...] Übersetzung nach SEYFARTH (1970).

178 Hierzu aktuell STENGER (2012) 189-216.

179 Vit. Mel. 10 und Pall. Laus. 61.

180 Einen knappen Überblick über das Personal bietet etwa MIELSCH (1987) 133f. Zur Bedeutung der senatorischen Besitzungen als Wirtschaftsfaktor vgl. auch knapp CAMERON (1994) 136f. u. $139 \mathrm{f}$. 
übertrieben, wenn hier dem Fortbestand der senatorischen Anwesen ein Höchstmaß an Bedeutung sowohl als existenzielle Grundlage des senatorischen Lebensstils und der aristokratischen Distinktion als auch hinsichtlich des politischen, kulturellen und wirtschaftlichen Überlebens des caput mundi zugemessen wird.

An dieser Stelle soll nun der archäologische Befund einbezogen werden. Zwischen 1902 und 1904 wurden im Zuge der Errichtung des Ospedale dell'Addolorata auf dem Caelius nahe S. Stefano Rotondo bauliche Überreste und Kleinfunde verschiedener spätantiker Stadthäuser der Senatsaristokratie entdeckt (Abb. 18) ${ }^{181}$. Darunter sind besonders erwähnenswert die Domus Gaudentii und die sog. Domus Symmachorum, deren Reste nördlich der modernen Via di S. Stefano Rotondo ergraben wurden, sowie südlich davon die Domus Valeriorum. Diese sollen im Folgenden näher betrachtet werden. Am klarsten zeichnet sich der Befund an der Domus Gaudentii (Domus di Gaudenzio) ab, dessen Inhaber durch eine Mosaikinschrift ${ }^{182}$ im triclinium (G), die als GAVDEN-TIVIV[as] zu lesen ist, namentlich bekannt ist. Die domus selbst ist mit ihrer Grundfläche von etwa $1.300 \mathrm{~m}^{2}$ eher als ein Anwesen mittlerer Größenordnung ${ }^{183}$ einzustufen. In den Besitz des Gaudentius dürfte die domus Anfang des 5. Jhs. gelangt sein. Neu errichtet war sie jedenfalls nicht. Noch in der zweiten Hälfte des 4. Jhs. scheinen diverse Umbauten (Abb. 19) ${ }^{184}$ erfolgt zu sein, welche die weit ältere domus, die ursprünglich wohl in antoninischer Zeit aus der Zusammenlegung zweier insulae ${ }^{185}$ entstanden war, durch Umgestaltung der Räume und ihrer Disposition den veränderten spätantiken Repräsentationsbedürfnissen anpassen sollte.

Auffällig ist die Aufwertung des Bankettbereichs. Die westliche Abschlusswand des triclinium $(\mathrm{G})$ schloss nun eine Apsis ab. Außerdem erfolgte eine räumliche Erweiterung um die Portikus im Osten (F), die durch Verengung der Zugänge im Norden und Osten nun deutlicher als Bestandteil des Bankettbereichs zu erkennen ist. Ferner wurde durch das Vermauern der seitlichen Säulendurchgänge eine klarer definierte Blickachse, die vom Innenhof mit seinem Wasserspiel (C) in gerader Linie auf die Apsis im triclinium (G) verlief, geschaffen. Indem der direkte Durchgang zwischen dem vestibulum (A) und dem tablinum (E) geschlossen wurde, entstand überdies eine zusätzlich verlängerte Wegführung, die nun zwangsläufig über den Innenhof führen musste. Dabei wurde durch Abtrennung des westlichen Teils des vestibulum noch ein zusätzlicher Empfangsraum (B) geschaffen, der für die hierarchische Abstufung in der salutatio ${ }^{186}$ genutzt werden

181 Abbildung nach PAVOLINI (2000) 147, Abb. 1. Vgl. hierzu auch GRIESBACH (2010) Taf. 13, Abb. 18; PAVOLINI (2006) Fig. 3; nach der Erstpublikation GATTI (1902) 145-163. Aktuell vgl. MACHADO (2019) 241-243 u. $250 \mathrm{f}$. Vgl. hierzu auch den Plan nach dem aktuellen Grabungsbefund von 2015 in BOTTIGLIERI/PALLADINO (2015) 2, Fig. 2; [www.fastionline.org/docs/FOLDER-con-2015-1.pdf].

182 Vgl. SPINOLA (2000) Fig. 4.

183 Vgl. HILLNER (2004) 212; NIQUET (2000) 32 und GUIDOBALDI (1986) 165-237, hier $218 \mathrm{f}$.

184 Abbildung nach SPINOLA (2000) Fig. 2.

185 Vgl. den Grabungsbericht von SPINOLA (1993) 473-483; nachfolgend ders. (2000) 152-155. Vgl. jetzt auch MACHADO (2019) 244-247.

186 Zur republikanischen Zeit vgl. GOLDBECK (2010) 119-166; knapp zur Spätantike KRAUSE (1986) 21-23. Der apsidale Raum (triclinium) konnte hier als sog. Privatbasilika ebenfalls als Empfangsraum 


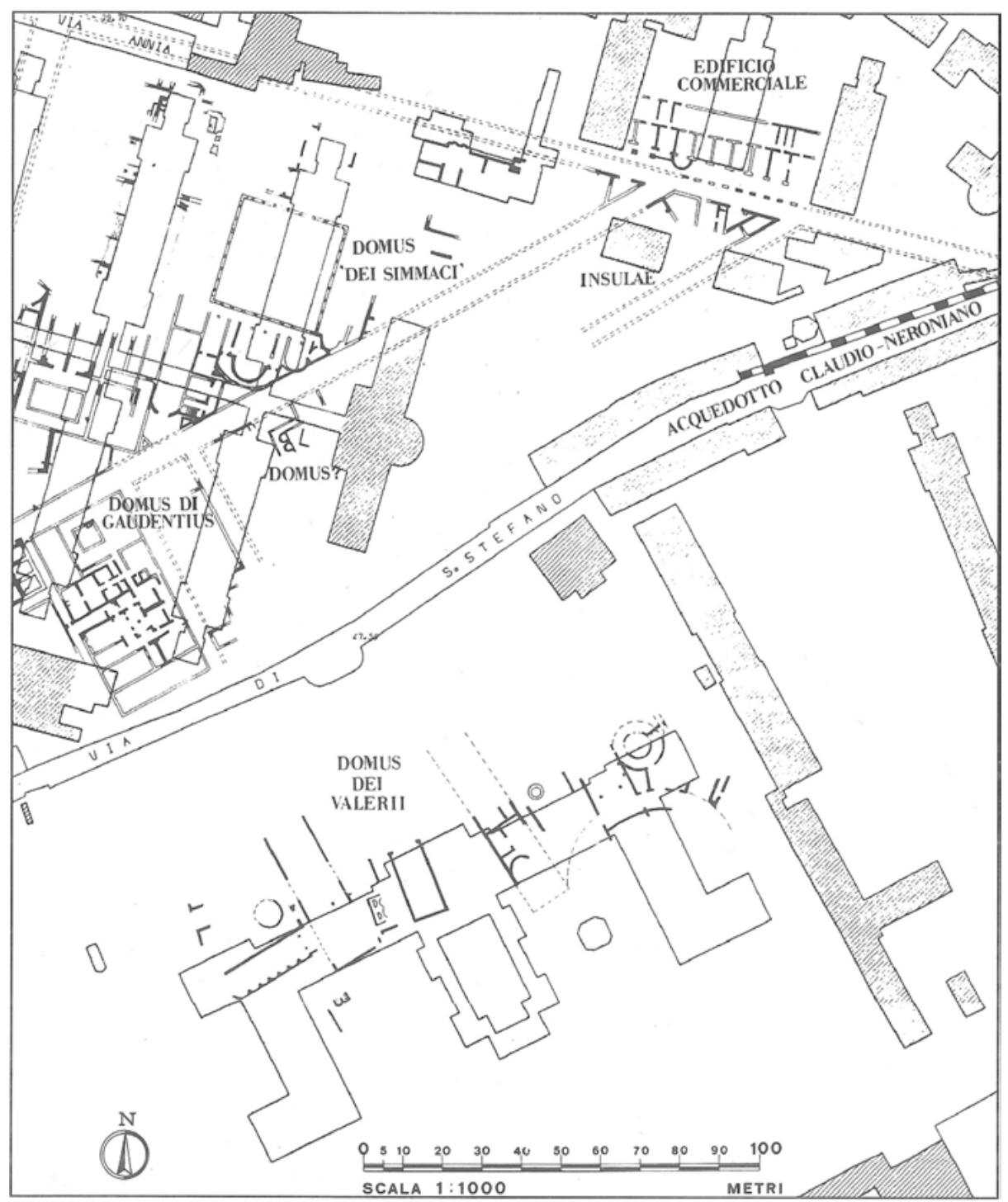

Abb. 18: Spätantike Bebauung auf dem Caelius (nach Pavolini 2000).

konnte. Aus dem Haus stammt des Weiteren ein 2,35 m hohes Standbild des Antinoos ${ }^{187}$ im Habitus des Dionysos mit Thyrsos und Weinlaubkranz, welches bereits Ende des

genutzt werden. Vgl. u. a. BORG (2007) 65-67; BORG/WITSCHEL (2001) 114 und SCHNEIDER (1983) 68; ausführlich jetzt KIEFER (2016) 55-74.

187 Abbildung in SPINOLA (1992) Fig. 7; zum „Antinoo Casali“vgl. SPINOLA (1993) 481- 483 und ders. (1992) 953-979, hier 970ff. und GUIDOBALDI (1986) 218f; ferner NIQUET (2000) 32; zur Statue MAM- 

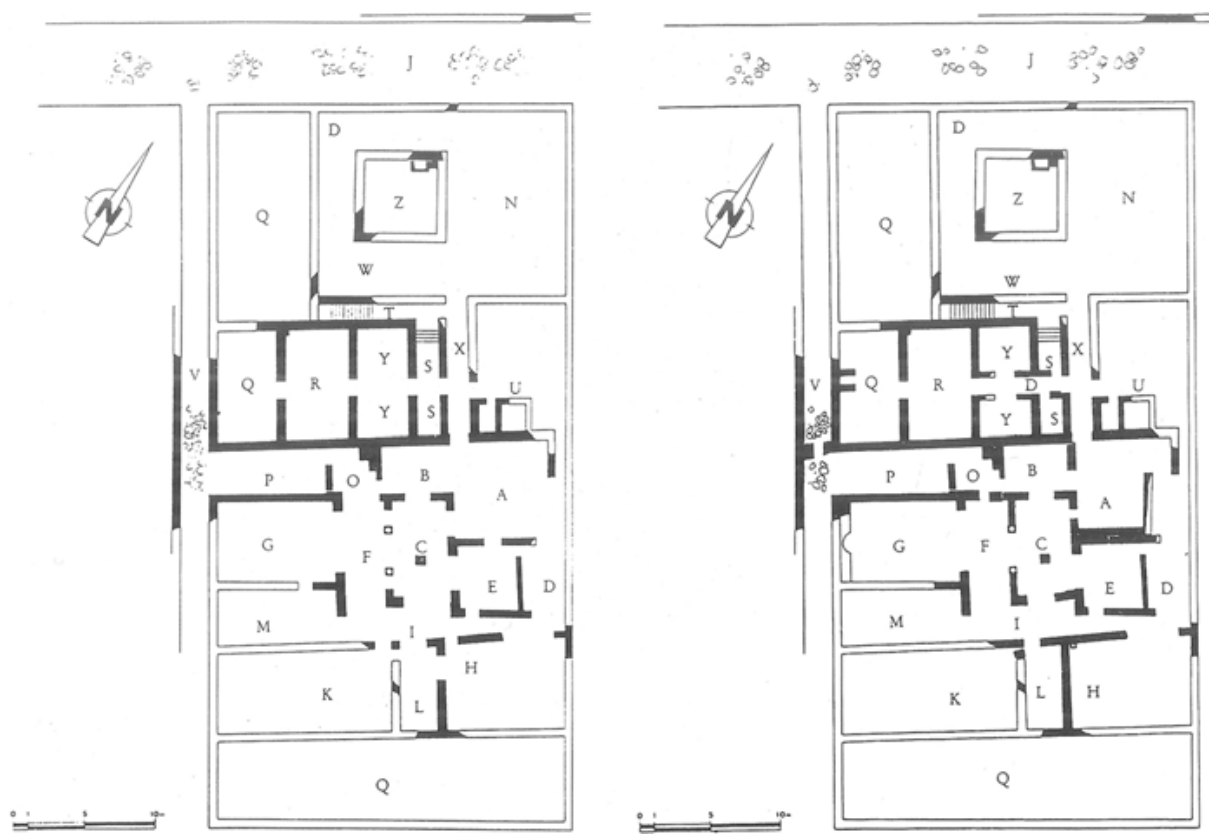

Abb. 19: Plan der Domus Gaudentii mit erster und zweiter Bauphase (nach Spinola 2000).

18. Jhs. aus einer Nische der domus, vielleicht der Apsis des triclinium, entnommen wurde. ${ }^{188}$ Eine solche Antiquität aus dem 2. Jh. wertete Haus und Hausherr gleichermaßen auf. Die domus des Gaudentius wies sich so als ein kulturkonservierender, musealer Raum aus, der den feinen Geschmack, den Bildungsgrad und auch die finanzielle Potenz des dominus widerspiegelte.

Jener Gaudentius, ${ }^{189}$ den uns Symmachus als amicus meus vorstellt und als Besitzer der domus infrage kommt, war offensichtlich kein alteingesessener stadtrömischer Aristokrat, sondern zeichnete sich mehr durch Geisteskraft und Mäßigung aus als durch eine edle Abstammung. ${ }^{190}$ Zum Befund würde dies hervorragend passen. Die Statue des

BELLA (2008) 170; SPINOLA (2000) 449f., Kat.-Nr. 38 und MEYER (1991) 47 f. Aufbewahrungsort: Kopenhagen, Carlsberg Glyptothek Inv.-Nr. 1960.

188 Erwähnung findet die Statue u. a. bereits in PLATNER (1837) 502.

189 PLRE 2, 493 (Gaudentius 3; vic. Afr. 409); Symm. ep. 4,38; 7,45; 9,133. Zur Identifizierung vgl. aktuell u. a. MACHADO (2019) 247-250; WARD-PERKINS (2012) 53-80, hier 73-75; BISHAM (2008) 276f.; CHRISTIE (2006) 240 f.; HILLNER (2004) 92; SODINI (2003) 25-56, hier 35f.; SPINOLA (2000); NIQUET (2000) 32; grundlegend SPINOLA (1992) 967-970.

190 Symm. ep. 4,38 (398/399): mens et modestia origine sua ac stripe nobilior. Zum ordo senatorius (vir clarissimus) scheint Gaudentius bereits durch Geburt gehört zu haben; Symm. ep. 7,45: vir generis senatorii (vgl. auch Symm. ep. 4,38); eine Identifizierung mit Gaudentius 5 (PLRE 2, 493), dem Vater des Aëtius diskutiert ZECCHINI (1983) 118f. Dass es sich bei Gaudentius um einen Angehörigen des ordo senatorius aus der Provinz handeln könnte, vermutet auch HILLNER (2004) 92. 
„Antinoo Casali“ belegt zumindest eine Neigung zur klassisch-paganen Kunst, ihrem Kulturgut und ihren Bildungsidealen. Der Hausherr war scheinbar ein Neuankömmling auf dem Caelius, der eine ältere domus mittlerer Größe erworben hatte, im Sinne der spätantiken Repräsentationsgepflogenheiten modernisierte ${ }^{191}$ und mit einer Statuensammlung aufwertete. Hierbei entsteht der Eindruck eines Mannes, der mit seinem Haus auf die Anerkennung der alteingesessenen senatorischen Häuser abzielte und dementsprechend deren Lebensstil und repräsentativen Habitus für sich adaptierte.

Ein spätes Beispiel dafür, dass die Unterhaltung einer eigenen domus in Rom unverändert ein erstrebenswertes Gut darstellte, liefert der Streitfall des Auxiliaris, ${ }^{192}$ der, aus Gallien stammend, noch in den 440er-Jahren ein Haus in Rom erwarb und darüber in Streit mit den Vorbesitzern geriet. Der gesamte Fall ist insofern sehr interessant, da er belegt, dass der stadtrömische Immobilienmarkt zur Mitte des 5. Jhs. keinesfalls darnieder lag, sondern durchaus als vital, wenn nicht sogar aufgrund steigender Nachfrage und geringer Verfügbarkeit als angespannt zu beurteilen ist. ${ }^{193}$ Im Zusammenhang mit der für die Domus Gaudentii festgestellten Zerstörung und Aufgabe nach 410, ${ }^{194}$ die immer wieder exemplarisch für den Niedergang der senatorischen domus angeführt wurde, ${ }^{195}$ ist das Gegenbeispiel, welches der Fall des Auxiliaris liefert, besonders wichtig.

Zumindest die Kontinuität der senatorischen domus lässt sich auch am folgenden Beispiel festmachen. Die sog. Domus Symmachorum (Domus dei Symmaci), die nördlich des Anwesens des Gaudentius in Teilen ergraben wurde (Abb. 20) ${ }^{196}$, kann hierfür exemplarisch herangezogen werden. Der Besitzer des riesigen Anwesens wird insbeson-

191 So auch Publius Ampelius, Vater des Priscus Attalus, der sein neu erworbenes Haus in Rom nach dem neuesten Geschmack (wohl u. a. Marmorinkrustationen, Statuen, etc.) ausstatten ließ. Vgl. Symm. ep. 5,54,2; hierzu HILLNER (2004) 93 und GUIDOBALDI (1986) $216 \mathrm{f}$.

192 PLRE 2, 206 (Auxiliaris 1 und 2; PPO Gall. 431-435); Nov. Val. 8,1-2 (440/441). Vgl. HILLNER (2004) 92f., 94 u. 239 (Anhang 1 Auxiliaris); LANCON (2001) 56; MATHISEN (1989) 167f. Ferner wäre auch Publius Ampelius anzuführen, Vater des Priscus Attalus, der schon im 4. Jh. ein bescheidenes Haus von der Mutter des Postumianus erwarb (Ampelius 3 PLRE 1, 56 f.; Symm. ep. 5,54 u. 5,66), oder der aus Syrakus stammende Senator Iulius Naucellius (Naucellius 1 PLRE 1, 617f.; Symm. ep. 3,12 u. 3,14), der ebenfalls ein Haus auf dem Caelius um 400 erwarb; ferner Serena und Galla Placidia, die gleich mehrere Stadthäuser in Rom unterhielten; auch ein Nachfahre des Mallius Theodorus scheint sich in Rom angesiedelt zu haben (Anicius Manlius Severinus Boëthius; Enn. ep. 8,1; 8,31; 8,37 u. 8,40). Vgl. HILLNER (2004) 92-94.

193 So HILLNER (2004) 106.

194 Brandschäden sind vor allem im Eingangsbereich festgestellt worden, wobei aber eine Weiternutzung einzelner Funktionsräume sich gleichfalls feststellen ließ. Vgl. SPINOLA (1993) $482 \mathrm{mit}$ Anm. 131 und PAVOLINI (1993a) 53-70, hier 61; nachfolgend PAVOLINI (2006) 88 und ders. (2004) 418434, hier 420.

195 Vgl. etwa BRANDENBURG (2012) 231 u. 234; SANTANGELI VALENZANI (2012) 219-227, hier 225; MACHADO (2012b) 111-138, hier 119 f. u. $121 \mathrm{f}$; SPINOLA (2000) 155; GUIDOBALDI (1999a) 59; PAVOLINI (1993b) 443-505, hier 454 und SPINOLA (1992) 958 u. 979f.; ferner auch SPINOLA (1995) 109f. [LTUR 2]; ferner ELLIS (1988) 565 - 576, hier vor allem zur domus im Osten mit dem Schwerpunkt auf Ephesus. 196 Abbildung nach CARIGNANI (2000) Fig. 2. 


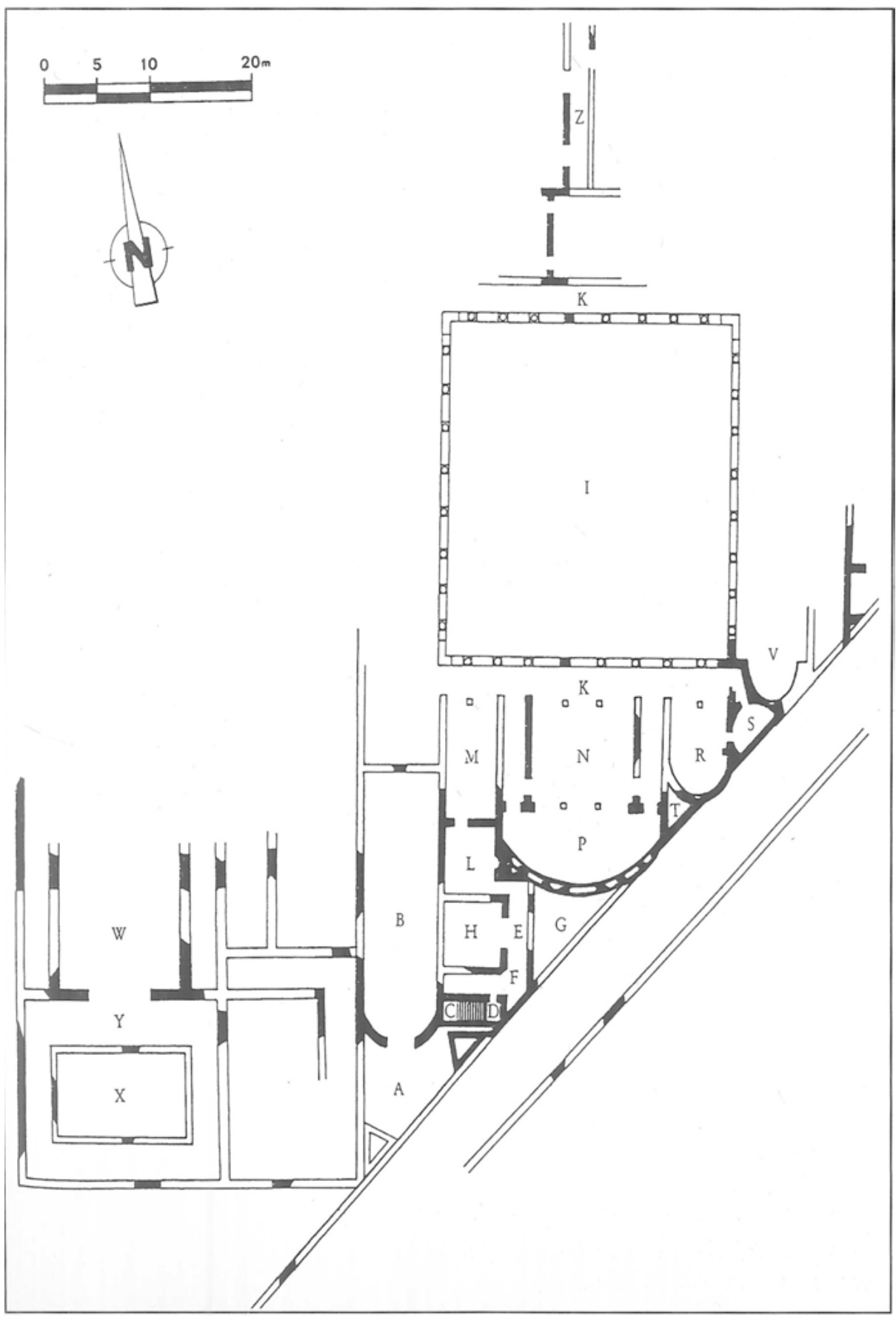

Abb. 20: Plan der sog. Domus Symmachorum. 


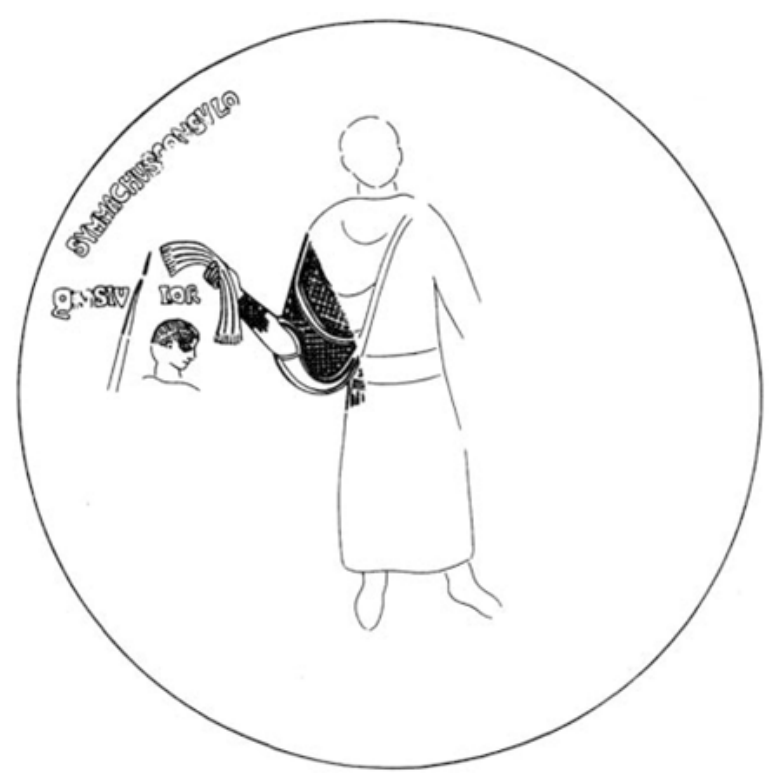

Abb. 21: Umzeichnung Glasschalenfragment.

dere in der italienischen Forschung ${ }^{197}$ mit dem berühmten Redner und Stadtpräfekten Quintus Aurelius Symmachus identifiziert, der sich in zahlreichen seiner Briefe mit seinem Caelium nostrum ${ }^{198}$ befasste und sich selbst auch als Caelii montis habitator ${ }^{199}$ bezeichnete. Aus dem Grabungsbefund der domus scheinen vor allem die Ehreninschriften $^{200}$ sowie eine fragmentarisch erhaltene Glasschale mit figürlichem Dekor und Inschrift (Abb. 21) ${ }^{201}$ diese Annahme zu stützen. Die Inschrift wurde dem Quintus Aurelius Symmachus signo Eusebius von seinem Sohn Quintus Fabius Memmius Symmachus im Jahr 402 oder wenig später gesetzt. Damit ist für dieses Areal die reprä-

197 Im Grabungsbericht CARIGNANI (1993) 483 - 494; ferner GUIDOBALDI (1995e) 183f. [LTUR 2] und zuvor bereits COLINI (1944) 272-282.

198 Symm. ep. 3,12. Vgl. auch Symm. ep. 7,18f.

199 Symm. ep. 3,88; Instandsetzungsarbeiten, Malereien und Mosaikböden sind Gegenstand der Briefpassagen Symm. ep. 6,70; 8,42; 9,17 u. 9,50.

200 CIL 6, 1699 (ILS 2946): EVSEBII / Q AVR SYMMACHO VC / QVAEST PRAET PONTIFICI / MAIORI CORRECTORI / LVCANIE ET BRITTIORVM / COMITI ORDINIS TERTII / PROCONS. AFRICAE PRAEF. / VRB. COS. ORDINARIO / ORATORI DISERTISSIMO / Q. FAB. MEMM. SYMMACHVS / V. C. PATRI OPTIMO; gefunden im zentralen Bereich der Villa Casali auf dem Caelius (Domus Symmachorum?); aus diesem Bereich stammt auch CIL 6, 1782 eine für Virus Nicomachus Flavianus senior gesetzt Ehreninschrift, die Ebenfalls von Q. Fabius Memmius Symmachus (prosocero optimo) in Auftrag gegeben wurde. Hierzu vgl. NIQUET (2000) 26f. und SPINOLA (1992) 966 mit Anm. 19.

201 Abbildung nach SPERA (2013) Fig. 4; Original: PACETTI (2001) 168-170, Kat.-Nr. 1.2.1; heute Museo Nazionale Romano, Crypta Balbi, Inv.-Nr. 401160. Das Stück stammt aus dem Bereich der Basilica Hilariana, vgl. PAVOLINI (1990) 171-176, hier 175. 
sentative Präsenz der Symmachi2 ${ }^{202}$ über mehrere Generationen hinweg hinreichend belegt. $^{203}$

Im Fall des Fragments einer teilweise mit Goldfolie überzogenen Schale ${ }^{204}$ verweist ebenfalls eine Inschrift ${ }^{205}$ auf die Symmachi. Selbige wird wie folgt gelesen: SYMMACHVS CONSVL O[rdinarius(?)] // Q(uintus) F(abius) M(emmius) S(ymmachus) IV[n]IOR. ${ }^{206}$ Mitunter wird die Inschrift auf eine Darstellung bezogen, die Memmius ${ }^{207}$ und seinen Vater, den Konsul von 391, zeigt. ${ }^{208}$ Deutlich kleiner wäre Memmius links neben Quintus Aurelius Symmachus dargestellt. Nun kann aber auch die Hauptperson den gleichnamigen Konsul ${ }^{209}$ von 446 meinen, der wohl Sohn des Memmius war und würde damit die Anwesenheit der Symmachi in drei Generationen belegen. Sicher entscheiden lässt sich dies aber nicht. ${ }^{210}$

Auf einer Fläche ${ }^{211}$ von schätzungsweise $8.000 \mathrm{~m}^{2}$, die zahlreiche Versorgungsräume (C, D, E, F, S, T mit praefurnium $\mathrm{G}$ ), ein weitläufiges Vestibül (B), ein großzügiges Peristyl (I), weitere kleinere offene Bereiche (N, X) und verschiedenste Repräsentationsräume (H, L, M, N, P, R, V), sowie einen separierten Haustrakt (X, Y, W) umfasste, fanden Repräsentation und Wohnkomfort mehr als ausreichend Platz. Typisch ${ }^{212}$ für den spätantiken Repräsentationsbereich, finden sich auch hier bevorzugt apsidiale Raumformen (B, P, R, V). Auch wurde bewusst der Eindruck von Weite durch eine verlängerte Wegführung erzeugt. Wollte ein Besucher zu den Empfangs- und Reprä-

$202 \mathrm{Zu}$ den Symmachi grundlegend CAMERON (1999b) 477-505.

203 Noch L. Aurelius Avianus Symmachus signo Phosphorius hatte seine Hauptresidenz trans Tiberim; die domus wurde 374 von der aufgebrachten Volksmenge zerstört (Amm. 27,3,4 u. 27,3,8) und wohl ab 375 wiederaufgebaut (Symm. ep. 1,12; an den Vater). Vgl. HILLNER (2004) 62. Die Umsiedlung auf dem Caelius wird auf Quintus Aurelius Symmachus signo Eusebius zurückgehen (Symm. ep. 6,70; 8,42; 9,17 u. 9,50).

204 Hierzu vgl. auch BEYELER (2011) 36.

205 AE 2001,496.

206 Nach AE 2001,496; die ältere Lesung nach CARIGNANI (1990) 72-80, hier 75: Q(uintus) A(urelius?) [---] S(ymmachus) IV[n]IOR / SYMMACHVS CONSVL O[rdinarius?]. Vgl. SPINOLA (1992) 977 und noch HILLNER (2004) 36.

207 PLRE 2, 1046 f. (Q. Fabius Memmius Symmachus 10).

208 Vgl. aktuell SPERA (2013) 121-142, hier 121; BEYELER (2011) 36; zuvor PACETTI (2001) 168-170, Kat.-Nr. 1.2.1 mit weiteren Abbildungen und nun auch CARIGNANI (2000) 149-151, hier 149.

209 PLRE 2, 1046 (Q. Aurelius Symmachus 9).

210 SPERA (1992) 977; nachfolgend dies. (2000) 155 präferiert hier sogar Q. Aurelius Memmius Symmachus iunior 9 (PLRE 2, 1044-1046; Cos. 485). Vgl. auch PLRE 2, Stemma 22 und SCHÄFER (1991) 108-110, Nr. 100.

211 Vgl. CARIGNANI (2000) 149; dies sind die bisher archäologisch erschlossenen Bereiche im Süden und Süd-Westen, die jedoch nur etwa 1/3 der Gesamtanlage ausmachen.

212 Die Verwendung von Apsiden ist hier so übersteigert, dass die eigentliche Funktion der Apsis, die darin besteht, wenige ausgewählte Räume bzw. Punkte innerhalb der domus als zentralen Blickpunkt architektonisch besonders zu akzentuieren, regelrecht ad absurdum geführt wurde; zur architektonischen Bedeutung und repräsentativen Funktion der Apsis vgl. u. a. MIELSCH (2016) 64-72; ZIEMSSEN (2012) 87-110, hier 99-101; VON HESBERG (2005) 137-139; SCHWEIZER (2004) 45-50; GUIDOBALDI (1999a) 62. 
sentationsräumen, musste dieser vom Vestibül (B), welches ohnehin schon stark in die Länge gezogen war, erst zum Peristyl (I). Lang gezogene, unverstellte Blickachsen und Raumfluchten, insbesondere entlang der westlichen und südlichen Portikus, dürften das Gefühl räumlicher Weite noch zusätzlich verstärkt haben. Eine architektonische Schwerpunktsetzung lässt sich auch hier für den Bankettbereich ${ }^{213}(\mathrm{~N}, \mathrm{P})$ feststellen, der durch seine räumliche Größe, seine zentrale Disposition, aber auch durch seine weit gespannte Apsis ${ }^{214}$ im Raumgefüge besonders akzentuiert ist. Vom Scheitelpunkt der Apsis in einer axialen Linie über das Zentrum des Peristyls öffnete sich ein Panorama, welches an Abwechslungsreichtum, hervorgerufen durch den Wechsel von Lichteinfall (N, I) und Schatten (P, K) sowie Baulichkeit und Natur, vermutlich von keinem anderen Platz im Haus übertroffen wurde. Ein kunstvoll gestalteter Opus-sectile-Boden ${ }^{215}$ schmückte den offenen Innenhof und die Apsis. Eine Statuensammlung, zu welcher eventuell auch die als „Vittoria dei Simmaci“ bekannte Statue ${ }^{216}$ gehört hat, diente als Blickfang in den repräsentativen Räumen. Hinzu kommen Wandmalereien und kostbare Marmorarbeiten. ${ }^{217}$

Sowohl im Kreis der stadtrömischen Senatsaristokratie als auch in den Augen all jener, die vom Funktionieren des senatorischen Hauses abhängig waren, bedeutete die Aufgabe eines solchen Anwesens, sofern damit tatsächlich deren Funktionswandel oder sogar deren völliger Verfall intendiert war, eine ökonomische und gesellschaftliche Katastrophe. Eines der prominentesten Beispiele hierfür ist der Fall Melanias und Pinians aus dem Haus der Valerii, ${ }^{218}$ der an anderer Stelle ${ }^{219}$ bereits besprochen wurde. Der radikalen Besitzveräußerung soll auch die Residenz der Valerier zum Opfer gefallen sein. Ihr Hagiograph ${ }^{220}$ vermerkte hierzu, dass das Anwesen nicht nur für die übrigen

213 Die Raumform, auch in Verbindung mit dem Peristyl, erinnert etwa an die Villa Iovis auf Capri (Piano nobile Niveau 7) oder entfernt an die sog. Cenatio Iovis in der Domus Flavia auf dem Palatin (gegenüber der sog. Aula Regia) und den sog. Dreiexedrenbau in der Villa Adriana in Tivoli. Auch wenn hier die Benennung als Bankettbereich selbst nach funktionalen Gesichtspunkten (stibadium) naheliegend erscheint, wird dennoch immer auch von einer flexiblen Nutzung auszugehen sein. Zahlreiche weitere Beispiel sind von MORVILLEZ (1996) 119-139 und DUVAL (1997) 129-152 zusammengetragen worden. Es ist hierbei aber nicht immer angebracht, mit der Apsis im Bankettbereich auch ein stibadium zwingend vorauszusetzen (wie DUVAL (1997) 144), da die triclinium-Apsis im 1./2. Jh. n.Chr. nachweislich auch nur eine Sichtachse vorgeben konnte, vgl. VÖSSING (2004) 343, 349-352 u. 354. 214 Diese bot hervorragend Platz für ein stibadium. Vgl. VÖSSING (2004) 557-562 und DUNBABIN (1991) 121-148.

215 Schematische Zeichnung in CARIGNANI (2000) Fig. 3.

216 Abbildung in PAVOLINI (2007) Fig. 8; Aufbewahrungsort: Centrale Montemartini Inv.-Nr. MC2845. Vgl. u. a. TALAMO (1994) 168-175; zur Statuensammlung vgl. auch COATES-STEPHENS (2007) 173 u. 179-181; zu den noch umfangreicheren statuarischen Funden vgl. DANTI (1993) 123-142.

217 Z. B. Symm. ep. 1,12 (Marmorausstattung) oder Symm. ep. 2,2 und 9,50 (Empfehlung des Malers Lucillus). Vgl. hierzu HILLNER (2004) 135-137.

218 Vgl. Symm. ep. 1,2,3f.: Valerii Poblicolae; zu den verwandtschaftlichen Verhältnissen vgl. PLATTE (2013) viii oder DISSELKAMP (1997) 199 und CLEVENOT (1988) $139 \mathrm{f}$.

219 Hierzu Kap. 3.2.

220 Vit. Mel. 14. 
senatorischen Käufer unerschwinglich blieb, sondern selbst für das Kaiserhaus. Infolge der Eroberung Roms 410 soll das Haus schwere Schäden davongetragen haben, so dass am Ende das junge Asketenpaar es nur noch zu einem Spottpreis veräußert bekam.

Südlich der Domus Symmachorum wurden maßgeblich unter Leitung von Gatti ${ }^{221}$ bereits zu Beginn des vergangenen Jahrhunderts Strukturen eines weitläufigen senatorischen Anwesens entdeckt, welches entsprechend den in den Gärten um S. Stefano Rotondo aufgefundenen epigraphischen Zeugnissen als Domus Valeriorum (casa dei Valeri) bezeichnet wird. Eine Reihe von Inschriften, die von den Klienten des Hauses gestiftet wurden und wohl im Atrium zur Aufstellung gebracht waren, ermöglichen zumindest für das 4. Jh. eine Klärung der Besitzerfrage. Über den epigraphischen Befund lassen sich namentlich L. Aradius Valerius Proculus signo Populonius ${ }^{222}$ und Q. Aradius Rufinus Valerius Proculus ${ }^{223}$ als Besitzer des Anwesens ermitteln. Dazu kann anhand der statuarischen Ehrungen und Patronatstafeln ein weit gespanntes Klienten-Netz für dieses Haus nachgewiesen werden, welches sowohl verschiedene corporationes ${ }^{224}$ und die civitas Puteoli225 als auch einige civitates in Nordafrika, Sizilien, Spanien und sogar Thrakien ${ }^{226}$ umfasste.

Das bedeutendste Fundstück, welches zur Klärung der Besitzerfrage für Anfang des 5. Jhs. herangezogen wird, stellt ein schon von Bartoli $1691^{227}$ zeichnerisch festgehaltenes bronzenes Öllämpchen (Abb. 22) ${ }^{228}$ dar. Auf der tabula ansata ist zu lesen: DOMINVS LEGEM / DAT VALERIO SEVERO EVTROPI VIVAS ${ }^{229}$. Das Öllämpchen ist gestaltet in Form eines Schiffes. An dessen Bug steht Petrus. Am Heckruder nimmt Paulus Platz. Die gewählte Darstellung versinnbildlicht die Kirche von Rom, die ihren Primatsanspruch

221 Erstmals publiziert GATTI (1902) 145-176.

222 CIL 6, 1690 (ILS 1240); CIL 6, 1691; CIL 6, 1692 (ILS 1242 und CLE 892); CIL 6, 1693 (ILS 1241 und CLE 325) und CIL 6, 1694; zum Fund vgl. GEHN (2012a) 80f.; ders. (2012b) 15-30, hier 16-19; ECK (2010a) 217; HILLNER (2004) 140f. u. 264 (Anhang 1); NIQUET (2000) 30 und NÄF (1995) 46; ferner GUIDOBALDI (1995f) 207 [LTUR 2]; zum Grabungsbefund vgl. LANCIANI (ND 1990) Bd. 3, 77-80; zur Person vgl. PLRE 1, 747-749 (Proculus 11 u. 12; Cos. 340). Zu den Inschriften jetzt auch ROLLÉ DITZLER (2020) 137 und ECK (2016b) $112 \mathrm{f}$.

223 CIL 6, 1695; zur Person vgl. PLRE 1, 775 f. (Rufinus 11).

224 CIL 6, 1690: [...] CORPVS SVARIORVM ET CONFECTVRARIORVM / AVCTORIBVS PATRONIS EX AFFECTVS EIDEM IVRE DEBITO / STATVAM PATRONO DIGNO PONENDAM CENSVIT (vgl. CIL 6, 1693) und CIL 6, 1692: [...] COLLEGIVM PISTORVM / PATRONO PR(a)ESTANTISSIMO.

225 CIL 6, 1691: [...] VIRI PERFECTISSIMI ET PRIN/CIPALES ET SPLENDIDISSIMVS OR/DO ET POPVLVS PVTEOLANORVM / PATRONO DIGNISSIMO / CVRANTE SEP. CARITONE V. P.

226 Dies ist dem cursus honorum zu entnehmen; z. B. CIL 6, 1690: legatus pro praetore provinciae Numidiae, perequator census provinciae Callaeciae, praeses provinciae Byzacenae, consularis provinciae Europae et Thraciae, consularis provinciae Siciliae etc. sowie den Patronatstafeln CIL 6, 1684-1689; vgl. ROLLÉ DITZLER (2020) Abb. 43. Vgl. auch CIL 8, 24521.

227 Heidelberger historische Bestände - digital: [https://digi.ub.uni-heidelberg.de/diglit/bartoli1691].

228 nach BARTOLI (1691) 166, III Taf. 24; vgl. BRENK (2003) Fig. 187; heute Uffizien Florenz.

229 ILCV 1592; zur Inschrift vgl. HUSKINSON (1982) 58 u. 90. 


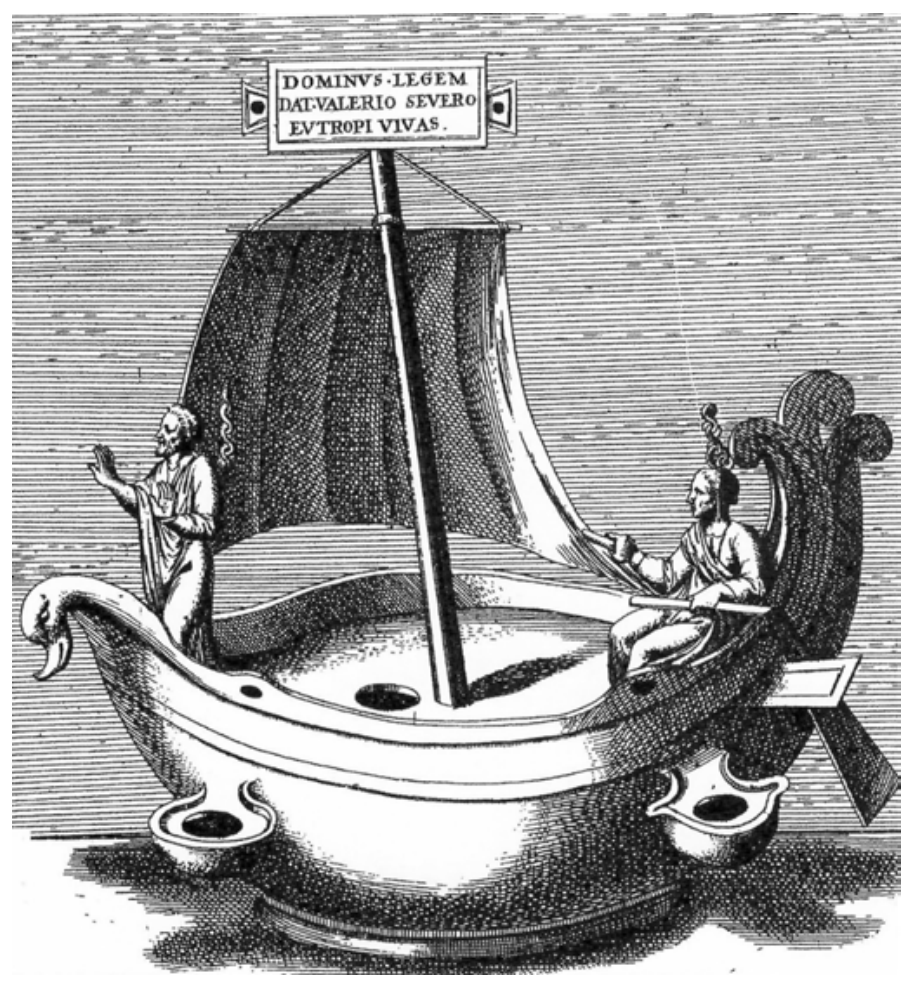

Abb. 22: Öllämpchen in Form eines Schiffs (Severus).

auf die beiden Apostelfürsten zurückführt. ${ }^{230}$ Das Lämpchen deutet zusammen mit weiteren christlich konnotierten Stücken, darunter zwei amulae mit dem Bildnis Christi und einem Apostel auf der Rückseite, ${ }^{231}$ eine vergoldete und eine silberne Kanne, ein Becher, zwei Löffel und ein weiteres Öllämpchen (Abb. 23) ) $32^{23}$ auf Geschenke hin, die höchst wahrscheinlich anlässlich der Taufe des Valerius Severus von Seiten der christlichen Senatsaristokratie gestiftet wurden. ${ }^{233}$ Das zweite Öllämpchen wurde wohl dargebracht vom Präfekten und Konsul Nonius Atticus. ${ }^{234}$ Die Fundstücke belegen nicht nur das weit gespannte Beziehungs- und Klientennetz der gens Valeria und die Besitz-

230 Vgl. hierzu MCLYNN (2012) 305-326, hier 316; SESSA (2012) 57f. u. 61 f. und BRENK (2003) 119f.; ferner im Zusammenhang mit den Goldgläsern des 4. Jhs., die eine vergleichbare Darstellung der Apostelfürsten zeigen, vgl. PIETRI (1961) 275-322, bes. 276.

231 Abbildung in BRENK (2003) Fig. 189.

232 nach BARTOLI (1691) 173, III Taf. 31; vgl. BRENK (2003) Fig. 188; verschollen.

233 Weiterführend vgl. BRENK (2003) 119-121; eine ausführliche Publikation aller Stücke steht nach wie vor aus.

234 Auf der tabula ansata: NONI ATTICI / V. C. ET INLVS/TRIS; zur Person vgl. PLRE 1, 586f. (Nonius Atticus Maximus 34; PPO It. oder PVR 383/384 und Cos. 397); zur Inschrift bereits DE ROSSI (1861) 198f. 


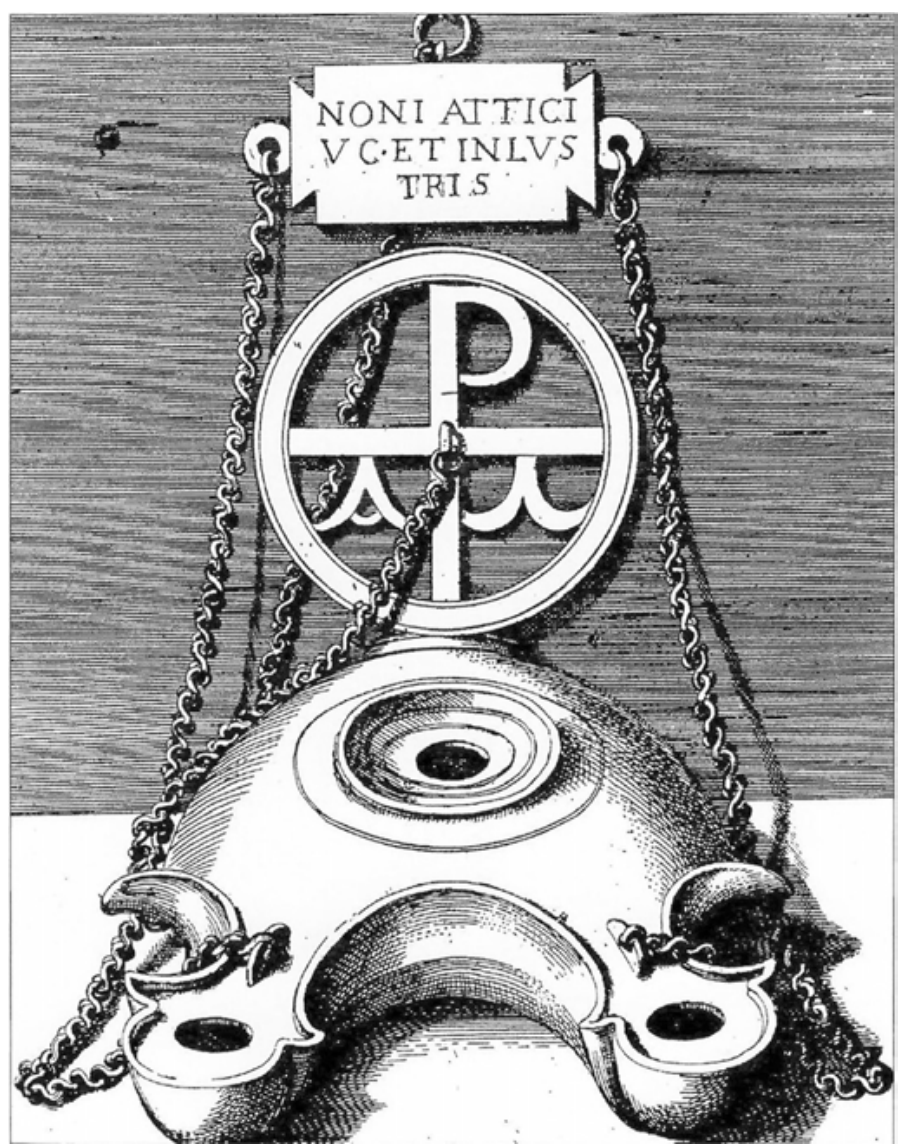

Abb. 23: Öllämpchen (Non. Atticus).

kontinuität, sondern legen auch Zeugnis ab für die Christianisierung der Valerii. Während L. Aradius Valerius Proculus signo Populonius sich allein schon durch die aufgelisteten Priesterämter ${ }^{235}$ als überzeugter Anhänger der alten Religion verstanden wissen wollte, bekennt sich Valerius Severus und mit ihm wohl auch sein Haus durch die Taufe zu Christus. Eben dieser Severus wurde mit dem Vater des Pinian, dessen Bruder ebenfalls den Namen Severus ${ }^{236}$ trug, identifiziert. ${ }^{237}$

235 Dieser war augur, pontifex maior, quindecimvir sacris faciundi, pontifex flavialis (vgl. z. B. CIL 6, 1690).

236 Vit. Mel.12; PLRE 2, 1001 (Severus 2); zum Bruder vgl. u. a. PLATTE (2013) 219f. und CLARK (1984) $100-102$.

237 So u. a. SESSA (2012) 57; BOWES (2008) 78f.; BRENK (2003) 113 u. 118f.; ders. (1999) 69-84, hier 81 und LEGA (2003) 77-105; zurückhaltender und kritischer HILLNER (2003) 129-145, hier 140-143 und weniger kritisch dies. (2004) 170 - 172 u. 285; zur Person vgl. PLRE 1, 837 f. (Severus 29). Vgl. auch Symm. ep. 7,116. Bereits RAMPOLLA (1905) 173 nahm an, dass das Anwesen im Besitz Melanias war, 
Besonders die statuarischen Funde aus diesem Areal zeugen von einer beachtlichen kulturellen Strahlkraft des Hauses. Unter den Fundstücken sind eine Statuengruppe mit Armor und Psyche ${ }^{238}$ und drei Dichter- bzw. Philosophen-Hermen aus dem 2. Jh. ${ }^{239}$ anzuführen, die, wie sich Brenk treffend ausdrückte, „die Anliegen des paganen Bildungsbürgertums “240 repräsentierten. Diese sind noch zu ergänzen um die bronzenen Statuetten zweier Philosophen, auf die zuletzt Franken ${ }^{241}$ aufmerksam gemacht hat. Jüngst erst haben Grabungen ${ }^{242}$ im südöstlichen Areal der domus überdies Überreste vorzüglicher Wandmalereien und Mosaiken des 1./2. Jhs. hervorgebracht. Neben floralen und geometrischen Mustern fanden sich hier auch figürliche Darstellungen, die der pagan-mythologischen Bildwelt entspringen. Ihr hohes Alter verliehen der domus - im wahrsten Sinne des Wortes - einen geradezu antiquarischen Anstrich, der vor allem die Ehrwürdigkeit des Anwesens und seiner Herren unterstrich.

Mit Blick auf die zugegebenermaßen nur rudimentär erschlossenen Raumstrukturen der domus (Abb. 24) ${ }^{243}$ wird gerade auch hier noch einmal die Bedeutung des senatorischen Hauses für das städtische Leben deutlich. Es ließen sich eine Vielzahl von unterschiedlichen Repräsentationsräumen feststellen, die für die gesellschaftliche und politische Kommunikation zwischen dem dominus und seiner Familie auf der einen Seite und den senatorischen Standesgenossen und Klienten auf der anderen ausgelegt waren. Die Gesamtfläche des Anwesens wird etwa auf $10.000 \mathrm{~m}^{2}$ geschätzt, worunter unter anderem eine Thermenanlage $(\mathrm{f}+\mathrm{h})$ mit einem kunstvollen Opus-sectile-Boden, diverse rechteckige aulae (r, d, t) und eine Portikus (a) mit 2,60 m hohen Säulen aus bigio antico aufzuzählen wären. ${ }^{244}$ Das Silbergeschirr, welches für die private Eucharistie ${ }^{245}$ genutzt werden konnte, und die Öllämpchen lassen vermuten, dass ferner auch eine

wohingegen DE ROSSI und GATTI Pinianus für den Besitzer hielten, was heute mehrheitlich angenommen wird. Vgl. HILLNER (2004) $170 \mathrm{f}$.

238 Abbildung in BRENK (2003) Fig. 177. Aufbewahrungsort: Galleria degli Uffizi, Inv.-Nr. 339.

239 Abbildung in BRENK (2003) Fig. 184; Aufbewahrungsort: Museo Nazionale Romano, Museo delle Terme, Inv.-Nr. 107503; MNR I,9 (1987) R33.

240 BRENK (2003) 121.

241 Abbildung in FRANKEN (2007) 201-221, Abb. 1a u. 2b. Der Fundkontext der 1664 aufgefundenen Statuetten geht aus einem Dokument der Bibliotheca Angelica (1678; c. 46r) hervor. Sie dienten als Bekrönung eines drei- oder vierbeinigen Klapptischs wohl ebenso wie zwei Greifen aus demselben Fundkontext (FRANKEN Abb. 4 u. 5). Aufbewahrungsort: Museo Nazionale del Palazzo di Venezia Inv.Nr. P. V. 9753 u. P. V. 9754.

242 Publiziert BARBERA/PALLADINO/PATERNA (2008) 75-98 mit entsprechenden Abbildungen 349-354; The Journal of Fasti Online: BOTTIGLIERI/ PALLADINO (2015) 1-21; PALLADINO/PATERNA (2006) 1-4 BARBERA/PALLADINO/PATERNA (2005) 1-7.

243 Abbildung nach BRENK (2003) Fig. 179 (BRENK nach PAVOLINI).

244 Knapp BRENK (2003) 116; ausführlicher PAVOLINI (1994/1995) 71-94; COLINI (1944) 253 - 258 und GATTI (1902) 145-163; ferner auch DE ROSSI (1886).

245 Vgl. HILLNER (2004) 133-135 und BRENK (2003) 120; allgemein DIEFENBACH (2007) 330 - 400. Ein bedeutendes Beispiel ist etwa das oratorium in der domus unter SS. Giovanni e Paolo am Clivus Scauri (vgl. Kap. 9.3); hierzu u. a. DIEFENBACH (2007) 379-381 und BRENK (2003) 82-113. 
Kapelle $^{246}$ zum Anwesen gehörte. Überdies konnten in der Grabungskampagne 2000/ 2005 die Überreste des südöstlichen Flügels, in welchem die angeführten Wandmalereien freigelegt wurden, ermittelt werden. ${ }^{247}$ Eine geschlossene, mit Fenstern durchzogene Portikus umgab offensichtlich ein großzügig bemessenes viridarium, welches vermutlich im Norden, ähnlich wie in der villa von Cercadilla, durch die im Halbkreis angeordneten Repräsentationsräume abgeschlossen wurde. Am meisten beeindrucken aber die enormen Raumdimensionen, die sich ohne Weiteres an den großen spätantiken villae wie in Piazza Armerina, Centcelles oder Chiragan messen lassen. ${ }^{248}$

Angenommen, dieses so bedeutende senatorische Anwesen wäre der unkontrollierten Vermögensveräußerung ${ }^{249}$ durch Melania und Pinian zum Opfer gefallen, hätte dies für viele Menschen zu einer existenziellen Krise führen müssen. ${ }^{250}$ Der archäolo-

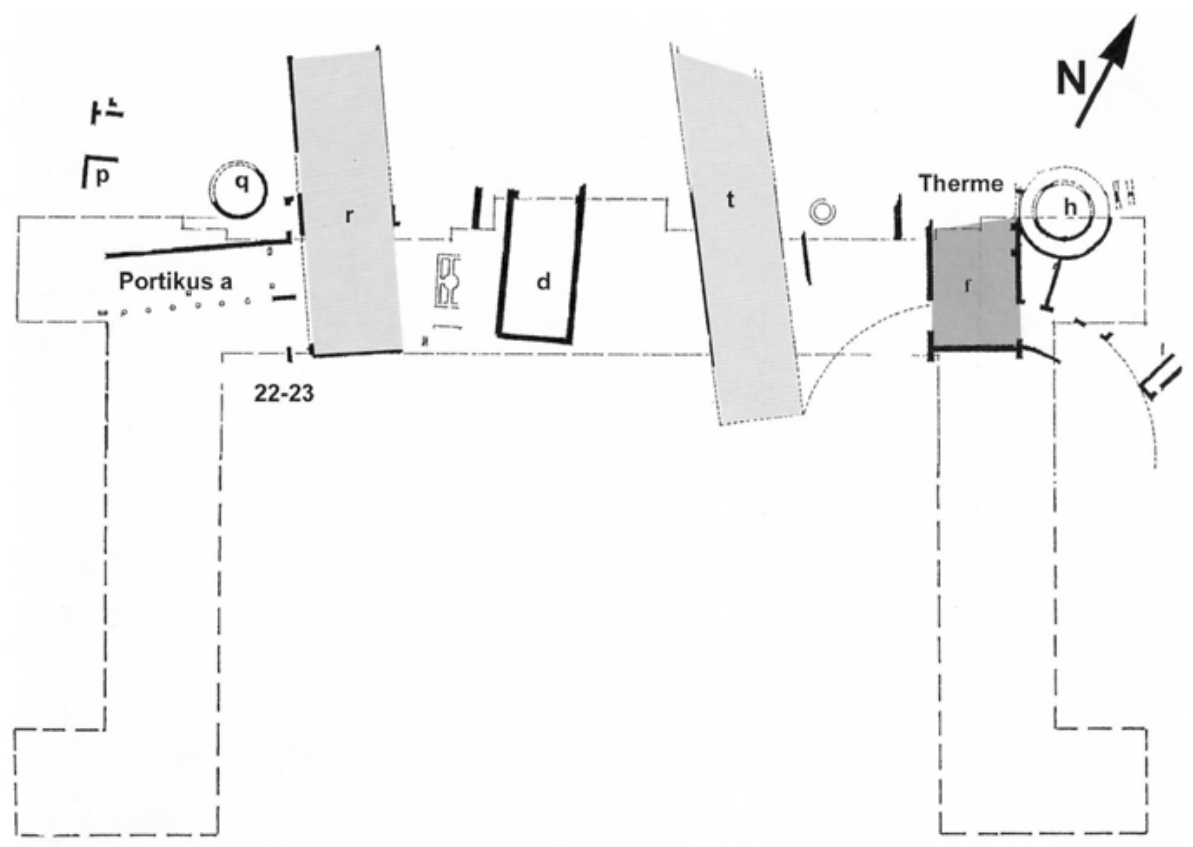

Abb. 24: Plan der sog. Domus Valeriorum (Brenk 2003 nach Pavolini).

246 Vgl. BRENK (2003) 39, 50 und 120; hier auch gestützt durch Vit. Mel. 5.

247 Vgl. BOTTIGLIERI/PALLADINO (2015).

248 Vgl. BRENK (2003) 116: deren Thermen im Vergleich zur Domus Valeriorum „geradezu minuskül“ erscheinen. So besaßen die aulae (r, d, t, f) und der Zentralbau (h) eine Breite von $12 \mathrm{~m}$ und mehr und zum Teil eine Länge von über $25 \mathrm{~m}$.

249 Die so weit ging, dass selbst die Bischöfe Nordafrikas (Alypius, Augustinus und Aurelius) zu Umsicht und nachhaltigem Wirtschaften rieten. Vgl. Vit. Mel. 20; vgl. zu dieser Episode auch BROWN (2002), $55 \mathrm{f}$.

250 Dementsprechend auch die Schutzmaßnahmen, die die kaiserliche Gesetzgebung vorsah: u. a. CJ. 8,10,2 (a. 222) zum Schutz der Anwesen vor Abriss und Ausplünderung des Inventars; CJ. 8,10,8 (a. 
gische Befund und die literarischen Zeugnisse geben es jedoch her, dass noch vor 410 der Besitz an Severus, den Bruder des Pinianus, übergegangen sein könnte. ${ }^{251}$ Hierfür spricht auch das in Sicherheit gebrachte Silbergerät, welches wohl kaum für ein Asketenpaar bewahrenswert gewesen wäre. ${ }^{252}$

Mit der senatorischen domus verband sich eine ökonomische, soziale und auch kulturelle Verantwortung, die gerade in schwierigen Zeiten als gesellschaftsstabilisierender Faktor an Bedeutung gewonnen haben muss. Das von Symmachus als morbus fabricatoris $^{253}$ und Wettbewerb in den „lukullanischen Werken“254 gerühmte senatorische Bau- und Ausstattungswesen trug eminent dazu bei, spätantikes Handwerk und Kunstschaffen am Leben $\mathrm{zu}$ erhalten. Ebenso wie das senatorische Haus als gesellschaftliches Zentrum des städtischen Lebens wichtig für die politische und soziale Kommunikation war, bot es auch Raum sowohl für die Bildungspflege als auch für die bildenden Künste und das literarische Schaffen. Diesbezüglich ließen sich zumindest für die angeführten Beispiele zwar Veränderungsprozesse aufzeigen, doch im Ganzen scheint hier die Kontinuität und Prosperität zu überwiegen. Auf ganz Rom ist dieses selektive Bild aber sicher nicht übertragbar.

\section{4 ,Jedes Haus ist eine Stadt" - zwischen senatorischer domus und Kaiserpalast}

Bevor auf die Fragen zu kommen ist, wie der öffentliche Charakter der domus und ihre Funktion im städtischen Raum zu bewerten ist und ob die senatorischen Anwesen hierbei vielleicht sogar stärker als zuvor in Konkurrenz zu den kaiserlichen Residenzen traten, bietet es sich an, das berühmte Diktum des Olympiodor ${ }^{255}$, wonach jedes Haus eine Stadt sei, voranzustellen:

Von den großen Häusern in Rom sagte er [Olympiodor] ${ }^{256}$, jedes einzelne enthalte in sich allein alles, was eine respektable Stadt aufweisen kann: ein Hippodrom, Plätze, Tempel, Quellen und ver-

377) zur Pflicht, die Häuser zu reparieren; CTh. 3,30,2 (a. 323) und CTh. 3,32,1 (a. 322) zur Wahrung des Besitzstandes; CTh. 4,14,1 (a. 424) zu Ersitzung und Eigentumsrecht (vgl. KASER 2(1993) 351 u. 420); Nov. Val. 8,1 und 8,2 (a. 440/441); Nov. Val. 23,3-4 (a. 447) gegen die Spekulanten im Baumaterialsektor. Vgl. hierzu ausführlich HILLNER (2004) 23-80 mit Blick auf die Besitzrechte und die Baugesetzgebung. 251 Auch die 8.000 protestierenden Sklaven werden von Severus angekauft (Vit. Mel. 10 und Pall. Laus. 61). Die Erwähnung eines Xenodochium Valerii (Greg. Magn. ep. 9,28) könnte für eine fortgesetzte der Präsenz der Valerii auf dem Caelius sprechen; zur Lokalisierung vgl. BRENK (2003) 114f.; ders. (1999) 72f. und HILLNER (2004) 173. Vgl. ferner auch GATTI (1902) 149.

252 Vgl. auch Aug. ep. 122,2; hierzu SCHLANGE-SCHÖNINGEN (2009) $135 \mathrm{f}$.

253 Symm. ep. 2,60,2. Vgl. hierzu auch HILLNER (2004) $135 \mathrm{f}$.

254 Symm. ep. 2,60,1 u. 7,36.

255 Vgl. zur Präsenz Olymiodors in Rom CHAFFIN (1993) 111.

256 Es handelt sich hierbei um einen Auszug, der auf der Überlieferung durch Photios beruht. 
schiedene Bäder. Daher äußerte der Autor: Jedes einzelne Haus ist eine Stadt, und eine Stadt birgt zehntausend Städte. ${ }^{257}$

Auf den ersten Blick könnte man meinen, Olympiodor neige zur Übertreibung, wenn er jeder der senatorischen Anwesen den Charakter einer Stadt in der Stadt, mit allen für das städtische Leben relevanten Einrichtungen verleiht. Tatsächlich ist es aber so, dass selbst, wenn die spätantiken villae ${ }^{258}$ gemeint wären, sich kein senatorisches Anwesen anführen lässt, welches alle fünf Bestandteile umfasst. ${ }^{259}$ Die zitierte Passage ist dem Siegeszug Theodosius II. und des vom theodosianischen Hof propagierten Optimismus des Jahres 425 verpflichtet. ${ }^{260}$ Doch auch unter Berücksichtigung, dass es sich hier um eine ,panegyrische“ Übertreibung handelt, bleibt allein schon der Umstand bemerkenswert, dass Olympiodor die großen senatorischen Häuser zum Gradmesser für das Wohlergehen und die Prosperität des Reichs sowie der Stadt Rom $^{261}$ werden lässt. In der Wahrnehmung des großstädtischen Charakters der Tibermetropole, ihrer Größe und Prosperität, nahmen die senatorischen Anwesen in der ersten Hälfte des 5. Jhs. allem Anschein nach einen erhöhten Stellenwert ein. Dies lässt den Schluss zu, dass die senatorischen Residenzen mehr denn je in den öffentlichen Raum der Stadt Rom ${ }^{262}$ eindrangen und gewissermaßen deren Topographie

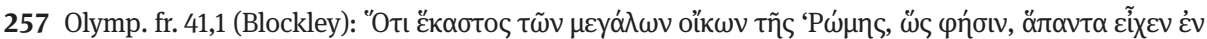

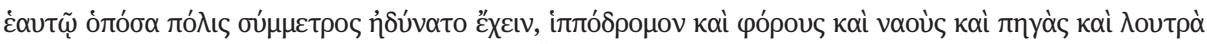

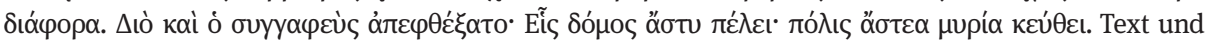
Übersetzung bietet auch HILLNER (2004) 123 mit Anm. 1.

258 Dass Olympiodor hier eher villae vor Augen hatte, vermutete COARELLI (1986) 1-58, hier 40 f; wobei dann schwer das Bild einer Stadt in der Stadt passt. Vgl. auch GRIESBACH (2010) 64 Anm. 79; BEHRWALD (2009) 132; ELLIS (1988) 569-572 u. 576 und BLOCKLEY (1983) 220 Anm. 81.

259 Einzelne und mehrere Bestandteile aber schon: z. B. am Palatin-Palast und Sessorium, an der Villa des Maxentius (Circus), an der Villa der Quintilier (Stadion, Nymphäum und Therme); dem forum des Petronius Maximus und dem der Sibidii, der Residenz des Neratius Cerealis (Tempel und Therme; vgl. Kap. 6.3). Am häufigsten lässt sich für die Nymphäen und Thermen ein archäologischer oder literarischer Beleg finden (vgl. auch Kap. 8.3); für Platzanlagen (fora privata?), Tempel (vielleicht auch Kirchen und Privatkapellen) und eine Pferderennbahn (Circus oder auch Garten-Stadion) können nur wenige Beispiele genannt werden. Mir ist hierbei kein senatorisches Anwesen bekannt, welches nachweisbar alle fünf Baubestanteile umfasst. Vgl. hierzu auch HILLNER (2004) 124-130; GUIDOBALDI (1986) 213- 215 u. $227 \mathrm{f}$. $260 \mathrm{Zu}$ Olympiodor als „Panegyriker“ der theodosianischen Dynastie vgl. CHAFFIN (1993) lxiv u. 170 Anm. 7 und MATTHEWS (1975) 385f.; ders. (1970a) 79-97, hier 97; so im Grunde auch HILLNER (2004) 141f. Zum Geschichtswerk vgl. aktuell STICKLER (2014) 85-102 und VAN NUFFELEN (2013) 130-152 mit der älteren Literatur.

261 Die Annahme, wonach Olympiodor hiermit die Dekadenz der stadtrömischen Aristokratie offenlegte, ist wohl nicht zutreffend, da die gesamte Passage keinerlei negative Implikation beinhaltet; so noch CAMERON (1999b) 493-498 und BALDWIN (1980a) 212-231, hier 215 Anm. 11.

262 Die Interpretation von GRIESBACH (2010) 64f., wonach hier eine Parzellierung der Stadt in viele „separate Städte“ (Häuser) angedeutet werde und die Grenze zwischen Stadt und Land von der Tür eines jeden Hauses markiert sei, ist m. E. eher abzulehnen; schon allein durch den öffentlichen Charakter dieser Anwesen kann nicht die Rede davon sein, dass „die Wirkung dieser Domizile der Reichen nach außen so hermetisch“ war, „daß sie wie autonome Gebäudekomplexe erschienen.“ (ebd. 65, wobei schon in 
für sich vereinnahmen konnten. Gerade für eine Zeit, in der das Kaiserhaus wieder stärker in Rom präsent war und dies durchaus durch sein öffentliches Auftreten und die kaiserliche Bautätigkeit deutlich signalisierte, erstaunt, dass nicht die kaiserlichen, sondern die senatorischen Domänen die Stadt Rom definieren. ${ }^{263}$ Es muss daher nicht verwundern, wenn ein senatorisches Haus im 5. Jh. in seiner Funktion als öffentlicher Raum gewissermaßen ,staatstragende‘ Bedeutung erlangen konnte.

Das Paradebeispiel hierfür liefert die Domus ad Palmam, ${ }^{264}$ in welcher sich 438 der Senat versammelte, um feierlich den Codex Theodosianus im Westen einzuführen. Weswegen nun einer der bedeutendsten Staatsakte des 5. Jhs. ausgerechnet in einem senatorischen Haus und nicht im Kaiserpalast oder der Curia Iulia zelebriert wurde, hat schon immer Fragen aufgeworfen, bis dahin, dass man sogar vermutete, das Senatsgebäude sei zu dieser Zeit aufgrund von Schäden nicht nutzbar gewesen. Wirft man aber nur einen Blick auf das Datum, den 25. Dezember, wird klar, dass hinter der Nutzung eines Privathauses auch praktikable Gründe stecken können. Im Gegensatz zum Senatssaal boten senatorische Anwesen oftmals beheizbare Säle, ${ }^{265}$ die vor allen in den Wintermonaten um einiges komfortabler waren. Die genaue Lokalisierung des Hauses gelang bisher jedoch nicht. ${ }^{266}$ Umstritten ist auch die Gleichsetzung mit der bei Cassiodor erwähnten Domus Palmata, ${ }^{267}$ die sich Anfang des 6. Jhs. im Besitz des Faustus Albinus iunior ${ }^{268}$ befunden haben soll. Wenn hier tatsächlich wachsende Palmen ${ }^{269}$

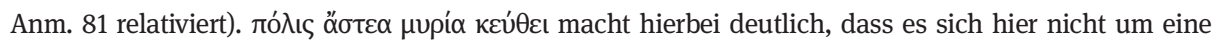
Separierung handelt, sondern die Summe der Häuser die Stadt bilden.

263 Anders Ammian und Claudian, die vor allem die altehrwürdigen Monumente und den Kaiserpalast auf dem Palatin vor Augen hatten. Amm. 16,10,1-17: im Besonderen das Forum Romanum, das Kapitol und das Trajansforum; Claud. VI. Cos. Hon. 39-52: Palatin. Hierzu u. a. BEHRWALD (2009) 78-96; CANCIK (2006) 9-17; LONG (2004) 1-15; KLODT (2001) 63-96 und BRANDT (1998) 153-158. Die senatorischen Häuser werden zwar als prägend für das städtische Leben dargestellt (Amm. 14,6,16f.), stehen aber unter starker Kritik. Vgl. STENGER (2012) 189-216.

264 CTh. gest. in sen. 1: Anicius Acilius Glabrio Faustus v.c. et inlustris tertio expraefecto, praefectus praetorio et consul ordinarius, in domo sua, quae est ad Palmam; vgl. HILLNER (2004) 132f.; MATTHEWS (2000) 32f. und ders. (1975) 357; zur Veröffentlichung des Codex Theodosianus vgl. auch Kap. 5.3; ferner zum Anwesen, welches nur literarisch zu fassen ist, KALAS (2015) 155f., 171 u. 204 und GUIDOBALDI (1999b) 52-54 [LTUR 4]; älter PLATNER/ASHBY (ND 2015) 187, 382, 428 u. $604 \mathrm{f}$.

265 Solch ein durch Hypokausten beheizter Saal findet sich etwa in der Domus Symmachorum (praefurnium G); ferner auch in der Domus Pinciana (halbrunder Saal).

266 Vgl. z. B. KALAS (2015) 155f.; LIVERANI (2007a) 169-193, hier 177-184; ATZERI (2008) 132-138; HILLNER (2004) 25; MATTHEWS (2000) 32-34; GUIDOBALDI (1999b); BAUER (1997) 35f.; GUIDOBALDI, (1995a) 99f. [LTUR 2] und MARCHETTI-LONGHI (1949-1951) 183-229, hier 222 u. 227. So wurde die domus u. a. nahe der Curia Iulia (KALAS; hier u. a. sogar mit dem Atrium Libertatis identifiziert), am Augustusforum (HILLNER) oder am Tellus-Tempel (nördlich des Venus-und-Roma Tempels? MARCHETTI-LONGHI) vermutet.

267 Cassiod. Var. 4,30 (porticus curva). Vgl. HILLNER (2004) 24f. mit Text und Übersetzung; An. Val. 66 (Rede des Theoderich ad Palmam) und Vit. Fulg. 27,13. Vgl. ebd. 132f. und von HILLNER unabhängig LIVERANI (2007a) 177-180. Gegen eine Gleichsetzung sprechen sich vor allem BAUER (1997) 35f.; ders. (1996) 114; H. BAUER, Porticus absidata. RM 90 (1983) 111-184 und GUIDOBALDI (1995a) 99 aus.

268 PLRE 2, 51f. (?Faustus Albunus iunior 9). 
gemeint sein sollten, so war die Ortsangabe überaus unpräzise formuliert. Die Angabe in domo sua, quae est ad Palmam dürfte so für den oströmischen Hof nahezu genauso abstrakt gewesen sein wie für den heutigen Leser.

Die domus muss entsprechende Räumlichkeiten für einen Staatsakt besessen haben. $\mathrm{Zu}$ denken ist etwa an eine großzügig bemessene aula apsidata, die in den Wintermonaten beheizt werden konnte. ${ }^{270}$ Überdies lässt sich erwarten, dass sich das Anwesen dergestalt in den öffentlichen Raum der Stadt einfügte, dass ohne große Verzögerung die öffentliche Verlautbarung vor dem stadtrömischen Volk erfolgen konnte. Dass die senatorischen Anwesen zum Teil über entsprechende Platzanlagen ( $\varphi$ ópol/fora) ${ }^{271}$ verfügten, ist durch Olympiodor bezeugt und für Anicius Acilius Glabrio Faustus sogar archäologisch nachweisbar. Das sog. Forum Sibidii dürfte eine solche Platzanlage gewesen sein. Drei Ehreninschriften, die Anicius Acilius Glabrio Faustus für seinen Vater Acilius Glabrio Sibidius signo Spedius ${ }^{272}$, seinen Schwiegervater Tarrutenius Maximilianus ${ }^{273}$ und für seinen Großvater oder Urgroßvater mütterlicherseits (proavus maternus) ${ }^{274}$ setzen ließ, haben sich davon erhalten. Die Funde lassen eine Lokalisierung des Forum Sibidii auf dem nördlichen Marsfeld vermuten, nahe des Palazzo Altemps an der Piazza di Sant'Apollinare, in dessen Gärten zwei der drei Statuenbasen entdeckt wurden. ${ }^{275}$ So dürfte in der antiken Topographie der Stadt das Forum Sibidii mittig zwischen der Via Triumphalis und der Via Flaminia, südlich des solarium des Augustus, etwa auf Höhe des Ustrinum Divi Antonini gelegen haben. Damit befand sich das forum in zentraler Lage zwischen den beiden wichtigsten nördlichen Ausfall-

269 So SOUTER (1949) 283. Vgl. auch HILLNER (2004) 133 Anm. 1.

$270 \mathrm{Zu}$ diesen Sälen im archäologischen Befund vgl. jetzt auch MIELSCH (2016) 52-72.

271 Vgl. HOFMANN (1989) 475.

272 CIL 6, 1678 (ILS 1281): SPEDII. / ACILIO GLABRIONI SIBIDIO V. C. ET OMNIBVS / MERITIS INLVSTRI LEGATO IN PROVINCIA ACHAIA / CONSVLARI CAMPANIA VICARIO PER GALLIAS / SEPTEM PROVINCIARVM SACRI AVDITORII COGNI/TORI FORI HVIVSCE INVENTORI ET CONDITORI PRI/MO PATRI REVERENTISSIMO ANICIVS ACILIVS / GLABRIO FAVSTVS V. C. LOCI ORNATOR TOGATAM / STATVAM OFFERENS PIAE NON MINVS QVAM DE/VOTAE MENTIS RELIGIONE PONENDAM / ERIGENDAMQVE CVRAVIT. Lesung nach AMELUNG (1903) Taf. 57; in eigener Betrachtung 2017; Vatikanische Museen, Galleria Chiaramonti Inv.-Nr. 1698; zur Person vgl. PLRE 1, 838f.

273 CIL 6, 1767 (ILS 1282): TARRVTENI. / TARRVTENIO MAXIMILIANO V. C. / ELOQVENTISSIMOQVE CONSVLARI / PICENI ANNO AETATIS NONODECIMO / VICARIO VRBIS ROMAE LEGATO AMPLIS/SIMI SENATVS SECVNDO SOCERO / EX OPTATISSIMO ANICIVS ACILIVS / GLABRIO FAVSTVS V. C. LOCI HVIVS / ORNATOR TOGATAM STATVAM / LIBENS OPTVLI. Lesung nach GORDON (1965) III Nr. 357; in eigener Betrachtung 2017; Vatikanische Museen, Galleria Chiaramonti Inv.-Nr. 1442; zur Person vgl. PLRE 2, 741 (Tarrutenius Maximilianus 3).

274 CIL 6, 37119 (ILS 8986, neu ediert unter CIL 6, 41389a); hier in einem Fragment (vormals zwei), welches heute auf dem Caelius aufbewahrt wird, fassbar; hierzu ausführlich NIQUET (2000) 253-259; älter BAUER (1997) 34 und PALMER (1990) 49f. DONDIN-PAYRE (1993) 32 u. 39f. sprach sich hier für Quintus Clodius Hermogenianus Olybrius (Cos. 379) und Petronius Probinus (Cos. 341) aus. Vgl. BAGNALL (1987) 216f. u. 292f.

275 Vgl. BAUER (1997) 34-37; PAPI (1995) 346 [LTUR 2] und PALMER (1990) 47 betreffend CIL 6, 1678 und CIL 6, 37119 in situ; CIL 6, 1767 (für Tarrutenius Maximilianus) stammte vom Campo Vaccio nahe des Forum Romanum; vgl. PALMER (1990) 49 Anm. 181. 
straßen der Stadt. Möglicherweise wurde es auf dem Areal des sog. Trigarium ${ }^{276}$ angelegt, welches vielleicht nahe der Fundstelle der Statuenpostamente zu verorten ist.

Als fori inventor et conditor primus ist Acilius Glabrio Sibidius signo Spedius benannt, der die Platzanlage vermutlich um 400 anlegen ließ. Sein Sohn Anicius Acilius Glabrio Faustus schuf hier als ornator eine Ahnengalerie. Damit diente diese Platzanlage den Sibidii als eine Art Ruhmeshalle des eigenen Hauses. ${ }^{277}$ Dies stellt eine Praxis dar, die ihre nächste Parallele in der statuarischen Ausstattung der senatorischen domus findet. ${ }^{278}$ Die Ehrungen auf diesem Platz lagen ganz im Ermessen des Anicius Acilius Glabrio Faustus, der auf diesem forum sozusagen das ,Hausrecht' nun schon in zweiter Generation für die Sibidii ausübte. Damit unterstand eine öffentliche Platzanlage Roms der Kontrolle eines senatorischen Hauses, was tatsächlich eine bedeutende Neuerung ${ }^{279}$ im 5. Jh. darstellt.

Für die Diskussion um die Domus ad Palmam und das Forum Sibidii könnte die Nennung der Equi palmati im Codex Theodosianus ${ }^{280}$ an Bedeutung gewinnen, auf die noch Dirksen ${ }^{281} 1850$ hingewiesen hatte. Falls nämlich das forum im Areal des Trigarium zu suchen ist, bestünde eine Berechtigung, anzunehmen, dass dieses funktional noch immer mit dem Rennbetrieb ${ }^{282}$ auf irgendeine Weise verbunden war. Die Domus ad Palmam $^{283}$ könnte so wiederum auf die equi palmati hinweisen, die hier auf dem

276 Hier eher CASTAGNOLI (1948) 140-148, hier 136: nördlich der Piazza Navona; dagegen COARELLI (1977) 807-846, hier 845: am Westende des Marsfelds entlang des Tibers; ders. (1993c) 89f. [LTUR 1]; dieser Verortung COARELLIs widersprachen u. a. PALMER (1990) 29-31 und QUILICI (1983) 59-85, hier 75. Die Präsenz der Rennställe (stabula factionum) ist durch CIL 6, 10044 belegt.

277 Vgl. BEHRWALD (2009) 138; HILLNER (2004) 126; NIQUET (2000) 25f.; DONDIN-PAYRE (1993) 144f.: bes. PALMER (1990) 50.

278 So bereits BEHRWALD (2009) 138: „Ähnliche Statuenprogramme sind aus römischen domus und privaten Parkanlagen bekannt.“ Vgl. NIQUET (2000) 25-33. Hier wären beispielsweise die Ehrenmonumente in der Domus Symmachorum oder das Standbild des „Jüngeren“ und „Älteren Consuls“ anzuführen.

279 Es existieren zwar weitere Platzanlagen des 4. Jhs., die BAUER als fora privata bespricht, doch diese können, da sie zumeist vom PVR verantwortet wurden oder lediglich eine statuarische Neuausschmückung umfassen, im engeren Sinne nicht als Privatstiftungen eines senatorischen Hauses gelten; so das forum des PVR Eurycles Epitynchanus (CIL 6, 31888; BAUER (1997) 41-45), des Eupraxius (CIL 6, 1177; ebd. 45 f.) und das sog. Forum Aproniani (CTh. 13,5,29; ebd. 28f.); zu dieser Einschätzung kommen vor allem BEHRWALD (2009) 135-139 und NIQUET (2000) 25f. u. 215-218.

280 CTh. 10,6,1 (a. 395 [396/7]; aus dem Osten): Dies betrifft die kaiserliche Pferdezucht, wohingegen mit equi Palmati und equi Hermogeniani die bedeutendsten Pferderassen gesondert aufgeführt waren. Vgl. auch CTh. 15,10,1 (a. 371; ad Ampelium PVR). Vgl. BERGES/NOLLÉ (2000) 303f. mit Übersetzung.

281 Vgl. DIRKSEN (1850) 299-303; noch berücksichtigt in JORDAN/HÜLSEN (1885) Bd. 1,2, 259.

282 Das Trigarium wird auch im 4. Jh. in der Notitia Urbis Romae in der Regio IX Circus Flaminius verortet, also eventuell durchaus nördlich der Piazza Navona. In diesem Gebiet auf dem Marsfeld dürften sich möglicherweise auch die stabula factionum befunden haben; auch Strab. 5,3,8 überliefert für die augusteische Zeit die Nutzung dieses Areals für den Rennbetrieb und die Pferdehaltung. Vgl. COARELLI (1993b) 339 [LTUR 1].

283 So DIRKSEN (1850) 302. 
Marsfeld möglicherweise gehalten wurden. ${ }^{284}$ Daraus ließe sich folgern, dass domus und forum in der Tat nahe beieinanderlagen. Die Domus ad Palmam könnte in diesem Fall den Namen der Zucht ${ }^{285}$ aufgreifen.

Noch ein weiterer Punkt spricht dafür, die domus und das forum zusammen in diesem Areal zu verorten. Haus und Platz lagen damit außerhalb des pomerium - zumindest dann, wenn die traditionelle Grenze des republikanischen Roms, die in etwa mit der Servianischen Mauer übereinstimmte, hier noch Gültigkeit besaß. ${ }^{286} \mathrm{Im}$ Jahr 438 hätte so die Verhandlung über das Inkrafttreten des Codex Theodosianus außerhalb der heiligen Grenze Roms stattgefunden. Erst nach diesem Akt, der selbstverständlich eine reine Formalität darstellte, hätte das Gesetz Aufnahme in der Stadt gefunden und damit offiziell Gültigkeit innerhalb der heiligen Grenzen der Urbs aeterna erlangt. Im Hinblick auf die beiden Ereignisse, die zu Beginn des 6. Jh. ad Palmam stattfanden, würde sich eine Verortung jenseits des pomerium ebenfalls anbieten. Zum einen legen die Angaben über den Einzug Theoderichs in Rom nahe, ${ }^{287}$ dass dieser zunächst Alt-St. Peter aufsuchte und dann über die Via Triumphalis der Stadt entgegenzog, wo er am ehesten von den versammelten Vätern auf dem Marsfeld ad Palmam, und zwar noch

284 Aus CTh. 15,10,2 (a. 381, ad Valerianum praefectum Urbi) geht hervor, dass die campanischen Städte zur Futterversorgung mit Bohnen, die für die Pferde der hauptstädtischen Rennparteien bestimmt waren, verpflichtet wurden, folglich diese Pferde in Rom gehalten wurden.

285 Nem. cyneg. 241-250. In ihrem Ursprung wird die Zucht im 3. Jh. n.Chr. in Kappadokien (Tyana) verortet und mit einem Palmatius/Palmatus in Verbindung gebracht, der unter Valerian enteignet wurde (Frag. Hist. Graec. 4,145); die Villa Palmati? (Itin. Hieros. 577, 6). Vgl. SCHLIEBEN (1867) 98f.; im Grunde nach GOTHOFREDUS (1741 ND 1975); im Wesentlichen übernommen BERGES/NOLLÉ (2000) 303f.; CAMERON (1976) $7 \mathrm{f}$. und JONES (1964) 414. Zur Übertragung des Namens der equi palmati auf einen Ort bzw. eine Landschaft vgl. auch MOREAU, Miszellen: KOYH 286 Dass diese trotz der späteren Erweiterungen in der Kaiserzeit noch präsent war, belegt etwa Eutrop. 8,5,2, wo es heißt, dass Trajan der einzige gewesen sei, der innerhalb des pomerium bestattet worden sei (Sockel der Trajanssäule); auch die von Claudian geschilderte Volkswahl auf dem Campus Martius (Claud. VI. Cos. Hon. 597-599) ergibt nur dann nach republikanischer Tradition Sinn, wenn die comitia consularia außerhalb des pomerium stadtfanden; ebenso die Waffenübungen auf dem Marsfeld (Prisk. fr. 30,5 (Blockley) und Marcell. Com. s. a. 455), hinsichtlich CTh. 14,10,4; zum pomerium allgemein vgl. DROGULA (2007) 419-452; KOLB (1995) 400 - 403 und RE XXI,2 (1952) Sp. 1867-1876. Für die Wiederanwendung der Grenzen des republikanischen pomerium könnten gerade auch die im 5./6. Jh. zu fassenden Bestattungen innerhalb der Stadtmauer sprechen (u. a. Crypta Balbi). Vgl. GRIESBACH (2010) 56 u. 66; ausführlich JONSSON (2005) 85-96 und MENEGHINI/SANTANGELI VALENZANI (1993) 89-111. Auch wenn das pomerium eine heidnische rituelle Stadtgrenze darstellt, ist anzunehmen, dass die Tradition und Achtung dieser Grenze, losgelöst vom heidnischen cultus, weiterhin bestand.

287 An. Val. 66 (Cron. min. I. 324): [...] venit ad Senatum et ad Palmam populum adlocutus. Vgl. auch Vit. Fulg. 27,13: in loco qui Palma Aurea dicitur, memorato Theodorico rege concisionem faciente, Romanae curiae nobilitatem, decus ordinemque distincis decoratam gradibus aspectaret; vgl. HILLNER (2004) 132 Anm. 9 mit Text und Übersetzung). Für gewöhnlich wäre anzunehmen, dass diese Rede von der rostra auf dem Forum Romanum aus erfolgte (Amm. 16,10,13: Constanitus II.; Pan. Lat. 2 (12) 47,3: Theodosius I.; Claud. VI. Cos. Hon. 587 f.: Honorius), weswegen eine räumliche Nähe zum Forum Romanum und der Curia Iulia angenommen wurde; so schon GREGOROVIUS (ND 1963) 135; nachfolgend $\mathrm{u}$. a. LIVERANI (2007a) 177-180; BAUER (1996) 114; GUIDOBALDI (1999b) 53 [LTUR 4]; MARCHETTI-LONGHI (1949-1951) 188f. und DE FRANCISCI (1946/1947) 306-310. 
außerhalb des pomerium, wo ein militärischer Habitus erlaubt war, ${ }^{288}$ in Empfang genommen wurde. Zum anderen konnte gerade hinsichtlich der Synode palmaris ${ }^{289}$ die Notwendigkeit bestanden haben, einen Ort außerhalb der heiligen Stadtgrenze auszuwählen, da Symmachus von den gegen ihn erhobenen Anklagen noch nicht freigesprochen war. ${ }^{290}$

Funktional hätte somit die Domus ad Palmam als Sitzungslokal die Aufgabe übernommen, wofür noch in republikanischer Zeit die sog. Curia Pompeia im Pompeiustheater $^{291}$ zur Verfügung stand. Falls diese Überlegungen ${ }^{292}$ das Richtige treffen sollten, hätte sich hier im Bereich des nördlichen Marsfelds ein privates Anwesen befunden, welches den Ansprüchen eines hoch offiziellen Tagungslokals des Senats gerecht wurde. Sollten an diesem Ort die Circusfraktionen präsent gewesen sein, so befanden sich das Forum Sibidii und die Domus ad Palmam mitten in einem politischen und gesellschaftlichen Brennpunkt des städtischen Lebens.

An dieser Stelle kann das gewonnene Bild anhand des von Petronius Maximus gestifteten forum komplettiert werden. Von dieser Platzanlage, die in ihrer architektonischen Gestalt allerdings ebenso wenig zu fassen ist, zeugen abermals nur epigraphische Funde. Zwei Inschriften, ${ }^{293}$ die im Garten der Società dei XII Apostoli aufgefunden wurden, nennen Petronius Maximus, welcher dreimal Stadtpräfekt und zweimal Konsul war, als conditor fori. Bereits Jordon/Hülsen verorteten die Platzanlage in der III. Region nordöstlich von S. Clemente an der modernen Via Labicana, im Bereich des IsisSerapis-Tempels und der sog. Porticus mit Piscina. ${ }^{294}$ Eine direkte Verbindung zu einer

288 Innerhalb des pomerium und i. B. in der Curia Iulia war dies nach alter Sitte nicht zulässig (vgl. Claud. VI. Cos. Hon. 594f.). Dies wurde aber nicht immer von den Herrschern beachtet und erfuhr so z. B. im Fall Constantius II. auch dementsprechend harsche Kritik (vgl. Amm. 16,10,1-17).

289 Acta Syn. 426 - 437. Hierzu vgl. WIRBELAUER (1993) 22 Anm. 61 und NÄF (1992) 431-446, hier 441. 290 Vgl. SESSA (2012) 208-246; WIRBELAUER (1993) und SCHÄFER (1991) 212-239. Hierzu vgl. auch die Verfahrensweise im Schisma von 418/419; vgl. z. B. Coll. Av. 33: Anweisung, dem Bonifatius den Zugang zur Stadt zu gewähren. siehe Kap. 5.2.

291 Berühmtheit erlangte dieser Tagungsort des Senats vor allem im Zusammenhang mit der Ermordung Julius Caesars 44 v. Chr. (Curia des Pompeius. Vgl. u. a. Suet. Iul. 80,88). Baumaßnahmen, die in der Zeit des Honorius zu datieren sind, bezeugen zwar die fortgesetzte Sorge um diesen Bau, verdeutlichen aber auch den ruinösen Zustand des Gebäudes; nach CIL 6, 1191 (ILS 793) sollen der Säulenumgang eingestürzt und das Innere zum Teil von Trümmern bedeckt gewesen sein. Vgl. BAUER (2001) 90f. und LTUR 5 (2001) $35 \mathrm{f}$.

292 Weiterhin denkbar bleibt eine Verbindung mit den Siegeszeichen der Wagenrennen und/oder den equi palmati. Die Diskussion um die Domus Palmata/Palmati (Cassiod. Var. 4,30 und Lib. Pont. 1,233) wurde hier bewusst ausgeblendet, da eine Übereinstimmung mit der Domus ad Palmam sehr strittig ist; anders HILLNER (2004) $24 \mathrm{f}$.

293 CIL 6, 1198: DOMINO RERVM HVMANARVM VALE[n]TINIANO AVGVSTO / PETRONIVS MAXIMVS V. C. FORI CONDITO $[r]$ / POST QVAT[t]VOR PRAEFECTVRAS ET DVOS ORDINARIOS / CONSVLATVS AVCTORI SIBI TOT HONORVM LOCA[vit]; Lesung nach BAUER (1997) 38. Von CIAMPINI um 1700 kopiert; publiziert von MURATORI, Novus thesaurus veterum inscriptionum I (1734) 406,3; vgl. BAUER (1997) Fig. 3. und CIL 6, 1197.

294 JORDON/HÜLSEN (1907) Bd. 1,3, 303f.; so auch HÜLSEN (1902) 266f.; nachfolgend PALMER (1990) 46f.; LEGA (1995) 312 [LTUR 2] und BAUER (1997) 38. 
entsprechenden domus kann zwar aufgrund fehlender archäologischer Befunde nicht zweifelsfrei bewiesen werden, wird aber durch die Nähe zum Oppius bzw. Esquilin und Caelius, auf welchem die Anicier nach Ausweis der literarischen Quellen mehrere Häuser unterhielten, ${ }^{295}$ durchaus nahegelegt. ${ }^{296}$

Die genauen Umstände der Gründung nennt die Inschrift CIL 6, 1197, in der es heißt: squalore summoto, ${ }^{297}$ was bedeutet, dass zuvor „Schmutz“ - vermutlich Trümmer entfernt werden mussten, um den Bau zu realisieren. Diese Angabe wird dann besonders interessant, wenn die Anlage auf öffentlichem Grund und nicht Privatbesitz errichtet wurde. Lanciani vermutete hinter den Strukturen, die 1885 beim Bau der Via Buonarroti zu Tage traten und als „Porticus mit Piscina“ benannt wurden, die Überreste des Isis-Serapis-Tempels, der für die Regio III ISIS ET SERAPIS namensgebend war. ${ }^{298}$ In zahlreichen Aufsätzen konnte de Vos diese Vermutung weiter stützen. ${ }^{299}$ Seither wurde immer wieder im Hinblick auf die beiden Inschriften vom Forum Petronii Maximi angenommen, dieses sei auf dem Areal des Isis-Serapis-Heiligtum errichtet worden. ${ }^{300}$ Vor allem Häuber und Schütz ${ }^{301}$ kommen in der erneuten Analyse der von Agostini verfassten Briefe, welche die Fundumstände festhielten, zu dieser Lokalisierung. Petronius Maximus erwarb wohl die Rechte an diesem Platz, der vermutlich seit der Tempelschließung ${ }^{302}$ keinen großen Nutzen für das öffentliche Leben mehr besaß und dementsprechend vernachlässigt worden war. Wie bisher deutlich gemacht wurde, hingen Erhaltungsmaßnahmen vor allem von der Funktionalität des Baus und seinem öffentlichen Nutzen ab. Im Fall der heidnischen Kultplätze erforderte dies die Desakralisierung und das Etablieren einer profanen Funktion. In diesem konkreten Fall gelang dies durch die Umgestaltung des Areals zu einer profanen Platzanlage.

Laut der Inschrift, die Petronius Maximus als zweimaliger Konsul und dreimaliger Präfekt ohne Nennung des Patriziustitels anführt, ergibt sich für den Bau eine Datierung zwischen 443 und 445. Petronius Maximus hatte demnach kein Amt inne und stiftete die Platzanlage wohl als privatus. ${ }^{303}$ Das Forum Petronii Maximi stellte dabei keineswegs einen singulären Fall dar. So ging etwa die Basilica Hilariana, die bis etwa 415 Sitz des Kollegiums der dendrophoroi war, wahrscheinlich in den Besitz der Domus Symma-

295 Vgl. HILLNER (2004) 278-280 und PLATNER/ASHBY (ND 2015) 155, 181 u. 187.

296 Vgl. GUIDOBALDI (1995d) 140 [LTUR 2] und jetzt auch HERKLOTZ (2004) 56-57.

297 CIL 6, 1197: PETRONIVS MAXIMVS IIII PRAEFECTVS ET BIS CONSVL ORD(inarius) SQVALORE SVMMOTO; Lesung nach BAUER (1997) 39.

298 Vgl. LANCIANI (1888) 205-207.

299 Vgl. u. a. DE VOS (1997) 99-154; ders. (1996) 110-112 [LTUR 3] und ders. (1994) 130-159; vgl. auch ENSOLI (2000) $268 \mathrm{f}$.

300 Vgl. u. a. HERKLOTZ (2004); DE VOS (1997) und ENSOLI (1997) 306-321 u. 576-583.

301 Aktuell HÄUBER/SCHÜTZ (2010) 82-94, hier 87 f. mit Fig. 1 und jetzt auch HÄUBER (2014) 95-105. 302 Vgl. knapp ENSOLI (2000) 269 u. 279-283 (hier auch zu weiteren Isis-Heiligtümern der Stadt); ausführlicher DE VOS (1997) 123f. und COARELLI (1982) 54-58. Eine Aufgabe Ende des 4./Anfang des 5. Jhs., die mit der kaiserlichen Religionsgesetzgebung zusammenhängt, ist zu vermuten.

303 CIL 6, 1197 und CIL 6, 1198; vgl. hierzu aber auch die Überlegung BEHRWALD (2009) 137. 
chorum über. ${ }^{304}$ Auch ein Jupiter-Heiligtum auf dem Viminal könnte um die Wende vom 4. zum 5. Jh. in den Besitz der Neratii gelangt sein, dessen sakral-statuarische Ausstattung später vielleicht zur Ausschmückung einer kleineren Badeanlage diente. ${ }^{305}$

Hier ging es vor allem darum, sich möglichst zentrale Orte des städtischen Lebens für die eigene Repräsentation zu erschließen. Folglich trat Petronius Maximus auf seinem forum auch als Dedikant auf. Mit wenigstens einer Statue ehrte er Valentinian III. und unterstrich damit seine besondere Nähe zum Kaiser. ${ }^{306}$ Überdies bot sich mit der Platzanlage die Möglichkeit, verstärkten Einfluss auf den öffentlichen Raum und die umliegenden städtischen Einrichtungen zu nehmen. Die Dominanz des Petronius Maximus und seines Hauses in diesem Areal der Stadt fand so möglicherweise seine Entsprechung in den anlässlich seines Konsulats (443?) herausgegebenen Kontorniaten. ${ }^{307}$ Immerhin lag die stadtrömische Moneta in nächster Nähe. ${ }^{308}$ Des Weiteren könnten sich mit der Nähe zum Kolosseum und den für den Spielbetrieb wichtigen Gebäuden ${ }^{309}$ auch hier Einflussmöglichkeiten ergeben haben. ${ }^{310}$ Mit dem Forum Petronii Maximi verband sich für seinen Erbauer nicht nur eine gute Aussicht darauf, den eigen politischen und gesellschaftlichen Führungsanspruch mit Nachdruck öffentlichkeitswirksam zu präsentieren. Gleichsam konnte auch eine gewisse Kontrolle über den öffentlichen Raum und das Leben in der Stadt von diesem Ort ausgehen.

Umso bemerkenswerter ist es, dass mit der Domus Pinciana ein Fall für die AniciiPetronii überliefert ist, der genau in die entgegengesetzte Richtung weist: die Aneignung ihres Besitzes durch den Kaiser. Im Westen an die Horti Sallustiani angrenzend, die sich schon lange in kaiserlichem Besitz befanden, ging das Anwesen im 4. Jh. von den Acilii Glabriones $^{311}$ auf die Anicii über, um dann wiederum im 5. Jh. kaiserlicher Besitz zu werden. Eine Ehreninschrift, die den Namen der Anicia Faltonia Proba und des Sextus Claudius Petronius Probus trug, ${ }^{312}$ belegt zu Anfang des 5. Jhs. die Besitzerschaft der

304 Der Fund der in Kap. 8.3 besprochenen Glasschale spricht hierfür; vgl. HILLNER (2004) 36; SPINOLA (2000) 155; PAVOLINI (1993b) 483 Anm. 132 und CARIGNANI (1990) 72f. Vgl. jetzt auch PAVOLINI (2015) $345-375$, bes. $370-373$.

305 Dies betrifft eine Jupiter-Statue mit der Stifterinschrift (LSA 2538: dominus loci); vgl. hierzu Kap. 6.3. 306 CIL 6, 1198; hierzu auch STICHEL (1982) 100, Kat.-Nr. 105.

307 Vgl. hierzu Kap. 3.3.

308 S. Clemente?; vgl. knapp u. a. BRANDENBURG ³(2013) 151; KOLB (1995) 616 und R.-ALFÖLDI (1978) 188f.; ausführlicher COARELLI (1994) 23-66.

309 Etwa der Ludus Magnus. Vgl. hierzu COLINI/COZZA (1962) 7 ff. und knapp LTUR 3 (1996) 196f. und RICHARDSON (1992) $236 \mathrm{f}$.

310 Zum besonderen Engagement der Anicii in der Spielgebung vgl. auch Olymp. fr. 41,2 (Blockley); zur Person (Petronius Maximus?). Vgl. HENNING (1999) 28f. und CAMERON (1984b) 193-196.

311 Entsprechend CIL 6, 632 (ILS 5084a; a. 177): Horti Aciliorum. Vgl. JOLIVET/SOTINEL (2012) 137-160, hier 137 und ausführlicher GUIDOBALDI/JOLIVET (1995) 156f. [LTUR 2]; BROISE/JOLIVET (1994) 188-198; zuvor LANCIANI (1891) 132-155. Horti Luculliani vgl. BROISE/JOLIVET (1998) 189-204, hier 189-194. 312 CIL 6, 1754b (= CIL 6, 31921 = ILS 1269; a. 409): ANICIAE FALTONIAE / PROBAE AMNIOS PINEIOS / ANICIOSQVE DECRANTI / CONSVLIS VXORI / CONSVLIS FILIAE / CONSVLVM MATRI / ANICIVS PROBINVS V. C. / CONSVL ORDINARIVS / ET ANICIVS PROBVS V. C. / QVESTOR CANDIDATVS / FILII DEVINETI / MATERNIS DEDICAVERVNT. Vgl. auch CIL 6, 1751-1753 und CIL 6, 1755 für Probus und Proba, 
Anicier. Im Liber Pontificalis ist sodann ein Palatium Pincis ${ }^{313}$ aufgeführt, so dass zusammen mit den Funden von Flachziegeln (bipedes) ${ }^{314}$, die mit der Stempelung REI/PVB versehen sind, die kaiserliche Inbesitznahme und der aus kaiserlichen Mitteln finanzierte Ausbau zu einem palatium hinreichend sicher belegt sind. Mysteriös bleiben aber vor allem die Umstände des Besitzerwechsels und die kaiserliche Intention, die dahinterstand.

Die jüngsten Grabungen im Areal der Villa Medici und dem Konvent von Trinità dei Monti, die von Jolivet geleitet wurden, brachten die Überreste höchst repräsentativer Bauten zu tage. ${ }^{315}$ Unter dem Parnass, dem künstlich angelegten Hügel der Villa Medici, kamen zwei Zentralbauten zum Vorschein, die von Jolivet mit den in den Regionenkatalogen genannten templa duo nova Spei et Fortunae in Verbindung gebracht werden. ${ }^{316}$ Nördlich der Villa, im Bereich der Gärten des Konvents, befand sich ein gewaltiges Theater-Nymphäum, welches sich mit einer geschwungenen Portikus von $200 \mathrm{~m}$ Spannweite zum Marsfeld hin öffnete. ${ }^{317}$ Möglicherweise handelte es sich hier um das Nymfeum Iovis. In beiden Fällen sind es ältere Bauten, die sowohl im 4. als auch im 5. Jh. noch einmal eine Restaurierung erfahren haben. Die oben erwähnten Flachziegel stammten aus einer im Nord-Westen anschließenden Thermenanlage des 5. Jhs., ${ }^{318}$ die vermutlich genauso wie die beiden Zentralbauten und das Nymphäum in den neu entstandenen Kaiserpalast integriert wurden. Der Kernbereich des Palastes konnte bereits 1999 im Bereich der Piazzale der Villa Medici lokalisiert werden. ${ }^{319}$ Mehrere Repräsentationssäle, darunter ein halbrunder nach Süden orientierter Saal (Durchmesser $14 \mathrm{~m})$, eine aula apsidata (7,80x14,20 m) und ein rechteckiger Saal mit nach Osten gerichteter Exedra (7,20x10 m), konnten freigelegt werden. Verschiedene Galerien und Portiken verbanden die Gebäudeteile miteinander. Beachtenswert waren besonders die Funde, die vom Ausstattungsluxus zeugten. Gold- und Glastesserae einer Wand- bzw. Gewölbedekoration, Reste polychromer Mosaiken, Fragmente einer kostbaren Opus-

dessen Provenienz (Pincio?) jedoch nicht zu klären ist; zu den Inschriften vgl. NIQUET (2000) 119f. u. $123 \mathrm{ff}$.

313 Lib. Pont. 1,292f. (Vit. Silv. 100 -101): Tunc [Belisarius] fecit Silverium papam venire ad se in palatium Pincis et ad primum et secundum velum retenuit omnem clerum. Vgl. auch Prok. BG. 2,8,10 und Prok. BG. 2,9,5. Die Benennung als palatium zweifelte noch JORDAN/HÜLSEN (1871) Bd. 2, 402 an.

314 CIL 15, 1547. Vgl. JOLIVET/SOTINEL (2012) 139 mit Abb. 4; ausführlicher BROISE/JOLIVET (2009); zur Grabung an den Thermen der Domus Pinciana, die diese Ziegel zum Vorschein brachte, vgl. JOLIVET (2005) 299-304, hier 302-304 und ders. (1993) 440-443, hier 441f. mit Fig. 9.

315 Plan in JOLIVET/SOTINEL (2012) Abb. 2.

316 Vgl. JOLIVET/SOTINEL (2012) 137 f.; JOLIVET (2006) 327-331, hier 327-330; ders. (2005) $301 \mathrm{f}$.

317 Vgl. JOLIVET/SOTINEL (2012) 138f.; BROISE/JOLIVET (1998) 195-197 und dies. (1990) 472-474.

318 Vgl. JOLIVET (2005) 302-304.

319 Vgl. JOLIVET/SOTINEL (2012) 140 - 144; erstmals BROISE/DEWAILLY/JOLIVET (1999/2000) 1-17 und BROISE/DEWAILLY/JOLIVET (2000) 729-750; ferner JOLIVET (1987) 24-25 und die einschlägigen Beiträge zusammen mit BROISE in MÉFRA 96 (1984) 523f.; 97 (1985) 529 - 531; 98 (1986) 398; 99 (1987) 498500; 100 (1988) 525-527; 101 (1989) 513f.; 102 (1990) 472-474: 104 (1992) 493-495; 105 (1993) 440 - 443; 106 (1994) 450f.; 107 (1995) 496-501; 108 (1996) 451-455; 109 (1997) 441-443; 110 (1998) 499-503; 111 (1999) 481-484. Vgl. auch BROISE/JOLIVET (1998) 197-201. 
sectile-Verkleidung, darunter auch Stücke, die auf Marmor numidicum ein MäanderMuster aus Porphyr und Serpentin zeigen oder zu floralen Ornamenten ${ }^{320}$ gelegt sind, lassen die einstige Prachtentfaltung der Anlage greifbar werden.

Die kaiserliche Inbesitznahme und der Ausbau des Areals im 5. Jh. ist neben den Ziegelstempeln auch durch die Beschriftung eines von der Aqua Pinciana abzweigenden Bleirohrs, welches den Namen Valentinians III. trägt, ${ }^{321}$ gesichert. Die gestempelten Ziegel stellen hier die wichtigste Datierungsgrundlage dar. ${ }^{322} \mathrm{Im}$ Hinblick auf ähnliche Ziegelstempel, die am Mauerwerk von San Paolo fuori le mura zu finden sind, setzen Broise/Jolivet den terminus ante quem non 410 für die Errichtung des Hauptgebäudes, der Thermen und die Restaurierung des Nymphäums an. ${ }^{323}$ Demnach wären bis in das Jahr der Plünderung Roms die Anicier Eigentümer dieses Grundbesitzes gewesen. Gleich mehrere irritierende Punkte bedürfen hier einer Erklärung. Zunächst überrascht das plötzliche Interesse der Kaiser an einer neuen Residenz in Rom. Wie der Befund nahelegt, wurden offensichtlich keine Kosten und Mühen gescheut, um durch Größe und Pracht der neuen Residenz die Präsenz des Kaisers in Rom mit Nachdruck zu demonstrieren. Wenn der Vita Melaniae ${ }^{324} \mathrm{zu}$ glauben ist, lehnte das Kaiserhaus ein solches Ansinnen vor 410 noch ab. An kaiserlichen Palästen mangelte es in Rom sicherlich nicht. ${ }^{325}$ Dass hier ausgerechnet die Anicier betroffen und möglicherweise sogar die Leidtragenden waren, verkompliziert die Angelegenheit nur noch mehr. Beide Möglichkeiten, die freiwillige und die erpresste Besitzübergabe, stellen uns vor erhebliche Probleme. Die Aufgabe der domus auf dem Pincio, welche im Hinblick auf die Nennung der Proba als Zierde der Annii, Pincii und Anicii ${ }^{326}$ möglicherweise sogar als Stammsitz der Anicii-Petronii angesehen werden muss, ist selbst für die christliche clarissima femina Proba, die vielleicht die letzte Besitzerin des Anwesens war, ein kaum nachzuvollziehender Schritt.

Hieronymus gibt an, dass Proba zusammen mit ihrer Schwiegertochter Anicia Iuliana und Enkelin Demetria nach der Plünderung Roms 410 nach Africa umgesiedelt

320 Vgl. Aurea Roma (2000) Fig. 2; es handelt es sich hier durchweg um spoliiertes Material.

321 CIL 15, 7259: AQVA PINCIANA / D. N. FL. VALENTINIA/NI AVG. Vgl. JOLIVET/SOTINEL (2012) 145. Vgl. ausführlicher HEIL (1997) 292-296, hier $294 \mathrm{f}$.

322 Hinzu kommen Münzfunde, die bis in die Regierungszeit Valentinians I. zurückreichen, und das Füllmaterial der Zisterne (Ende 4./Anfang 5. Jh.). Vgl. JOLIVET/SOTINEL (2012) 144.

323 Vgl. JOLIVET/SOTINEL (2012) 144f. Zur Problematik, Ziegelstempel als Datierungsgrundlage heranzuziehen, vgl. aber auch STEINBY (1986).

324 Vit. Mel. 11-13; zur Domus Valeriorum vgl. Kap. 8.3.

325 Neben dem Palatin (zumindest nach Sid. ep. 2,13,4: Petronius Maximus 455), u. a. auch der Sessorialpalast (CIL 6, 1134-1136: Galla Placidia, Licinia Eudoxia und Valentinian III.), die Villa ad duas lauros (Prosp. Tiro 1375, s. a. 455: Valentinian III.) und drei Stadtpaläste (zwei in der Reg. I und einen in der Reg. X: Galla Placidia). Zur spätantiken Nutzung des Palatin-Palastes und seiner Instandhaltung vgl. zusammenfassend LÖX (2017) 154f. und ausführlicher WULF-RHEIDT (2017) 127-148.

326 CIL 6, 1754b; PLRE 2, 731f. (Proba 3). Vgl. hierzu auch SCHOTTENIUS CULLHED (2015) 19-23, 33f. und 64f.; HEINE (2008) 90-93; COOPER (2007b) 51-54 u. 66-68; DIEFENBACH (2007) 369f. SALZMAN ²(2004) 56; LANCON (2001) 60 u. 69 und DISSELKAMP (1997) 91; grundlegend NOVAK (1976). 
sei. ${ }^{327}$ Im fernen Bethlehem drückt dieser seine Verwunderung darüber aus, wie umfangreich doch die Güter waren, die Proba aus dem Besitz ihrer Vorfahren (avitae possesiones) losschlug. Hier ist auch die Rede davon, dass die Goten die Residenz der Proba in Rom niedergebrannt hätten. Doch muss solch eine Nachricht mit Vorsicht behandelt werden. ${ }^{328}$ Dieser Aufenthalt in Africa war jedenfalls nicht dauerhaft. Zu einem nicht genau zu bestimmenden Zeitpunkt nach 414 erfolgte die Rückkehr. ${ }^{329}$ Um die Mitte des 5. Jhs. sind so für die Nachkommen der Proba auch Besitzungen in Rom belegt: eine villa an der Via Latina. ${ }^{330}$ Wenn sogar noch bis zur Mitte des 5. Jhs. eine villa im suburbium in Familienbesitz gehalten wurde, lässt sich nur schwer glauben, dass der wohl um einiges wichtigere Wohnsitz auf dem Pincio, wo sich vermutlich auch ein ganzes Ensemble an Familienmonumenten ${ }^{331}$ befunden hat, kurzerhand einfach aufgegeben bzw. an den Kaiser veräußert wurde. Sollte nun aber die Besitzveräußerung unter Druck des Kaisers erfolgt, also faktisch einer Enteignung gleichgekommen sein, wäre dies für das 5. Jh. ein beispielloser Vorgang. Hinzu kommt, dass gerade die Anicii vor dem theodosianischen Kaiserhaus in höchsten Ehren standen und stets diesem gegenüber die Treue gehalten hatten. ${ }^{332}$ Die Motive einer solch harten Maßnahme sind so kaum nachzuvollziehen. Wenig wahrscheinlich ist aber auch, dass der Kaiser für das Anwesen der Anicier den angemessenen Preis aufbringen konnte. Jolivet scheint so auch eher dahin zu tendieren, dass das Anwesen unentgeltlich an den Kaiser überging. ${ }^{33}$

Als Erklärung hierfür wird eine im Zusammenhang mit der Plünderung Roms stehende Anekdote ${ }^{334}$ herangezogen. Hiernach soll eine Proba, die vom Elend in der belagerten Stadt so ergriffen war, dass sie diesem ein Ende setzen wollte, den Einlass der Goten durch die Porta Salaria befohlen haben. Ungeachtet des Wahrheitsgehaltes dieser

327 Hieron. ep. 130,7,2. Vgl. zum Brief aktuell GEORGIEVA (2016) 329-340; zur Umsiedlung nach Africa und der Verbindung zu Augustinus und Hieronymus BROWN ${ }^{2}(2000) 298$ u. 340 f.; KRUMEICH (1993) $127 \mathrm{f}$. u. $176-188$ und REBENICH (1992) 185, 189, 207 u. 230.

328 Vgl. Vit. Mel. 15 und Hieron. ep. 127,8,13f. zum Haus der Marcella, wo nicht die Rede davon ist, dass dieses zerstört wurde; hier mahnt auch HILLNER (2004) 84 Anm. 9 eher zur Vorsicht. Schäden werden zwar für die Horti Sallustiani vermeldet, nicht aber für den Pincio (Prok. BV. 1,2,24), weshalb auch JOLIVET/SOTINEL (2012) 149 einer möglichen Verwüstung durch die Goten eher skeptisch gegenübersteht. 329 Auch das Familiengrab befand sich in Alt.-St. Peter; dort war bereits auch ihr Gatte Sextus Petronius Probus († um 390) beigesetzt worden (CLE 1347; sog. Templum Probi); Cael. ep. ad Theod. (ACO 1,2,19) vom 15. März 432 setzt Probas Tod voraus.

330 Lib. Pont. 1,238 und ILCV 1765 (ILS 8988); hierzu noch Kap. 9.3. Vgl. auch BRANDENBURG ${ }^{3}(2013)$ 257 f.; MACHADO (2011) 500 - 505; BRENK (2003) 50 f. und HILLNER (2004) 85. Anicia Italica 2 (PLRE 2, 624), vermutlich eine Enkelin, ehelichte den PVR und Konsul von 451, Valerius Faltonius Adelfius (PLRE 2, 8f.). Vgl. hierzu auch HILLNER (2004) $85 \mathrm{f}$.

331 Eben vermutlich CIL 6, 1751-1755.

332 Vgl. Zos. 6,7,4. Vgl. auch MATTHEWS (1975) 297-300. Hierzu vgl. Kap. 4.1.

333 Vgl. JOLIVET/SOTINEL (2012) $149 \mathrm{f}$.

334 Prok. BV. 1,2,27 f. (vgl. auch Olymp. fr. 11,3). Das Verratsmotiv erscheint auch in der ersten Variante Prok. BV.1,2,14-24: Hier öffnen 300 Sklaven, die Alarich den Senatoren zum Geschenk gemacht hatte, die Tore (auch Soz. 9,9,2 spricht allgemein von Verrat); hierzu kritisch STICKLER (2017) 142f.; MEIER/PATZOLD 3(2013) 97-100; NÄF (2013) 87 und MATTHEWS (1970a) 93 mit Anm. 144. 
Beschuldigung, die in letzter Konsequenz den Aniciern Verrat unterstellte, kann allein schon das Gerücht dem Kaiser eine Grundlage für sein Handeln geboten haben. ${ }^{335}$ Die Äußerung des Hieronymus ${ }^{336}$, wonach Proba es selbst bei den ,Barbaren“ zu Ansehen gebracht hätte, war der Entkräftung solcher Vorwürfe sicherlich nicht dienlich. Die Vita Melaniae hatte Jolivet zumindest partiell vor Augen, jedoch nur in den Passagen, die vom Haus der Melania und des Pinians und dem abschlägig beschiedenen Verkaufsansinnen berichten. ${ }^{337}$ Entgangen sind ihm hierbei die kaum übersehbaren Parallelen, die im Vorwurf des Verrats ${ }^{338}$ und der Enteignung des Besitzes zu erkennen sind. Der Prozess gegen Melania und Pinian ${ }^{339}$ war Teil einer größeren Prozesswelle. ${ }^{340}$ Denkbar ist, dass auch die Anicii-Petronii hier hineingezogen wurden, zumal sie sich mit Stilicho durchaus gut arrangiert hatten und nach 410 der Verdacht des Verrats auf ihnen lastete. So könnte das Anwesen der Anicier auf dem Pincio tatsächlich ,proskribiert‘ worden sein. Dies konnte dem Kaiser sogar nützen, denn eigentlich lag die Porta Salaria, durch welche die Goten in die Stadt gelangten, zum kaiserlichen Besitz in den Horti Sallustiani hin. Die Schuld den ,Nachbarn` auf dem Pincio zuzuschieben und im gesamten Areal durch die kaiserliche Präsenz das Sicherheitsgefühl zu erhöhen ${ }^{341}$, konnte den Kaiser entlasten. Der neue Besitz ist somit nicht allein nur ein weiteres Bauprojekt ${ }^{342}$ des kaiserlichen Restaurationsprogramms in Rom, wie dies von Jolivet/Sotinel ${ }^{343}$ wiederholt geäußert wurde. Hier ging es wohl auch um die Deutungshoheit über die Geschichte und die Geschichten, die die Plünderung Roms, die Rolle des Kaisers ${ }^{344}$ und die der stadtrömischen Senatsaristokratie betreffen.

Für die abschließende Bewertung ist festzuhalten, dass in der Tat ein verstärktes Ausgreifen der senatorischen domus in den öffentlichen Raum der Stadt Rom für die erste Hälfte des 5. Jhs. zu verzeichnen ist. Allerdings lässt sich hier kein Konflikt mit dem Kaiser erkennen. Die sog. fora privata stehen nicht in Konkurrenz zu den kaiserlichen Domänen. Zum Teil lassen sich hier auch Ehrungen für den Kaiser fassen. Die ,Privatisierung، öffentlicher Areale entlasteten den Kaiser und den Senat finanziell und stellte sicher, dass gerade jene städtischen Bereiche, die aus finanzieller Not oder religions-

335 So auch JOLIVET/SOTINEL (2012) 149.

336 Hieron. ep. 130,7,2.

337 JOLIVET/SOTINEL (2012) 149 mit Anm. 11 (Vit. Mel. 11-13).

338 So lässt sich der Abgang aus dem bedrohten Rom als „Landesverrat“ auslegen; ebenso die eigenmächtigen Zahlungen an ,Barbaren` (Vit. Mel. 19). Vgl. DEMANDT/BRUMMER (2013) 17f. [1977]; nachfolgend KESSLER (1999) 218.

339 Vit. Mel. 19 und Vit. Mel. Lat. XXXIV. Hierzu vgl. Kap. 3.1.

340 Vgl. Zos. 5,45,5-7. Das prominenteste Opfer war Serena; vgl. DEMANDT/BRUMMER (2013) [1977]. 341 Die fortifikatorische Bedeutung der Residenz wird vor allem im Zuge der justinianischen Rückeroberung Italiens deutlich, wenn Belisar eben hier sein Hauptquartier einrichtet (Prok. BG. 2,8,10 u. 2,9,5. Vgl. hierzu LILLINGTON-MARTIN (2013) 599-630, hier 620-625; JOLIVET/SOTINEL (2012) 146f. u. 150. 342 Der Ausbau wird ohnehin eher in die Zeit Valentinians III. zu datieren sein. Vgl. JOLIVET/SOTINEL (2012) 151-158.

343 JOLIVET/SOTINEL (2012) $150 \mathrm{f}$.

344 Vgl. auch BROISE/DEWAILLY/JOLIVET (1999) 56-64. 
politischen Erwägungen weniger Aufmerksamkeit fanden, dennoch instandgesetzt wurden und wieder einen Nutzen erhielten. Für die stadtrömische Senatsaristokratie verband sich hiermit eine Möglichkeit, die eigene Repräsentation auf den öffentlichen Raum auszuweiten, den Einfluss über Stadtareale zu erhöhen und ihren Häusern sogar eine ,staatstragende‘ Bedeutung zu geben. Dies wurde letzten Endes zugelassen. Die Aneignung senatorischen Besitzes durch den Kaiser stellt dagegen einen stark situationsgebundenen Ausnahmefall dar, der allerdings aufzeigt, welche große politische Bedeutung einer senatorischen domus zufallen konnte.

\subsection{Zusammenfassung: Repräsentationsdomänen}

Anknüpfend an die Aufarbeitung und Besprechung des epigraphischen Materials durch Niquet (2000) wurde dargelegt, von welch entscheidender Bedeutung die öffentlichen Ehrungen für die Kommunikation und Manifestierung des gesellschaftlichen Leitbildes waren. Hinsichtlich der statuarischen Ehrungen in der ersten Hälfte des 5. Jhs. ließ sich zunächst feststellen, dass entgegen der Auffassung Machados ${ }^{345}$ zumindest für Rom kein gravierender Einbruch zu verzeichnen ist. Gerade in krisenhaften Zeiten, die von politischer Instabilität und einer wachsenden gesamtgesellschaftlichen Verunsicherung gekennzeichnet waren, stellten die Ehrungen einen gesellschaftsstabilisierenden Faktor dar, der Ordnung suggerierte und Orientierung bot. So waren auch die Kaiser darauf angewiesen, immer neu herausragende Amtsträger zu präsentieren. Das bonum exemplum wurde hier zwischen dem Kaiser und dem Senat bzw. der Senatsaristokratie verhandelt. Hierbei wurde offensichtlich ein Kompromiss erzielt, der jegliche religiösen Inhalte ausblendete.

Sowohl für die inneraristokratische Distinktion als auch für die gesellschaftliche Verortung der Senatsaristokratie gegenüber dem Kaiser und dem Volk war die Spielgebung eine wichtige Kommunikationsplattform. Es ließ sich hier nach den Motiven fragen, die hinter solchen extravaganten spectacula standen. Ein entscheidender Punkt, der von Puk weitestgehend außer Acht gelassen wurde, ist die Möglichkeit, über die Spielgebung, insbesondere in Gestalt der venationes, dem Volk von Rom eine optimale Realität zu suggerieren. Überdies wurde gerade in der senatorischen Spielgebung, die das umfangreiche senatorische Beziehungs- und Klientennetz nutzte, der Zusammenhalt zwischen Zentrum und Peripherie gestärkt. Mit der wachsenden Bedeutung des senatorischen Spielgebers für die Finanzierung und der zunehmenden Selbstverantwortlichkeit für die Spielstätten, Tierbeschaffung und gewisse Sparten der Spielgebung (reparatio muneris) stiegen die repräsentativen Freiheiten. Die vielfältigen Repräsentationsmedien, die auch weiterhin pagane Motive zeigen konnten, zeugten hiervon.

345 Vgl. u. a. MACHADO (2010a); vgl. auch NIQUET (2000) 13. In jüngerer Zeit ist das Erklärungsmodell von BORG/WITSCHEL (2001) 47-120, bes. 49 erschienen. 
Mit der domus und den sog. fora privata als Zentrum senatorischer Repräsentation und Lebensführung befassten sich die beiden abschließenden Unterkapitel. Im Unterschied zu Hillner wurden hier auch die archäologischen Funde verstärkt miteinbezogen. Ins Bewusstsein zu rufen, ist hier nicht nur der außerordentliche Wohnluxus und das große Repräsentationsstreben, sondern auch die essenzielle Bedeutung der senatorischen Besitzungen für das kulturelle, soziale und auch ökonomische Leben in Rom und dem Rest der römischen Welt. Entsprechend dieser Funktionsvielfalt, welche unzählige Existenzen an die senatorischen Besitzungen band, stellte die senatorische domus einen bedeutenden sozialen und politischen Kommunikationsraum dar, in welchem die Senatsaristokratie ihre gesellschaftliche und politische Führungsaufgabe nicht nur demonstrieren, sondern ihr auch unmittelbar nachkommen konnte. An der Wohnbebauung auf dem Caelius und der literarischen Überlieferung ließ sich dies festmachen. Entgegen dem Postulat vom Niedergang und Ende der senatorischen domus ${ }^{346}$ überwog bei den hier besprochenen Anwesen doch eher der Eindruck anhaltender Kontinuität und Prosperität.

Die große Bedeutung der senatorischen domus wurde insbesondere auch durch das Diktum des Olympiodors bestätigt, wonach jedes Haus eine Stadt sei. Hinsichtlich der Wahrnehmung der Topographie Roms wurde ersichtlich, dass nun die senatorischen Häuser zum Gradmesser der Größe und Prosperität Roms und des Reichs erhoben wurden. Seine Entsprechung in der städtischen Urbanistik fand dies auch in den sog. fora privata. Hier ließ sich tatsächlich ein verstärktes Eindringen der senatorischen domus in den öffentlichen Raum der Stadt feststellen. Damit verbunden war die Ausweitung des senatorischen Einflusses auf öffentliche Einrichtungen und ganze Stadtareale.

Der außergewöhnliche Fall der Domus Pinciana lässt aber auch eine gegenläufige Entwicklung erkennen, die die kaiserliche Präsenz wieder stärker zur Geltung brachte. Der gesamte Fall hat allerdings mit dem politischen Klima nach der Plünderung Roms zu tun und ist das Ergebnis einer politischen Notwendigkeit, die möglicherweise auch von den Aniciern akzeptiert wurde. Hier liegt ein Ausnahmefall vor. Mit der Aneignung des anicischen Besitzes und dem Bau eines neuen Kaiserpalastes wird nicht die Dominanz im öffentlichen Raum durch den Kaiser zurückgefordert. Eingebüßt hatte er sie ja nicht. Sie war lediglich in manchen Bereichen schwächer ausgeprägt und ließ der Senatsaristokratie mehr Freiheiten, die wohl bereitwillig zugestanden wurden.

346 MACHADO (2012b) und ELLIS (1988). 